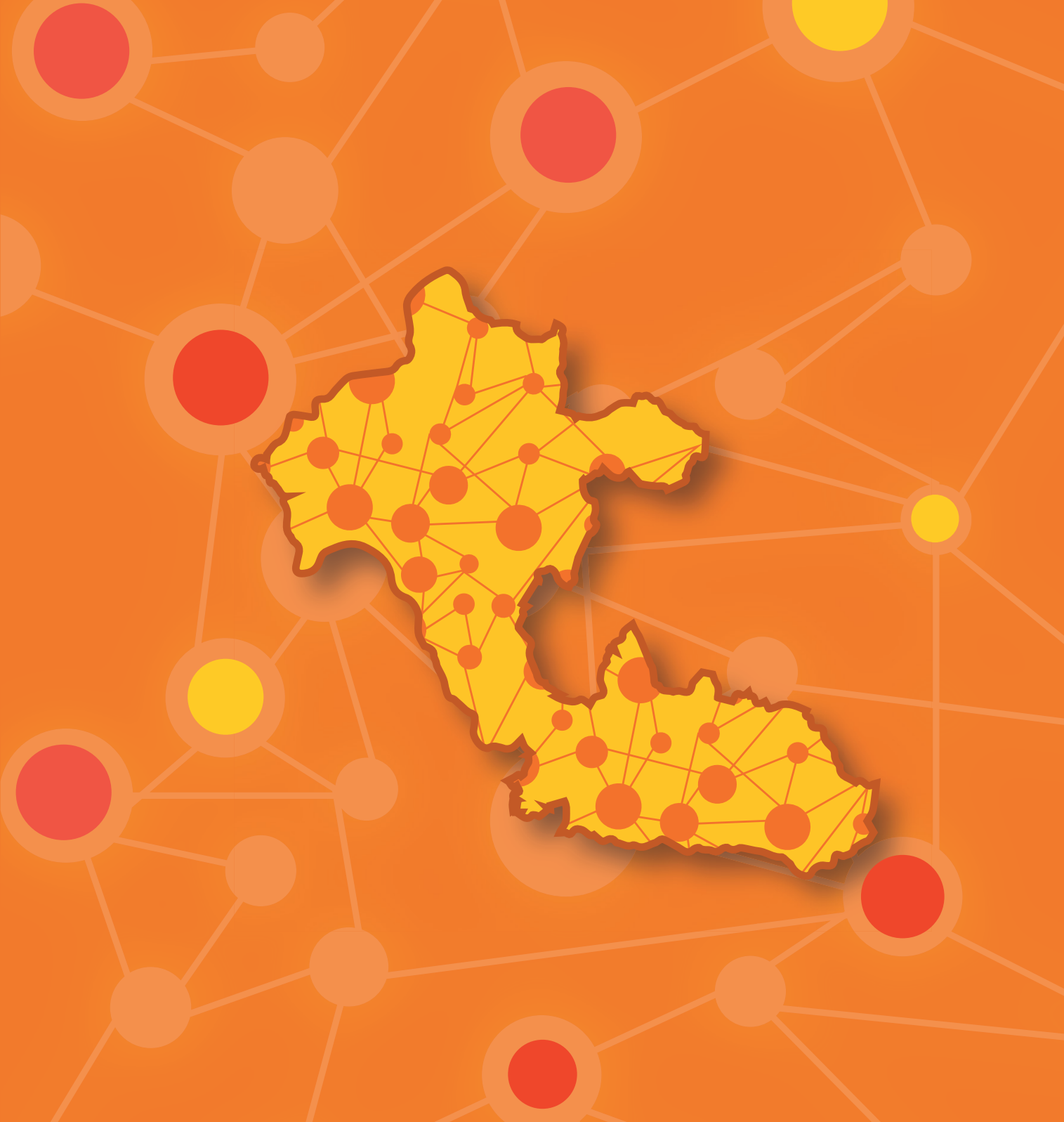

\title{
La investigación: Transformando el contexto
}
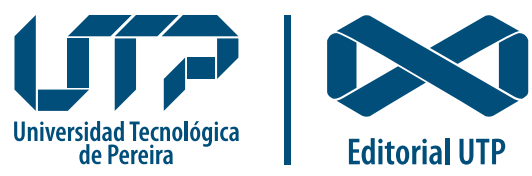

Julio Cesar Murillo García Jhon Estiwar Gómez Palacio Carolina Saldarriaga Ramírez

Wilson González Vanegas 



\section{La investigación: Transformando el contexto}

Julio Cesar Murillo García Jhon Estiwar Gómez Palacio Carolina Saldarriaga Ramírez Wilson González Vanegas

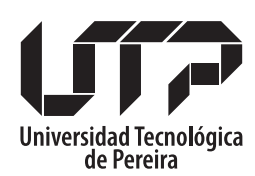

Vicerrectoría de Investigaciones, Innovación y Extensión Universidad Tecnológica de Pereira 
La investigación : Transformando el contexto / Julio César Murillo García y otros. - Pereira : Editorial Universidad Tecnológica de Pereira, 2020

155 páginas. -- (Colección Trabajos de investigación).

e-ISBN: 978-958-722-496-2

1. Desarrollo sostenible 2. Tecnologías de la información y la comunicación 3. Comprensión lectora 4. Aprendizaje significativo 5. Paisaje cultural cafetero 6 . Metodologías de investigación 7. Investigación narrativa 8. Teoria de grafos

9. Inferencia estadística 10 . Sistema dinámico no lineal

CDD. 001.42

La investigación: Transformando el contexto

(C) Vicerrectoría de Investigaciones, Innovación y Extensión

(C) Universidad Tecnológica de Pereira

Publicación financiada con recursos de la Vicerrectoría de Investigaciones, Innovación y Extensión de la Universidad Tecnológica de Pereira

eISBN: 978-958-722-496-2

Trabajo de Investigación

Universidad Tecnológica de Pereira

Vicerrectoría de Investigaciones, Innovación y Extensión

Editorial Universidad Tecnológica de Pereira

Pereira, Colombia

Coordinador editorial:

Luis Miguel Vargas Valencia

luismvargas@utp.edu.co

Teléfono 3137381

Edificio 9, Biblioteca Central "Jorge Roa Martínez"

Cra. 27 No. 10-02 Los Álamos, Pereira, Colombia

www.utp.edu.co

Montaje y producción:

María Alejandra Henao Jiménez

Universidad Tecnológica de Pereira

Pereira 


\section{CONTENIDO}

\section{CAPÍTULO 1.}

Desarrollo sostenible territorializado: una apuesta multidimensional en los asentamientos del río Otún1. /

Spatial sustainable development: a multidimensional bet in settlements

at Otún river.

Julio Cesar Murillo García

\section{CAPÍTULO 2.}

TIC y Lenguaje: fortaleciendo habilidades lectoras. /

ICT and Language: strengthening reading skills

Jhon Estiwar Gómez Palacio

\section{CAPÍTULO 3.}

Ferias de la memoria. Una metodología de investigación narrativa para los estudios de memoria e identidad. /

Caso de estudio transformaciones de la cultura cafetera....

Carolina Saldarriaga Ramírez

\section{CAPÍTULO 4.}

Inferencia estadística automática empleando embebimientos de espacios de Hilbert y computación Bayesiana aproximada / Automatic statistical inference based on Hilbert space embeddings and approximate Bayesian computation

Wilson González Vanegas 



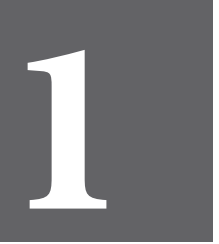

CAPÍTULO

UNO 



\title{
Desarrollo sostenible territorializado: una apuesta multidimensional en los asentamientos del río Otún ${ }^{1}$
}

\section{Spatial sustainable development: a multidimensional bet in settlements at \\ Otún river}

\author{
Julio Cesar Murillo García ${ }^{2}$ \\ Universidad Tecnológica de Pereira \\ Julio.murillo@utp.edu.co
}

1 Capítulo derivado de la investigación, "Fenomenología a la territorialidad y la desterritorialización del sujeto habitante en los asentamientos del Río Otún en Pereira (1950-2000)" tesis para optar al título de Magister en geografía de la Universidad Tecnológica y Pedagógica de Colombia.

2 Docente Universidad Tecnológica de Pereira UTP, vinculado al Departamento de. Humanidades. Integrante Grupo de investigación en estudios políticos y jurídicos. 


\section{Resumen}

La dinámica territorial de los barrios Risaralda, San Juan de Dios y Salazar Robledo, ubicados sobre las orillas del río Otún al borde norte de la ciudad de Pereira, se ha constituido en dinámica de tensión-conflicto a partir de la confluencia desigual y asimétrica de lógicas que buscan apropiar y/o controlar procesos sociales sobre este espacio. De esta manera, tanto la institucionalidad, a través de políticas pública de orden territorial, como el sujeto que cotidianamente habita este espacio movilizan lógicas de apropiación/ control que, al ser desiguales y contradictorias entre sí, terminan por acentuar condiciones de vulnerabilidad económica, social, ambiental y política en el habitante mismo y en su entorno inmediato.

Abordar el estudio de esta dinámica implicó analizar e interpretar los campos de representación territorial que tanto la gobernanza como el sujeto habitante despliegan y asumen para dar sentidos a su acción. De esta forma, se determinaron campos de representación que para la gobernanza se encuentran definidos por racionalidades económicas de capital a escala mundo y que configuran en la política pública territorial de la ciudad vocaciones y propósitos, así como plataformas de funcionalidad territorial. Igualmente se determinaron campos de representación del sujeto habitante que desde marcos históricos de vulnerabilidad económica y social configura cada uno de sus vínculos territoriales.

De fondo, este tipo de abordaje permitió delimitar marcos de comprensión sobre la política pública territorial que, actualmente, direcciona las transformaciones de la ciudad y que está sustentada, exclusivamente, sobre dimensiones económicas del desarrollo que la configuran desarticulada y excluyente. De esta manera, se plantean reflexiones críticas que encuentran en el desarrollo sostenible territorializado su correlato, al ser esta una propuesta de alternativa fundamentada en la resignificación misma del desarrollo y la sostenibilidad, a partir de visiones integradoras y 
holísticas de las dimensiones humanas y de las concepciones del buen vivir y el bien estar.

Palabras claves: Desarrollo Sostenible Territorializado, Territorialidad, Sujeto habitante.

\section{Abstract}

Various conflictive logics of territorial appropriation overlap in the neighborhoods Risaralda, San Juan de Dios, and Salazar Robledo, which are located in the north border of the city of Pereira on the Otún river shore. Those logics seek to appropriate and control their own social processes over this space creating tense dynamics. Contradictions occur between the logics of the governance and the logics of the residents. The governance through spatial public policies tries to claim and control the space and so do the residents through their daily routines. As a consequence, this interaction exacerbates economic, sociopolitical, and environmental vulnerability for the residents and their immediate environment.

For the study of this problem, I analyzed and interpreted how the residents and the governance display spatial representation that gives sense to their behavior. I state that representation from the governance's standpoint entails the economic rationality of global capital. This representation shapes the vocations and purposes of the city's spatial public policy, as well as the platforms of territorial functionality. On the other hand, representation from the resident's standpoint entails historical frameworks of economic and social vulnerability that have created relations with the space.

This approach allowed me to delimitate frameworks of understanding with regard the spatial public policy orienting the transformations of the city. I argue that this policy is solely based on the economic dimensions of development. For this reason, the policy operates in dislocated and discriminatory 
ways. Consequently, I raise critical reflections based on spatial sustainable development as an analog narrative. Alternatively, my propose aims to the redefinition of development and sustainability from an integrative and holistic view that takes in account the human dimensions and the conceptions of good living, and wellbeing.

Keywords: spatial sustainable development, territoriality, subject inhabitant.

\section{Introducción}

Desde las demandas de la planificación física y del desarrollo territorial sostenible, la legislación colombiana, a través de la Ley de Desarrollo Territorial (Ley 388 de 1997) y la Ley General Ambiental de Colombia (Ley 99 de 1993), limita el uso y ocupación de las áreas definidas en los planes de ordenamiento territorial municipal como "suelos de protección hídrica", suelos donde no se pueden asentar poblaciones ni hacer ningún tipo de construcción. Sin embargo, es corriente, en casi todo el territorio colombiano, la ocupación de las orillas de los cauces por parte de poblaciones de bajas condiciones sociales y de vulnerabilidad, un fenómeno tan vigente como histórico de profundas raíces socioeconómicas que termina por impactar lo ambiental, lo social y lo políticoadministrativo tanto en sus configuraciones verticales (de relaciones multinivel, escala local y regional) como horizontales (coordinación transectorial y políticas territoriales).

El fenómeno se instala más allá de la lógica ordenadora instituida en la década del 90 y es un signo de la configuración urbana asociada al desplazamiento forzado, la inequidad social, la capacidad adquisitiva, "las ciudades en general han sido construidas a partir de múltiples migraciones impuestas y/o no planificadas (...) y atravesadas por las variables propias que ha adquirido el sistema político y económico, signado por el capitalismo dependiente" (Torres, Atanassova y Rincón, 2007, 
p. 134); es decir, más allá de la necesaria protección de suelos y de la configuración de ciudades sostenibles, quedan conflictos estructurales sin ser resueltos: la insuficiencia de suelo urbano, la ausencia o precariedad de la política de vivienda, la planificación insipiente o vinculada a intereses exclusivamente económicos (Torres, Atanassova y Rincón, 2007).

En medio de ello, un sujeto transversalizado por condiciones de insatisfacción social y económica (NBI) desplazamiento forzado o consolidación de vínculos sociales- afectivos que ocupa el espacio, lo construye y apropia, "las personas que inmigran al casco urbano de un municipio, sin capacidad adquisitiva para comprar o arrendar una vivienda, se asientan en zonas de alto riesgo (...) con el fin de acceder al suelo" (Amorocho Pérez, 2012 , p. 15). Un sujeto que torna su espacio en territorio en tanto albergue, refugio, hábitat, "Albergue de la población de menores recursos (...) deficientes en lo que se refiere a servicios públicos, equipamientos comunales y espacio urbano y habitacional" (Hernández, 2007, p. 49).

La incidencia de las políticas públicas de orden territorial en la ciudad de Pereira sobre estas franjas de ocupación no están exentas de la lógica nacional. El Plan de ordenamiento iniciado en el 2000 (Concejo de Pereira, 2000) y ratificado en sus líneas generales para el 2016 (Concejo Municipal, 2016) introduce lógicas de apropiación/ control vinculadas a modelos económicos de competitividad y localización de centralidadesclúster (Zambrano y Bernard, 1993; Barón, 2002; Martínez, 2010) que entran a transformar no solo la ciudad con propósitos y vocaciones territoriales: a) centro de negocios y de servicios de alcance regional; b) enclave turístico proyectado nacional e internacionalmente; c) polo de desarrollo industrial- agrícola; d) territorio líder en sostenibilidad ambiental (Concejo de Pereira, 2000, p. 5; Concejo Municipal, 2016, p. 7). Sino y puntualmente los asentamientos de la orilla del río. 
La vigencia del POT significó para el sujeto habitante de estas orillas una lógica desterritorializante, que ha conllevado hasta hoy la pérdida progresiva de procesos de apropiación espacial que operaron desde la década del cincuenta: procesos de ocupación y valor del suelo; procesos de vocación e identidad como principal refugio; procesos de vinculación territorial y representación social que encuentran en la casa y en las redes de subsistencia su principal base. Procesos que ante la consolidación de marcos y disposiciones normativas sobre el ordenamiento territorial (la Ley 388 del 97 por ejemplo) derivan en lógicas de fragmentación y ruptura ante la inminencia de la reubicación, la venta de predios, y el abandono institucional del sector. La política pública territorial guiada desde la gobernanza desterritorializa y transgrede territorialidades del sujeto, provocando con ello nuevos contextos de tensión- conflicto que antes de posibilitar soluciones (como se verá) al complejo panorama social que se vive sobre estos sectores los agudiza.

El sujeto y el territorio son objeto así de articulación al ordenamiento que se propone por la gobernanza, que a partir de allí los define bajo representaciones de sub-normalidad, como lo señala tanto el POT de 2000 (Concejo de Pereira, 2000, p. 26). Como el POT 2016, "los asentamientos subnormales que se identifiquen sobre suelos de expansión se reconocerán en los diferentes planes parciales" (Concejo Municipal, 2016, p. 91). O desde lo "invasivo" como lo señala el diagnostico UP7 (Secretaria de planeación, 2010) "existen un gran número de mejoras localizadas en predios de mayor extensión sobre los que se han asentado familias bajo procesos informales en su mayoría por invasión" ( $p, 34)$ toma cuerpo la informalidad, que al estar relegada de los estándares urbanísticos, genera contextos de amenaza y riesgo natural "el análisis de los diferentes factores, arrojó como resultado una zonificación de riesgos para el conjunto de viviendas localizadas entre el río y la Av. del Río" (Secretaria de planeación , 2010, p. 43). 
Sujeto y espacio, quedan articulados bajo la nueva lógica de control y apropiación de procesos sociales establecidos por el ordenamiento territorial, al declararse la zona, "como Áreas Naturales Protegidas de interés urbano para la recuperación del paisaje, espacio público y la mitigación de riesgos naturales los tramos urbanos del río Otún" (Concejo de Pereira, 2000, p. 26). Y al trazar en los objetivos y estrategias del sistema ambiental municipal para la base natural, suelos de riesgo y amenaza natural y tectónica (Concejo Municipal, 2006) medidas que deben, "incluir, dentro de cada programa de ejecución del POT, proyectos de reubicación y mitigación del riesgo" (p. 46) A partir de allí, el territorio deja de ser refugio para la subsistencia, proceso autoconstruido para la realización en el mundo de la vida, transfigurándose en modelo de desarrollo: plataforma funcional de servicios que toma este fragmento y lo articula "funcionalmente" a sus vocacionespropósitos y sistemas estructurantes.

Se sustenta con esto un conflicto que más allá de la declaratoria de suelos de protección (Concejo de Pereira, 2000) necesaria para los planteamientos de sostenibilidad y conciencia medio ambiental, en el marco de Leyes como la 388 de 1997, o el Decreto Ley 1541 de 1978³ más allá del mejoramiento progresivo de los asentamientos informales mecanismo definido para el bienestar y calidad de vida de los habitantes ${ }^{4}$; y más allá de la ampliación del sistema estructurante de espacio público ${ }^{5}$ que se propone con la inclusión de las fuentes hídricas como corredores ambientales; se define desde la desarticulación de políticas públicas de orden

3 Mediante el cual se reglamentan las normas relacionadas con el recurso de aguas en todos sus estados en el territorio colombiano y en especial en lo correspondiente a la gestión que ejercen los municipios frente al "dominio de las aguas, cauces y riberas, y normas que rigen su aprovechamiento sujeto a prioridades, en orden a asegurar el desarrollo humano, económico y social, con arreglo al interés general de la comunidad".

4 Contemplado en la ley marco para el ordenamiento territorial (ley 388 de 1997), en los artículos, 3 (función pública del urbanismo), numeral 4; 8 (acción urbanística); 10 (determinantes de los planes de ordenamiento, numeral 5); 31 (suelo urbano). Igualmente en el POT de la ciudad de Pereira, artículo 16 (políticas a mediano plazo sobre uso y ocupación del suelo urbano y de expansión urbano).

5 Ley 388 de 1997, (artículos 34 (suelo urbano) y 37 (espacio público en actuaciones urbanísticas). Y en el POT de Pereira de 2000artículo 16 (políticas a mediano plazo sobre uso y ocupación del suelo urbano y de expansión urbano). 
territorial que no integra en su concepción de desarrollo y sostenibilidad las fricciones que persisten sobre el poblador, sobre su insatisfacción social, sobre sus necesidades básicas insatisfechas (NBI) y sobre la fragmentación de su medio ambiente natural y cultural.

De esta forma, se configuró un problema de investigación centrado sobre la comprensión de esa dinámica desterritorializante, un conflictos que emerge sobre la territorialidad del sujeto habitante y se disipa sobre el contenido mismo de la política pública de ordenamiento, un conflicto que más allá de sus dinámicas y racionalidades permitió hacer valoraciones críticas sobre la forma como se gobierna en materia de ocupación de suelos en la ciudad de Pereira y a la par la posibilidad de plantear alternativas que fueron sintetizadas a través del desarrollo sostenible territorializado (Massiris, 2009 ) (Gutierréz, 2012) como forma de aportar al debate por un ordenamiento territorial equitativo, justo en sus componentes socio espaciales, enmarcado en la igualdad social y territorial, la gobernabilidad y la cohesión social, así como el respeto de arraigos e identidades de quienes lo habitan.

Metodológicamente se tomó el 2000 como referente temporal, por corresponder al año en el cual se implementó el Plan de Ordenamiento Territorial del Municipio de Pereira (Acuerdo 18 de 2000) que entra a definir la política de ocupación y uso del suelo urbano, los suelos de protección para la sostenibilidad y conservación de los recursos naturales, la articulación de procesos de informalidad a políticas de reubicación y mejoramiento integral, el manejo administrativo de áreas de reubicación, en general el ordenamiento del fragmento denominado paso urbano del río Otún a su paso por el municipio de Pereira, más concretamente los barrios Risaralda, San Juan de Dios y Salazar Robledo ubicados sobre esta franja en la comuna Otún y que a la luz de los lineamientos que introduce el POT de 2000, así como su continuidad para el año 2016, serán transformados bajo la racionalidad de esta mirada del ordenamiento. 
Igualmente, se tomaron dos referentes de territorialidad en el sujeto habitante, dada su trascendencia e importancia en la configuración de representaciones, por un lado el habitante que ocupó predios desde 1950 y que ante la vigencia de la política territorial de la ciudad introducida en el año 2000 es desterritorializado, estos primeros habitantes fueron el producto de oleadas migratorias cuyo contexto socioeconómico se encontraba atravesado por la violencia que los expulso de su territorio originario,

llego a la orilla del río corriéndole a la violencia en Anserma nuevo (...) es que en esa violencia quedamos nosotros fue llevados (...) mi papá llego acá hermano sin saber qué hacer cuando llegamos nosotros aquí a Pereira le toco dejar las mechitas allá viendo que teníamos allá una finca la verraquera" (Entrevista 2_1; min: 21:54) $\mathrm{y}$ por condiciones económicas que terminaron limitando su acceso al suelo, "Yo por ejemplo para ganarme la comida me iba y cargaba agua le llenaba las canequitas a doña Martha a doña Luisa (...) eran pobres igual que nosotros pero tenían comida nosotros no (Entrevista 1_4; min: 2:07).

Por otro lado, el habitante que tomó predios hacia el año 2000, momento en el que los espacios vacíos y fragmentados configuraron el paisaje en la avenida del río, un contexto físico que sumado a la condición socioeconómica del poblador que va a ocupar terrenos configura asentamientos informales sobre lo que anteriormente fueron predios de otros pobladores ya reubicados,

Con 150 pesos nos fuimos a buscar un apartamentico para arrendar (...) esperemos a ver si conseguimos otra cosa más favorable...entonces nos vinimos por los lados de la avenida del río ¡buscando a ver! resulta que vimos ese terreno entonces le dije yo a mi señora ¿será que ahí está nuestra casa será que nos metemos ahí? (Entrevista 8_1; min: 1:33).

El abordaje metódico, se ejecutó desde la etnografía y el análisis documental, implementando así técnicas de recolección cualitativa, como la entrevista y la revisión de información en 
fuentes documentales. A partir de allí, se realizaron entrevistas a profundidad y semiestructuradas con 5 habitantes llegados en las oleadas de 1950 y 5 de la oleada 2000 en las que predomina el relato, la vivencia, los significados que posee el habitante sobre su territorio, sobre la política pública y sobre las dinámicas que se manifiestan allí; igualmente se revisaron planes de ordenamiento territorial y disposiciones normativas derivadas de éste que fueron ubicadas en tres momentos de la política de ordenamiento en la ciudad (2000, 2006 y 2016) focalizando en ellos componentes vocacionales, objetivos y estrategias definidas para su implementación (tabla 1)

Tabla 1. Síntesis del diseño metodológico, Elaboración propia.

\begin{tabular}{|c|c|c|c|}
\hline \multicolumn{4}{|c|}{ Diseño metodológico } \\
\hline Método & Técnica & Procedimientos & Resultados \\
\hline Documental & \begin{tabular}{l}
$\quad$ Recolección \\
de entrevistas \\
con Habitantes \\
históricos del \\
lugar que se \\
reubicaron o se \\
negaron a ello; \\
habitantes \\
nuevos que \\
toman predios \\
luego del POT de \\
2000 \\
\\
\multicolumn{1}{c}{ Revisión } \\
documental sobre \\
política pública \\
territorial del \\
municipio y los \\
asentamientos
\end{tabular} & $\begin{array}{l}\text { Análisis- interpretación: } \\
\text { Contextos del sujeto y del } \\
\text { territorio: } \\
\text { Análisis- Interpretación de } \\
\text { impactos socioeconómicos sobre } \\
\text { el sujeto y el territorio luego de } \\
\text { implementado el POT del } 2000 \text { en } \\
\text { la ciudad }\end{array}$ & $\begin{array}{l}\quad \text { Esto permitió } \\
\text { analizar dinámicas } \\
\text { desterritorializantes } \\
\text { de la Política } \\
\text { pública sobre el } \\
\text { sujeto habitante }\end{array}$ \\
\hline
\end{tabular}

Finalmente, la información etnográfica/ documental fue cruzada para su comparación desde cuatro dimensiones: social, económica, ambiental y político- administrativa; obteniendo con ello correlaciones entre el sujeto y la gobernanza que permitieron comprender críticamente el fenómeno analizado sobre la desterritorialización al habitante y los vacíos en la política 
pública aún vertical y jerarquizada. Con ello se procedió desde el desarrollo territorial sostenible a plantear posibilidades de transformación que iniciaron situando al habitante en un papel relevante de la construcción de ciudad y terminaron por definir distintas dimensiones de lo sostenible integradas de forma holística a la política pública territorial (tabla 2)

Tabla 2. Síntesis correlación por dimensiones

\begin{tabular}{|c|c|c|}
\hline Dimensión & Objetivo & Resultados \\
\hline $\begin{array}{l}\text { Sociocultural } \\
\text { Económica } \\
\text { Ambiental } \\
\text { Político- } \\
\text { administrativa }\end{array}$ & $\begin{array}{l}\text { Reflexionar sobre la política pública } \\
\text { territorial en el marco del desarrollo } \\
\text { sostenible territorializado: una política } \\
\text { integral holística para proporcionar } \\
\text { sostenibilidad efectiva. } \\
\text { Plantear una política territorial que } \\
\text { tome en cuenta la condición } \\
\text { socioeconómica del sujeto habitante en } \\
\text { relación con su territorio (dimensión } \\
\text { social- económica- política) }\end{array}$ & $\begin{array}{l}\quad \text { Esto permitió interrogarse } \\
\text { por la política pública desde } \\
\text { marcos de significación del } \\
\text { habitante: una política pública } \\
\text { territorial que pasados } 14 \text { años } \\
\text { continúa sin incluir e integrar el } \\
\text { desarrollo sostenible } \\
\text { territorializado }\end{array}$ \\
\hline
\end{tabular}

\section{Marco Teórico}

Analizar dinámicas territoriales de escala local sobre asentamientos catalogados por el ordenamiento territorial como informales implicó el debate del territorio como una categoría relacional en la que complejas interacciones entre actores sociales confluyen en relaciones de tipo solidaria o conflictiva para apropiar- controlar el espacio (Santos, 2000; Haesbaert, 2011) A partir de allí, el análisis se centró sobre una espacialidad: los asentamientos ubicados a lo largo del río Otún, a su paso por la franja urbana de la ciudad de Pereira, y sobre unos actores sociales que, según los resultados obtenidos, son antagónicos tanto en sus formas de representación territorial, como en las acciones que cada uno ejecuta: la gobernanza actor de transformación políticojurídica (Farinós y Romero, 2007) y el sujeto habitante (Lindon, 2002) actor social de lo cotidiano. 
Sobre este carácter relacional del territorio, geógrafos como Milton Santos y Henri Lefebvre, ya desde décadas del setentaochenta, plantearon elementos que dotaron de contenido esta categoría. En este sentido, Santos (2000) define la interacción "indisoluble, solidaria y también contradictoria, de sistemas de objetos y de acciones” (Santos, 2000, p. 54). y Lefebvre (2000) plantea una dialéctica de producción y reproducción social del espacio, "en conexión con las fuerzas productivas (...) elaborado por una voluntad y por un pensamiento colectivo" (Lefebvre, 2000, p. 89) que en términos políticos es, "producto de una actividad que implica lo económico, lo técnico, pero que va mucho más allá: productos políticos, espacios estratégicos" (p. 96) Más recientemente, Montañez y Delgado (1998), al asumir el carácter relacional del territorio, lo definen como un "escenario de las relaciones sociales y no solamente el marco espacial que delimita el dominio soberano de un Estado" (p. 122) señalando más adelante como éste, "contiene límites, transmite la idea de cerramiento (...) está ligado a la idea de poder político, estatal o privado en todas las escalas". (p. 123)

De este modo, la dinámica social- territorial que confluye sobre los barrios Risaralda, San Juan de Dios y Salazar Robledo, se definió por dos actores sociales en los alcances de esta investigación: el sujeto que desde su condición de habitante construye cotidianamente el territorio, lo vive, representa, significa (Soja, 2008); sujeto que espacializado, es "motor de la vida social" (Lindón, 2009, p. 10), que a través de su actuar en el mundo, de su habitar, "hace y modela los lugares y al mismo tiempo, recibe el influjo de los lugares que habita" (p. 10). De otro lado el sujeto de la gobernanza que define los límites y horizontes del ordenamiento y gestiona la ciudad (Farinós y Romero, 2007; Fernández, 2005). Es la territorialidad que planifica y direcciona la producción social de espacio, que define la vocación de servicios y enclave de la ciudad y que materializa la plataforma funcional de servicios como lo expresa el plan de ordenamiento. 
Sin embargo, la confluencia no es horizontal por el contrario se define asimétrica- desigual. El sujeto apropia el espacio por necesidad y subsistencia, "los pueblos o los grupos más subalternizados se territorializan mucho más por apropiación que por dominación" (Haesbaert, 2013, p. 27). La gobernanza lo hace desde racionalidades de mayor alcance, "verticalidades, flujos, áreas luminosas, grandes sistemas de ingeniería, redes, nuevas órdenes, formas de organización y políticas planetarias, así como la producción incesante de normas tanto de la esfera pública como privada" (Silveira, 2009, p. 2). Este es el sentido de la asimetría que desemboca en relaciones de tensión y conflicto entre un sujeto que busca apropiar un territorio para la subsistencia, situando en este espacio condiciones válidas para sopesar los contextos de insatisfacción social que lo rodean y consolidando con ello sentidos que estrechan arraigos y pertenencias; con una gobernanza que busca empoderar espacio de control, de planeación y gestión sobre modelos de ciudad en el circuito de competitividad capitalista, neoliberal,

El mundo puede ser representado como un patrón de fuerzas sociales que interactúan, en el cual los estados juegan un papel intermedio, aunque autónomo, entre la estructura global de las fuerzas sociales y sus configuraciones locales dentro de países particulares (...) el poder es visto como algo que emerge de los procesos sociales. (Cox, 2013, p. 148)

De allí el proyecto de plataforma funcional y de vocación turística que adquiere este paso urbano del río Otún en el ordenamiento territorial de la ciudad desde el año 2000 (Concejo de Pereira, 2000) hasta su continuidad en el 2016 (Concejo Municipal, 2016) y, con ello, la gobernanza sobre este fragmento de ciudad que obliga al habitante a reubicarse o vender. La gobernanza terminó por delimitar fronteras de ordenamiento, declarar nuevos usos y vocaciones del suelo y zonas de protección ambiental municipal (CARDER, 2008) de recuperación paisajística bajo la figura de parque lineal ecoturístico o malecón Otún (CARDER- 
PNN, 2010) de espacio público, de corredor ambiental integrado al sistema funcional de ciudad y de mejoramiento de entornos, mitigación de riesgos y el mejoramiento de asentamientos; en las que ni el sujeto, ni las relaciones democratizantes (Farinós y Romero, 2007) encontraron cabida alguna.

El problema como se observa no radica en la tensión sujeto/ gobernanza algo tan natural en la diversidad de miradas sociales, radica en el tipo de política pública que orienta el ordenamiento de la ciudad de carácter desterritorializante para el sujeto, política alejada de prácticas de gobernanza multinivel- participativas,

Es necesario superar las tradiciones, distribuciones competenciales rígidas - cuando no ineficientes- por nuevos principios y nuevas formas de diseñar y aplicar las políticas territoriales o las políticas que tienen impacto territorial. Desarrollo territorial sostenible, gobernanza y territorialidad (entendida no solo como especificidad territorial e identidad que otorga derechos, sino también como caldo de cultivo de donde surge la ownership (empresa colectiva estructurada), que permite a los actores de un territorio participar activamente en la elección de la visión territorial deseada para el propio territorio, concebido en interrelación con el resto del territorio-red (...) son las piezas clave de este nuevo y emergente paradigma de la planificación de las políticas (Farinós y Romero, 2007, p. 11).

Política pública que para (Ortiz, 1998) debería expresar e integrar la escala del sujeto que habita, no solo como actor participante sino como dimensión categórica, a partir de la distinción y la definición del ámbito, delimitado por las áreas que requieren de un tratamiento diferenciado, considerando los factores limitantes, las complejidades y características funcionales y relacionales peculiares del sujeto y del territorio, como de los recursos o valores a preservar, o bien para eliminar situaciones de desigualdad y de desequilibrio territorial. 
Es por eso, que en la lectura territorial del ordenamiento analizado sobre los barrios que ocupan la franja del río Otún a su paso por la ciudad de Pereira se planteó el desarrollo sostenible territorializado (Gutierréz, 2012) como concepción contrapuesta a esas relaciones sociales hegemónicas del desarrollo que excluyen e imponen al habitante racionalidades desterritorializantes. Lo que emerge con esta concepción de la política pública es un nuevo marco de institucionalidad que entra en dialogo con quienes habitan y hacen territorio y a su vez con las necesidades propias del ordenamiento y el desarrollo, es decir, la "articulación y equilibrio entre las estructuras y los elementos sociales, económicos, ambientales y políticos institucionales" (Gutiérrez, 2012, p. 242). Una epistemología definida por el buen vivir y el bien estar como fundamentos del desarrollo, "no es posible pensar en un desarrollo que separe sociedad, cultura, economía y naturaleza” (p. 241).

Sobre esta misma línea, en referencia a la resignificación del desarrollo y con este de la política territorial, Massiris (2009), desde la perspectiva del desarrollo territorial de los países que en América Latina vienen proponiendo modelos alternativos a la hegemonía del desarrollo, propone,

Armonizar los objetivos de desarrollo económico (crecimiento, productividad, competitividad), con los de desarrollo social (erradicación de la pobreza, inclusión social) y de aprovechamiento sostenible de los recursos naturales y protección de las condiciones ambientales (conservación de biodiversidad, prevención de desastres, reversión cambio climático) que hagan posible el desarrollo humano integral y sostenido" (p. 106)

Las posibilidades son vastas si se toman de referente los virajes que desde epistemologías del buen vivir y el bien estar se vienen posicionando, "La inmigración de población hacia la ronda de un río amerita una perspectiva teórica que permita ver las complejas relaciones que se establecen entre la población que origina el movimiento inicial y el vínculo con (...) ese lugar" (Amorocho Pérez, 2012, p. 18). Planteamientos que encuentran 
su principal base operativa en la holística del sujeto y de la vida social, en la multidimensionalidad que es interacción equilibrada entre lo económico, social, lo político, cultural y ambiental,

En lo social prima la equidad y la justicia social y territorial; en lo cultural, la identidad, el arraigo y la pertenencia territorial (Dimensión 1); en lo económico, la igualdad social y territorial (Dimensión 2); en lo ambiental, la sostenibilidad y armonía ambiental y territorial (Dimensión 3); en lo político institucional, la gobernabilidad y la cohesión social (Dimensión 4). (Gutiérrez, 2012, p. 243)

De esta forma, la apuesta teórica desde la cual se fundamenta esta investigación plantea reflexiones con sentido crítico sobre la dinámica territorial en las orillas del río Otún a su paso por la comuna Otún en la ciudad de Pereira; reflexión que se dirige tanto sobre la realidad conflictiva- asimétrica de la política de ordenamiento como, sobre alternativas posibles en las que el sujeto habitante tenga cabida.

\section{Resultados}

\section{Desarticulación dimensional de la política pública territorial}

Esta reflexión, parte de la mirada crítica a los procesos de fragmentación territorial iniciados hacia el año 2000 sobre los asentamientos del río Otún en la ciudad de Pereira con la entrada en vigencia de la política pública de ordenamiento que, al estar sujeta a racionalidades económicas funcionales al capital, terminaron por reconfigurar estos espacios y por desterritorializar lógicas habitantes ya territorializadas cincuenta años antes. En este sentido, toma forma la fragmentación del territorio al ser declarada una política de usos del suelo vinculada a la protección sobre asentamientos ya existentes en el río Otún y al trazar, una política cuyos objetivos consolidan la zona de planificación Otún bajo el carácter de protección hídrica, paisajística o de suelos (tabla 3). 
Tabla 3. Desarticulación dimensional en las orillas del río.

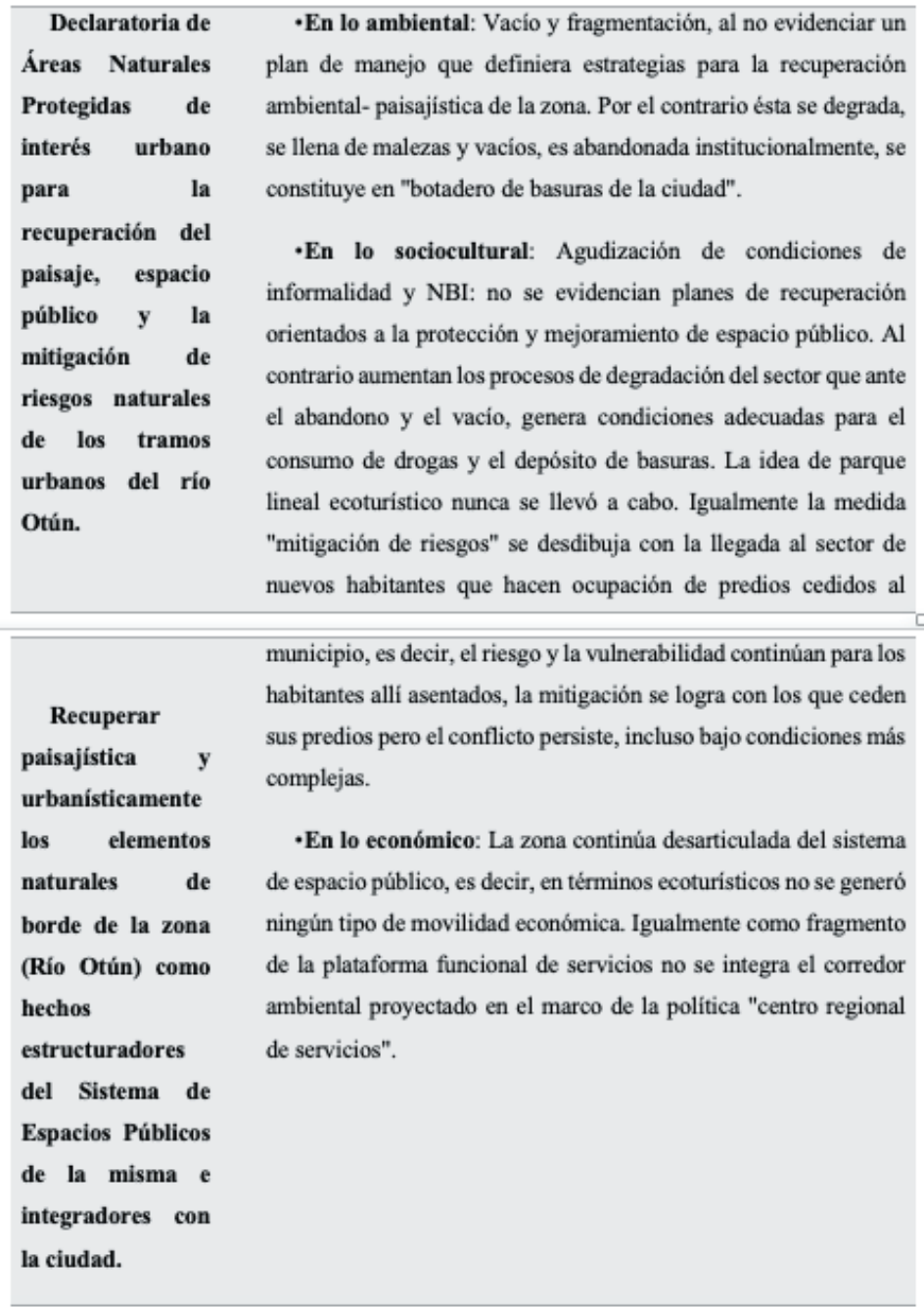

Elaboración propia.

Como se observa, la declaratoria de protección ambiental en el ordenamiento territorial de la ciudad (Concejo de Pereira, 2000) no articuló políticas claras en sentido multidimensional. Desde una óptica ambiental, por ejemplo, se pueden visualizar sobre estos asentamientos pasados veinte años de su vigencia y 
cuatro de su renovación bajo un nuevo decreto de ordenamiento (Concejo Municipal, 2016) una serie de espacialidades vacías y degradadas que antes de proteger y generar bien- estar para quienes allí habitan, han terminado por fragmentar la zona. Sobre ello el Informe de los recursos naturales y del medio ambiente elaborado por la Contraloría municipal de Pereira (2009) en el que se examinan acciones de la política pública entorno al cuidado ambiental, dice,

Es evidente falencias en la estructura organizacional de la Secretaría en cuanto a su desempeño ambiental puesto que no se observa un responsable que direccione las actividades en cuanto al área ambiental competente, no se ha incorporado una política ambiental ni un plan de acción ambiental, así como una metodología o Documento matriz que arroje indicadores de seguimiento que establezca los registros de los Planes de Manejo Ambiental adoptados y las obras realizadas (p. 282)

Igualmente, el diagnóstico de la Unidad de Planificación 7 (UP7) plantea, "El Corredor Ambiental del Tramo Urbano del Río Otún tiene particular importancia en la UP7, donde se registran problemas de riesgo, alteración del paisaje y pérdida de zonas forestales protectoras" (Secretaria de planeación, 2010, p. 70).

Focalizando la mirada analítica sobre dimensiones sociales contenidas en el ordenamiento territorial se leen intensiones de articulación como "Es necesario articular los parques, plazas, plazoletas, zonas recreativas y áreas verdes existentes, como parte del Sistema de Espacios Públicos Efectivos" (Concejo Municipal, 2016, p. 81) Sin embargo, este referente no se ha hecho efectivo; el espacio público antes que equitativo-justo ha alterado las relaciones de informalidad de la zona y ha incrementado condiciones sociales de vulnerabilidad, es más para el diagnóstico UP7 (Secretaria de planeación , 2010) es un territorio que se encuentra fuera de los cálculos del espacio público urbano, 
Esta franja en la actualidad no puede ser considerada como un espacio público efectivo, y que, para poder lograr el objetivo del Plan de Ordenamiento de consolidar esta zona como el Parque Lineal del Río Otún, es necesario tomar medidas inmediatas para evitar que se sigan construyendo los espacios que aún están libres, y plantear una seria estrategia de recuperación de la zona de protección del río, incluidos procesos de reubicación de estas viviendas. (p. 72)

Lo que se lee es un incremento de las inequidades, una zona sobre la cual aumentaron los lugares de consumo de drogas y de depósito de residuos, con ello la inseguridad y las enfermedades, así se encuentra expresado tanto por el habitante, "estaba abandonado, estaba vacío (...) y porque se metían mucho los ladrones a esas partes a fumar vicio (...) a robar" (entrevista 3_3: min: 6:00) como por el diagnostico UP7 (2010).

La totalidad de los espacios públicos existentes en la Unidad de Planificación 7 , son de carácter local, diseñados para las necesidades básicas de la población, que según manifiestan los habitantes requieren de mantenimiento y acompañamiento de programas sociales que incentiven el uso y apropiación de estos lugares, para reducir su uso por jóvenes consumidores de sustancias psicoactivas. (p. 93)

Desde la dimensión económica, la dinámica en los asentamientos se vinculó al fragmento funcional de la plataforma de servicios, un sentido racionalizado (Silveira, 2009) que al territorializarse en las orillas del río proyectó un gran corredor ambiental- paisajístico, "desde la Laguna del Otún, hasta la desembocadura de este sobre el río Cauca" (Concejo Municipal, 2016, p. 26). Como parte de las vocaciones "ecoturísticas" y de "servicios" de la ciudad (Concejo de Pereira, 2000; Concejo Municipal, 2016) En esta vía luego de 20 años de representaciones que articularon discursivamente el territorio informal al territorio del progreso, no se evidencia transformación alguna, 
A diferencia de otras zonas de la ciudad, en la UP7 no se han presentado grandes transformaciones de usos, ni presión del mercado para cambiar su vocación. Algunas de las razones para que esta UP cuente con estas particularidades pueden ser las siguientes (...) Es un sector que ha sido considerado inseguro y peligroso; No se ha desarrollado ningún proyecto detonante que incentive el desarrollo y la inversión en la zona. (Secretaria de planeación, 2010, p. 177)

Al contrario, las condiciones de vida se hacen cada vez más difíciles,

Yo estoy en red unidos el departamento para la prosperidad (...) me dio a mí para una tienda yo tenía una tienda ahí, un negocio y todo, más sin embargo a ellos no les importó (...) yo iba pa delante con esa tienda ahora ya no tengo nada. (entrevista 11_1: $\min : 7: 42$ )

Lo que terminó por imponerse en última instancia fue la desigualdad social- territorial (Figura1).

Figura 1. Discurso del sujeto habitante nodo 2000.

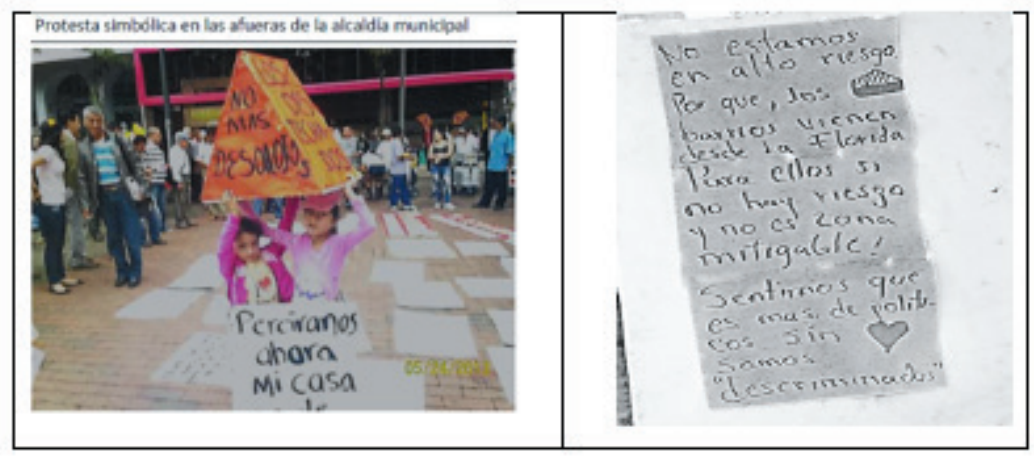

Tomado de álbum de entrevistada: Marina García. 


\section{Desarticulación territorial: la contradicción habitante- gobernanza}

La reflexión crítica sobre la política territorial implica igualmente el encuentro y correlación de territorialidades, que para el caso concreto fueron definidas por la gobernanza y por las representaciones que el sujeto habitante construye. Ello considerando que existen y se perciben contradicciones fuertes de significación social, económica, ambiental y política, entorno al desarrollo territorial que proponen ambas visiones: lo que en la gobernanza es equivalente no lo es en los sentidos de mundo del habitante. Es decir, existe una desarticulación entre sentidos y representaciones habitante- gobernanza que constituye uno de los núcleos fundamentales de conflicto en la política territorial, la política de inclusión- participación, por ejemplo, continúa siendo nominal en la mayoría de los casos y se reconoce su movilidad más en la racionalidad de mercado que desde el sujeto y sus particularidades (Farinós y Romero, 2007; Gutiérrez, 2010; 2012).

Para efectos del análisis propuesto se tomaron de referencia aspectos de la política pública incluidas en el ordenamiento territorial de la ciudad y desde allí se generan correlaciones de significado y representación con el sujeto habitante, tal como se muestra en las tablas.

Tabla 4. Representaciones sobre la política ambiental.

\begin{tabular}{|c|c|}
\hline \multicolumn{2}{|c|}{ Dimensión ambiental } \\
\hline Representaciones del sujeto habitante: & Politica gobernanza \\
\hline $\begin{array}{l}\text { "Da tristeza porque puede más adelante } \\
\text { puede que vayan destruyendo el barrio } \\
\text { Risaralda a medida que dicen que quieren } \\
\text { tumbar todas las casas a medida que dicen que } \\
\text { van a volver eso diferente" (entrevista } 3 \text { 3: } \\
\text { min: } 1: 10 \text { ) }\end{array}$ & $\begin{array}{l}\text { Garantizar el desarrollo territorial del } \\
\text { municipio de una forma equilibrada y } \\
\text { ambientalmente sostenible, reduciendo } \\
\text { los desequilibrios territoriales y } \\
\text { mitigando los impactos ambientales }\end{array}$ \\
\hline
\end{tabular}




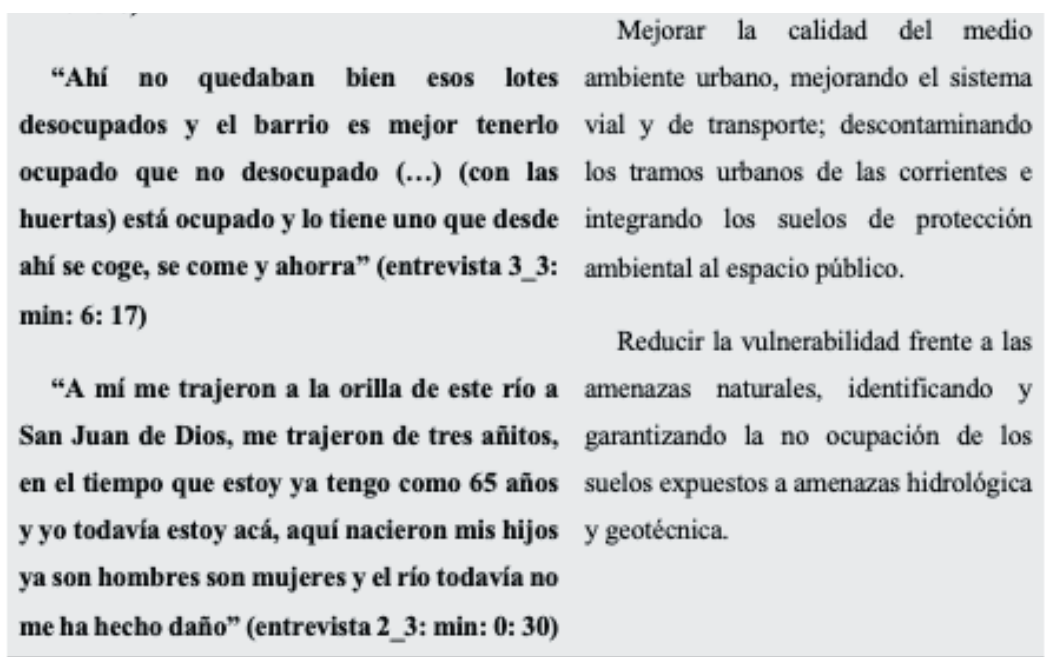

Elaboración propia.

Lo que evidencia la tabla 4 al correlacionar contenidos de la política territorial ambiental con relatos del sujeto habitante, es precisamente lo que se viene afirmando una clara desarticulación de ambas perspectivas. En este sentido mientras la gobernanza visualiza el desarrollo territorial sostenible desde la "integración de suelos de protección" y la "no ocupación" de estos; para el habitante estos lotes nunca debieron haberse desocupado al agudizar ciertos conflictos (basuras- delincuencia) o debieron intervenirse mediante proyectos que los involucrara (fragmento de entrevista 3_3 tabla 4) Igualmente, la "reducción de vulnerabilidades" como vía para "mejorar la calidad del medio ambiente urbano," escapa a los campos de representación del habitante al encontrar significados sobre la convivencia histórica con un cauce que nunca ha hecho daño (fragmento de entrevista 2_3 tabla 4).

Frente a esto, la Contraloría municipal de Pereira (2009) en auditoría realizada al componente ambiental de la Secretaría de Gobierno señala que "no se realizaron programas por parte de la Secretaria donde se involucre la comunidad en campañas para la protección ambiental, así como inversión en investigación para el 
desarrollo de temas ambientales" (p. 454). En igual sentido, Díaz Giraldo (2007) pone en evidencia la desarticulación de la política territorial con los campos de representación del sujeto al plantear, "la problemática ambiental no puede ser vista como un esquema espacio -temporal estático, cuya expresión pueda ser abordada a partir de acciones puntuales y sin un reconocimiento de los procesos que la han configurado" (p. 30).

En la misma vía, Cubillo Quintero (2008) propone que

Cada problemática ambiental exige unos conocimientos, saberes, métodos y la participación de agentes sociales que no se pueden definir sin conocer cómo se desenvuelven, influencian y son influenciados por el ambiente. Los aspectos culturales son prerrequisito para explicar las razones históricas, sociales y políticas de cada problemática ambiental. (p. 1)

Tabla 5. Representaciones sobre la política ambiental.

\section{Dimensión política}

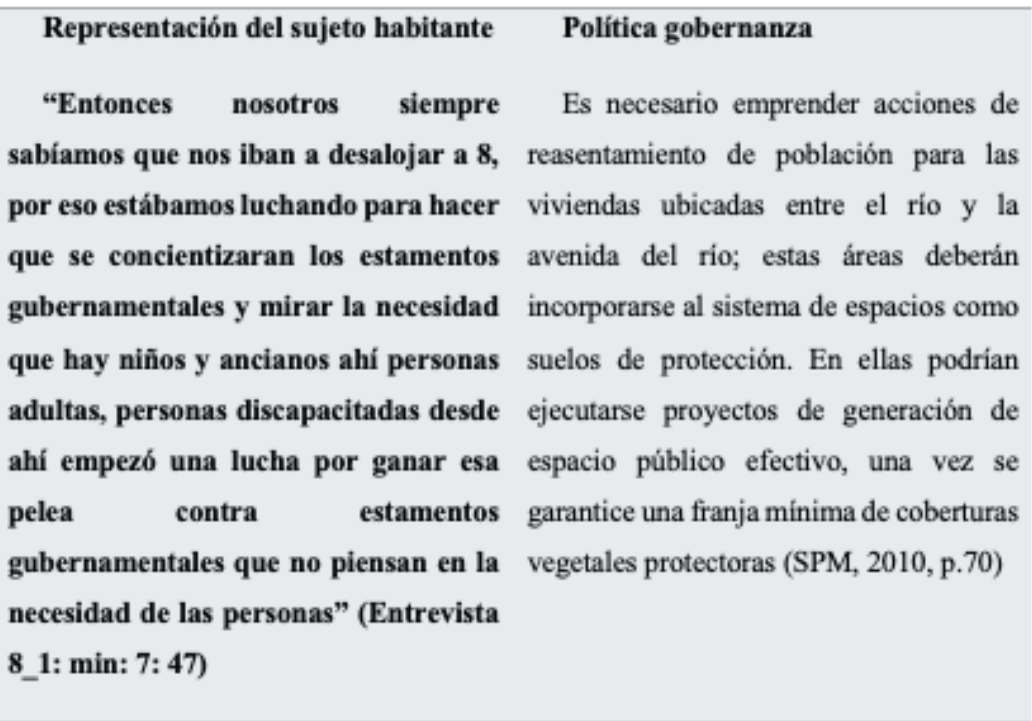

Fuente: Elaboración propia. 
Los contenidos de la tabla 5 permitieron delimitar tensiones de orden político entre la gobernanza y el sujeto. Tensiones alrededor del "reasentamiento", la "ejecución de proyectos" y las disposiciones normativas del suelo, frente a lo cual el sujeto declara actitudes de resistencia, "nosotros siempre sabíamos que nos iban a desalojar (...) por eso estábamos luchando" (entrevista 8_1, tabla 5).

Esto, ubicó campos de reflexión alrededor de la cohesión social, la aceptación político- institucional o el reconocimiento de la gobernanza, dado, que el sujeto significa y dirige acciones que permiten verificar oposiciones y resistencias a una política territorial en la cual no se siente participante, ni incluido. En esta dirección, Cubillo Quintero (2008) concluye sobre los procesos de desarticulación de la política pública y el sujeto asentado sobre la cuenca del Consotá, "en conclusión, los procesos de informalidad en el tramo de la cuenca del río Consotá, confrontan las pretendidas políticas integrales y de largo plazo auspiciadas desde las diferentes escalas territoriales" (p. 22).

Como elemento adicional, en la descripción de procesos políticos de resistencia en la cuenca del río Otún, que denotan la ausencia de cohesión social y de reconocimiento institucional, la narración de la entrevistada Martha Agudelo señala que

Cuando se ganó lo de la corte constitucional (Sentencia T- 631/13) teníamos que hacerle un desacato al señor alcalde por incumplir la norma que le ordena la honorable corte, el señor no lo hace, la defensoría no lo hace cumplir, la personería, nadie de aquí lo hace (...) le dieron 21 días para responderle a todas las familias, no lo ha hecho, él no lo va a hacer (...) me tocó ir meterme a la oficina al defensor yo sabía que él está de parte de ellos yo simplemente le exigí mis derechos (...) me voy para Bogotá a tocar puertas ya tengo citas (...) me voy a armar un campamento en la casa de Nariño voy a llevar carteles, voy a poner que somos Pereira, desalojados por el señor Vásquez, que no tenemos defensor del pueblo acá en Pereira. (Entrevista 10_4: min: 0:24) 
Esto conduce desde un punto de vista crítico, a "Revisar el tipo de propuesta de cultura y sociedad que subyace en la actual forma del ser social y a los presupuestos filosóficos y éticos que la orientan" (Gutiérrez, 2012, p. 242).

Finalmente, al revisar dimensiones sociales- económicas en la política pública territorial, en correlación con las representaciones del habitante se observaron igualmente lógicas desarticulantes, que permiten ubicar campos de reflexión sobre la inequidad y la desigualdad social- territorial contenidas en la política pública de ordenamiento. En este sentido, ante las racionalidades sociales de la gobernanza el habitante propone sus propias lecturas, sentidos y significación (tablas 6 y 7 ).

Tabla 6. Representaciones sobre la política social.

\begin{tabular}{|c|c|}
\hline \multicolumn{2}{|l|}{ Dimensión Social } \\
\hline Representaciones del sujeto habitante: & Politica gobernanza \\
\hline "ahí está de arrimada la viejita también está donde & Constituir el espacio público \\
\hline la hija, quedo sin casa también, como vivian de bueno & en el principal elemento \\
\hline $\begin{array}{l}\text { ahí hombre, es que eso ahí vivian muy bueno" } \\
\text { (entrevista 2_2: min: 0: 19) }\end{array}$ & $\begin{array}{l}\text { articulador y estructurador del } \\
\text { desarrollo espacial de la ciudad. }\end{array}$ \\
\hline "En San Joaquín hermano y esas casas donde las & Consolidar el desarrollo del \\
\hline hicieron eran a un lado de ese basurero donde botaban & casco urbano, aprovechando su \\
\hline todas las basuras de aquí de Pereira allá en San & capacidad instalada en servicios \\
\hline Joaquín entonces a mí no me gustó por allá, dije yo por & e infraestructura. \\
\hline allá no me voy" (entrevista 2_3: min: 3 : & Impulsar procesos \\
\hline $\begin{array}{l}\text { "En Málaga fue otra (...) uno enseñado a vivir en } \\
\text { este barriecito que este barrio hermano toda la vida ha } \\
\text { sido muy sano Risaralda este barrio es muy sano } \\
\text { hermano, por aquí no se escucha que robaron a } \\
\text { alguien" (entrevista } 2 \text { 3: min: } 5: 27 \text { ) }\end{array}$ & $\begin{array}{l}\text { Mejoramiento Integral en } \\
\text { asentamientos sub-normales, } \\
\text { generando un entorno urbano } \\
\text { con mejor calidad de vida. }\end{array}$ \\
\hline
\end{tabular}

Fuente: Elaboración propia. 
Tabla 7. Representaciones sobre la política económica.

\begin{tabular}{|c|c|}
\hline \multicolumn{2}{|l|}{ Dimensión Económica } \\
\hline Representaciones del sujeto habitante: & Política gobernanza: \\
\hline $\begin{array}{l}\text { "Supongamos Ancízar con esas piezas que él tiene } \\
\text { ahí con eso paga servicios y todo (...) esa es la pensión } \\
\text { mía donde yo no tuviera eso no sé qué hijuepuercas } \\
\text { tuviera yo" (entrevista 2_3: min: 7: 10) } \\
\text { "Toda de material no había nada de bareque (...) } \\
\text { me quede contenta con mi casa pero era una parte } \\
\text { muy lejos donde yo tenía que transportarme con los } \\
\text { muchachos (...) tenía que darles todos los días el } \\
\text { pasaje (...) la casa muy buena pero lo económico para } \\
\text { uno estudiar y levantarse la comida no estaba bien" } \\
\text { (entrevista 3_2: min 8:50) } \\
\text { "como uno no tiene oportunidades de empleo y de } \\
\text { vivienda, hoy en día sí es un poco más fácil acceder a } \\
\text { una vivienda por el ahorro programado que existe, } \\
\text { anteriormente tenía uno un sueldo de dos mínimos } \\
\text { (...) y uno si acaso trabaja de día para comer de noche } \\
\text { (entrevista 2_3: min: 8: } 52 \text { ) }\end{array}$ & $\begin{array}{l}\text { Manejar las zonas de } \\
\text { protección de los principales rios } \\
\text { y quebradas del municipio como } \\
\text { corredores ecológicos } \\
\text { estructurantes del espacio } \\
\text { público, que integren las grandes } \\
\text { áreas ecoturisticas rurales con los } \\
\text { parques urbanos. } \\
\text { Conectar, articular e integrar } \\
\text { el sistema de áreas de } \\
\text { conservación y reserva turistica } \\
\text { del municipio, a través de vías } \\
\text { escénicas y paisajisticas y de } \\
\text { cables aéreos, que permitan su } \\
\text { valoración y disfrute, así como su } \\
\text { integración con los centros } \\
\text { urbanos de la región } \\
\text { metropolitana }\end{array}$ \\
\hline
\end{tabular}

Fuente: Elaboración propia.

Los enunciados alrededor del mejoramiento integral y la calidad de vida contenidos en el POT, encuentran sus tensiones y conflictos con las representaciones que el habitante tiene sobre las condiciones de vida deterioradas, así el entrevistado Ancízar Murillo sintetiza términos como "arrimados" y describe los territorios de reubicación como "botaderos" o de entornos "peligrosos", recurriendo a remembranzas de un buen vivir en dónde antes se habitaba, las orillas del río. Es decir, en el sujeto que habita no conviven las representaciones de la gobernanza asociadas al "desarrollo espacial" o el "mejoramiento integral", la ausencia de inclusión en las políticas propuestas puede ser un 
signo que defina esta actitud; como lo pueden ser también los campos propios de significación que rodean al habitante y son movilizados más desde su misma subsistencia. Así, el desarrollo para el habitante se entiende mejor si se focaliza el bien- estar de su hábitat, "es que eso ahí vivían muy bueno" (entrevista 2_2 tabla 6). Que desde una política que promete más de lo que materializa, una política teleológica que sirve de base a lecturas topo-fóbicas (Tuan, 2007) como lo evidencia el entrevistado Ancízar Murillo sobre los posibles espacios de reubicación.

Frente a la dimensión económica, Díaz Giraldo (2007) visualiza un modelo en el que

Aún persistela "orientación desarrollista" yla naturaleza concebida como "recurso"; la "orientación optimista" de la aplicación tecnológica y el crecimiento económico, en un contexto que ahora le exige metas relacionadas con la sustentabilidad, la mitigación y adaptación al cambio climático global. (p. 9)

Y Gutiérrez (2012) propone "superar la perspectiva economicista o productivista del desarrollo expresadas en concepciones limitadas del crecimiento económico y la conservación o preservación del medio ambiente y los recursos naturales" (p. 253).

Como se evidencia en la tabla 7, el proyecto económico sobre los asentamientos del río está relacionado directamente con la movilidad ecoturística, de allí las racionalidades gobernanza sobre "corredores ecológicos estructurantes" que "integran áreas" de la ciudad a través de "vías escénicas". Esta vocación del territorio a pesar de contener elementos que deben ser tenidos en cuenta en la planificación territorial dado su énfasis en la protección medioambiental, no encuentra en el sujeto habitante, marcos de representación al ser esta una visión que no incluye campos que en términos de subsistencia sean significativos para el sujeto, porque no trasciende en su necesidad inmediata al contrario los agudiza negativamente. 
La desarticulación aquí se hace más evidente, dado, que la dimensión económica representa para la gobernanza un objetivo primordial: como sistema estructurante ambiental y enclave ecoturístico de carácter regional. Para el sujeto esta dimensión no aparece en sus rejillas de sentido, ninguno de los entrevistados dio cuenta de este aspecto; cuando es mencionado (en fragmentos muy pequeños de las entrevistas) se alude a creencias lejanas sobre algún proyecto que se adelanta en la zona,

Supuestamente eso es protección de la CARDER (...) con los días nos dimos cuenta que era que la CARDER no tenía dinero entonces que no podía sacar todas las personas de ahí (...) iban a hacer un malecón ahí o yo no sé qué es lo que van a hacer ahí, el caso es que no tienen dinero. (Entrevista 8_1: min: 10:05)

El sujeto se encuentra instalado en su propio sentido del mundo, "donde no tuviera eso no sé qué hijuepuercas tuviera yo" (entrevista 2_3, tabla 7), "era una parte muy lejos donde yo tenía en qué transportarme" (entrevista 3_2, tabla 7), "uno si acaso trabaja de día para comer de noche” (entrevista 8_1, tabla 7). El proyecto ecoturístico el sujeto no lo incluye, no lo hace parte de su constitución, al contrario, necesita que el habitante salga de la zona para poder desplegarse; en igual medida el habitante no lo incluye en sus representaciones, es un proyecto lejano sobre el cual ha escuchado algún relato inexacto.

\section{Reflexión crítica desde el desarrollo sostenible territorializado}

Finalmente, para plantear un escenario prospectivo, de alternativas claras y posibles, se ubicó como referencia de trabajo desde la propuesta teorizada por Gutiérrez (2012) el quatrivium o cuadriga del desarrollo sostenible (Figura 2) como propuesta alternativa que al integrar las dimensiones sociocultural, económica, ambiental y político- institucional, configura otros sentidos que trascienden "la imposibilidad del sistema de producción capitalista para lograr un desarrollo socialmente 
equitativo y justo" (p. 243). Es decir, una política de ordenamiento territorial que se centre en el sujeto y sus necesidades de hábitat, más que en la negociación espacial de los territorios.

Figura 2. Cuadriga del desarrollo sostenible, componentes, objetivos e intersecciones.

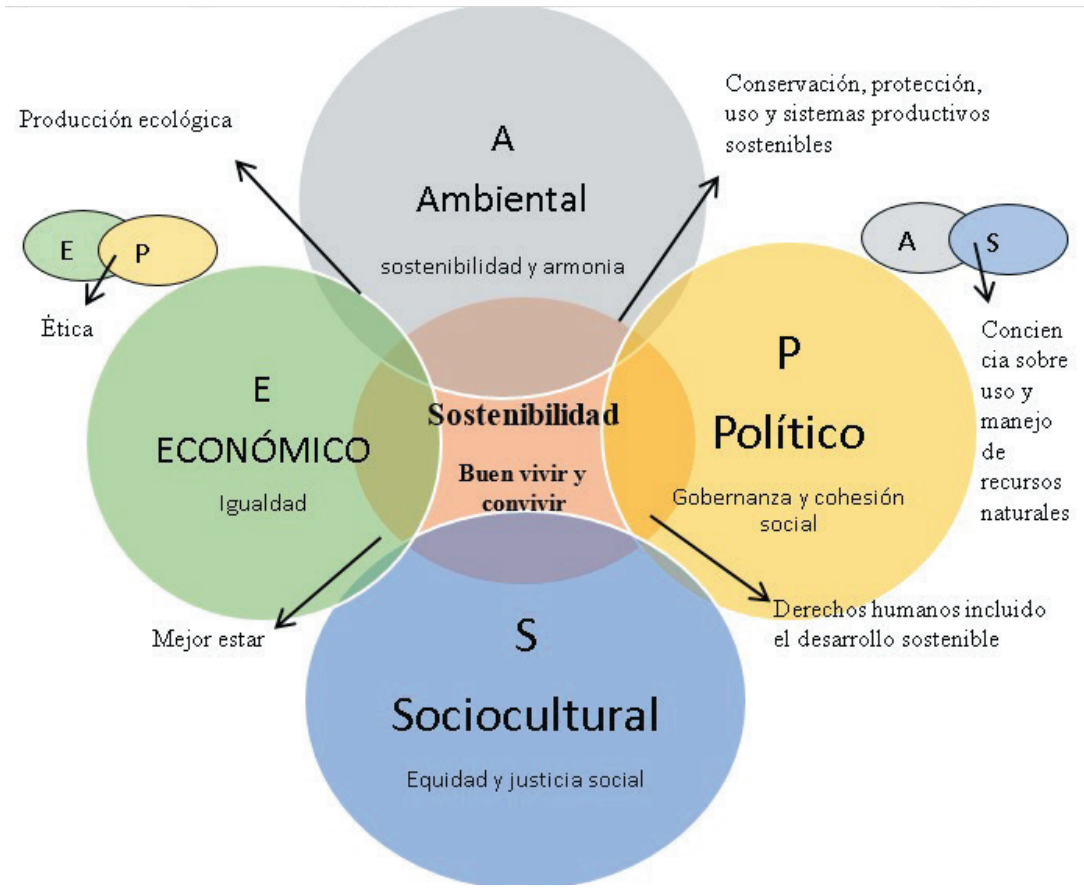

Tomado de Gutiérrez (2012)

Sobre esta base, en la cual se evidencian interacciones multidimensionales de desarrollo, fundamentado en principios del buen vivir y convivir; se plantearon una serie de reflexiones alrededor de la tensión- conflicto presente en los asentamientos de las orillas del río Otún.

De esta forma al evidenciar lógicas de fragmentación/ desarticulación en la política territorial sobre estos asentamientos, lo que debe primar es una resignificación de la misma a partir de la articulación de sus dimensiones. Esto implica asumir de 
forma tangible la propuesta teorizada por Gutiérrez (2012) en torno al desarrollo sostenible territorializado, como marco conceptual- metodológico de acción que reoriente las dinámicas de territorialización y re-territorialización, así:

- Se plantea la construcción dialógica, "diálogo entre las ciencias" (Gutiérrez, 2012, p. 246) y como campo de mayor amplitud, diálogo entre saberes, pues, allí se recogen las representaciones y significados del habitante. De este modo, más allá de indicadores de participación e inclusión, se necesita consolidar verdaderos escenarios de diálogo en los cuales los habitantes sean constructores de políticas junto a sentidos institucionales de mundo. Aquí, la academia juega un papel fundante pues desde allí se pueden articular saberes y metodologías que involucren a la comunidad en el conocimiento de su propio territorio.

- Como construcción dialógica, la base sobre la cual se sustenta se encuentra determinada por un nuevo modelo sostenible, en el que tanto la territorialidad del habitante como el proyecto de ciudad se cohesionen: principio ético- político. Con ello, la prioridad queda definida por un buen vivir que involucre al sujeto habitante, que dimensione sus condiciones sociales- económicas tanto como su contexto de informalidad e insatisfacción (NBI).

- La multidimensional y la multiterritorialidad (Haesbaert, 2011; Fernández Macano, 2009) en la cual cada una de las dimensiones del territorio se integren equilibradamente, "más que un "territorio" unitario como estado o condición definidos de manera clara y estática, debemos priorizar, pues, la dinámica combinada de territorios múltiples" (Haesbaert, 2011, p. 282) .

Ya instalados propiamente sobre los barrios Risaralda, San Juan de Dios y Salazar Robledo, materializando estos postulados del desarrollo territorial sostenible a la realidad contextual que los transversaliza de inequidad e injusticia social- territorial. Se propone una serie de elementos derivados del diálogo social como elemento definitorio de la política pública de ordenamiento. Si la intensión de la gobernanza radica en la protección medioambiental 
de las fuentes hídricas a partir de corredores ambientales, así como la mitigación de riesgos y vulnerabilidad social ante amenazas naturales, ¿cuál es la alternativa posible que permita su construcción con el sujeto habitante? Si se reconstruyen diálogos con el sujeto para determinar sus universos de sentido, y a partir de allí se definen acciones que integren cada uno de estos campos de representación se tendría una política incluyente en la cual se integran diferentes sentidos de mundo y no exclusivamente uno.

Esto impactaría sobre la cuadriga del desarrollo sostenible así:

- Ambientalmente: se podría trabajar de la mano en la preservación del territorio de protección con algunos habitantes que demuestren interés en esta tarea. Sobre esto, la entidad ambiental de la ciudad tiene alguna experiencia al impulsar las huertas urbanas, por ejemplo, la propuesta podría cambiar, como zona de reserva ecoturística, como jardín botánico o continuar como huerta, lo importante sería integrar al habitante, capacitarlo en estas labores y posibilitar su subsistencia.

- El impacto sería inmediato sobre una política que al integrar elementos ambientales con elementos del espacio público no ha sido funcional hasta ahora, que al contrario ha generado nuevos conflictos territoriales y agudizado las condiciones NBI del habitante. Al integrar al sujeto se generan procesos de articulación entre dimensiones sociales, con la equidad; políticas, con la cohesión social; económica, con la igualdad; cultural, con la identidad y el arraigo.

- Socialmente: se hace necesario generar posibilidades equitativas y justas sobre el habitante que ha resistido a la reubicación, al integrar en esta dimensión sus campos de representación social, económico y afectivo; si la dificultad ha radicado en la ruptura de sus medios de subsistencia al alejarlo de su zona histórica de trabajo, la alternativa está en reubicarlo desde una perspectiva de ciudad concentrada, es decir, cerca al lugar donde habita, pero además bajo condiciones laborales que le posibiliten ingresos si su subsistencia depende de su casa- refugio (Bachelard, 1975). 
- Sobre este aspecto hay un referente importante desde la sentencia t- 631/13 con el entrevistado Héctor Fabio García quien fue reubicado tras el fallo de la corte suprema de justicia, además, de brindarle condiciones de vivienda digna, se le aportaron formas de subsistencia a partir de la entrega de un vehículo motor para su trabajo.

- En cuanto al habitante que hace apropiación de predios de manera informal, se plantea igualmente un componente de equidad y justicia, así, como de igualdad; al dar solución primero a su condición de insatisfacción de vivienda, segundo, a las condiciones inadecuadas, de hacinamiento, de servicios inadecuados y de alta dependencia económica en las que se encuentra este al habitar sobre territorios de informalidad. Esto, introduce además un elemento de viraje en las representaciones gobernanza sobre este sujeto, al considerarlo desde sus NBI y no desde lo que hoy se viene configurando como "invasor" por ejemplo:

- Económicamente: desde esta dimensión es necesario restablecer y generar condiciones de igualdad social- territorial con el habitante de los diferentes nodos, pues, uno de los elementos de mayor fuerza en lo contextual y en lo vinculante es precisamente esta dimensión. La apuesta es así integrar esta condición del sujeto como prioridad de la política territorial, proveer de empleo o de posibilidades del mismo a través de la capacitación y fundamentalmente resolver las necesidades insatisfechas entorno a la vivienda.

- Culturalmente: desde esta dimensión, se requiere generar escenarios de interacción armónicos y equilibrados entre territorialidades. Este, es uno de los principales aspectos de crítica sobre la concepción de territorio como apropiación/ control hegemónico, la intensión es posicionar la multiterritorialidad como componente del desarrollo sostenible, de allí lo dialógico de la propuesta. De esta forma, las identidades y arraigos entran en diálogo y concertación continua en marcos de respeto e inclusión. Política: desde esta dimensión, se requiere definir procesos de cohesión social territorial. Si en las actuales condiciones el sujeto no reconoce positivamente la gobernanza y correlativamente 
la gobernanza sitúa campos de representación sobre el sujeto que son excluyentes, no se puede plantear cohesión social, al contrario, se genera conflicto y tensión; el elemento fundamental de dicha cohesión está dado por lo dialógico, por lo incluyente, por la construcción multiterritorial, dando lugar a un marco democrático en sentido amplio que favorece la construcción del desarrollo en sentido del buen vivir y el buen estar como plantea el desarrollo sostenible territorializado.

\section{Conclusiones}

El análisis de las acciones emprendidas desde la gobernanza en materia territorial, así como, sobre las acciones de construcción, resistencia o reconstrucción que hacen los sujetos que habitan estos espacios para apropiar y ejercer control del territorio, se constituyen hoy día en aspectos fundamentales de estudio que deben ser abordados desde marcos epistemológicos y metodológicos que permitan no solo transvalorar los contenidos y conceptos del desarrollo planteado históricamente por el pensamiento neoliberal, sino, enfocar otras posibilidades y alternativas como los propuestos por el buen vivir y el bien estar. De allí que se haya concretado una investigación que desde recorridos por la territorialidad del sujeto y la gobernanza llega hasta el posicionamiento de reflexiones críticas sobre la base de otras alternativas y posibilidades de desarrollo. Esto, permite concluir:

Sobre las categorías de análisis que fueron empleadas

La dinámica territorial analizada sobre las orillas del río Otún es de carácter relacional. Al ser una dinámica en la que se manifiestan diferentes escalas de apropiación/ control de territorio desde diferentes intenciones, representaciones $y$ racionalidades. De esta manera, confluyen fuerzas y relaciones sociales de poder que para el sector se encuentran definidas por la gobernanza y por el sujeto que cotidianamente construye su territorio. Abordar la investigación geográfica desde el enfoque 
relacional del territorio implica la comprensión de lógicas sociales y políticas, multiescalares, multidimensionales y dinámicas que trascienden lecturas sobre éste como simple base del desarrollo o como sustento físico que permite otras relaciones; el territorio es por el contrario parte integral del mismo proceso social y de la misma dialéctica humana.

Plantear políticas territoriales en las que el territorio es visto más allá de su potencial físico y de su condición de plataforma para el desarrollo, implica reconocer el sujeto que lo habita y lo construye, focalizar la mirada sobre sus dinámicas sociales de subsistencia y sus lógicas de apropiación/ control, así como sobre sus representaciones sociales y territoriales. El sujeto habitante es así una categoría de análisis de orden prioritario en la elaboración de este tipo de política pública, pensar el territorio, ordenarlo, planificar sobre éste al margen de la construcción cotidiana del habitante genera, como se observó sobre los asentamientos de la margen sur del río a su paso por el perímetro urbano de la ciudad, conflictos y tensiones que a cambio de una buena vida y un bien estar, agudizan las contradicciones sociales territoriales.

Plantear posiciones críticas sobre concepciones del territorio que toman de base el desarrollo como crecimiento económico y la sostenibilidad como despensa para ese crecimiento, resulta insuficiente; la propuesta debe trascender esta posición política para instalarse en alternativa viable desde lo otro posible. De esta manera, el desarrollo sostenible territorializado permite encontrar operativa y estructuralmente caminos de reflexión y comprensión sobre otros marcos epistemológicos, marcos de equidad y justicia, pero también de cohesión social y conciencia medioambiental; marcos que transvaloran concepciones del desarrollo para territorilizar el buen vivir y el bienestar. Marcos epistemológicos que se proponen como guía para el ordenamiento y la planificación territorial. 
Sobre el desarrollo sostenible territorializado

La dinámica territorial es multidimensional, en este proceso interactúan dinámicas sociales, económicas, políticas, ambientales, normativas, institucionales, emotivas, éticas. Es decir, el territorio es complejo, interactivo, dialectico, de allí que se deba rebasar los marcos establecidos en la máxima ganancia de conglomerados y grupos económicos dominantes y optar por un desarrollo territorial en el marco de la inclusión, la participación colectiva y la justicia espacial.

La dinámica territorial está sujeta a la interacción de múltiples territorialidades, de allí que la cotidianidad y la hegemonía establezcan puntos de fricción tensión que terminan acrecentando los fenómenos sociales conflictivos. En este marco, es importante diseñar políticas inclusivas de participación ciudadana, que inicia con procesos formativos del mismo sujeto frente a su acción política en el territorio y terminan con confluencias socialespolíticas sobre contextos y vínculos territoriales.

De esta forma, plantear reflexiones sobre la política territorial y sobre la subjetividad del habitante, implica el posicionamiento de escenarios necesarios de comprensión. Como escenarios de crítica sobre bases de información que permitan establecer tensiones, contradicciones y conflictos originados de la relación desigual y asimétrica entre fuerzas y relaciones sociales de poder. Como escenarios de alternativas posibles, de nuevas epistemologías que definan rumbos de acción y significación de la política pública territorial.

En este marco, el desarrollo territorial sostenible opera como bisagra entre una política pública que se viene fundamentando primordialmente desde concepciones económicas y entre su resignificación; bisagra que propone otros sentidos del desarrollo y la sostenibilidad territorial a través del buen vivir y el bien estar como nuevas concepciones que guíen el direccionamiento político 
social. Así, se parte del posicionamiento en las orillas del río, de un sujeto político que más allá de su situación de ocupación de riesgo hidrológico o de ocupación de suelos de protección, posicione sus condiciones de existencia que lo hacen ser al interior de un territorio. Un sujeto que en total despliegue de los principios rectores del ordenamiento territorial: Participación, Solidaridad, equidad territorial, Equidad Social y Equilibrio Territorial, tome participación activa en la definición de sus condiciones sociales y económicas ante la reubicación, o ante la permanencia en el territorio o ante las posibles alternativas que la multiterritorialidad permite construir.

\section{Referencias Bibliográficas}

Amorocho Pérez, A. (2012). Redes de inmigración, asentamientos informales y zonas de riesgo de inundación: el caso del Río de Oro en Santander (Colombia). Territorios, (26), 13-34.

Bachelard, G. (1975). La poética del espacio. México D.F.: Fondo de cultura Económica.

Barón, J. (2002). Las regiones económicas de Colombia: Un análisis de clúster. Bogotá: Centro de Estudios Económicos Regionales Banco de la República.

CARDER. (2008). Plan de ordenamiento manejo ambiental de la cuenca hidrográfico del Río Otún. Pereira.

CARDER- PNN. (2010). Acuerdo de Comisión Conjunta No 3, ACUERDO DE MANEJO PARA EL ÁREA DEL PARQUE LINEAL RÍO OTÚN. Pereira.

Concejo de Pereira. (2000). Acuerdo 18. Por el cual se adopta el plan de ordenamiento territorial del municipio de Pereira. Pereira, Colombia . Pereira . 
Concejo Municipal. (2006). Acuerdo 23. Por el cual se aprueba la revisión del plan de ordenamiento territorial del municipio de Pereira. Pereira .

Concejo Municipal. (2016). Acuerdo 35. Por el cual se adopta el plan de ordenamiento territorial del municipio de Pereira. Pereira, Colombia . Pereira.

Contraloría municipal de Pereira. (2009). Informe del estado de los recursos naturales y del medio ambiente. Vigencia 2008. Pereira.

Cox, R. (2013). Fuerzas sociales, estados y órdenes mundiales: Más allá de la Teoría de Relaciones Internacionales . Relaciones Internacionales Número 24,

Cubillo Quintero, L. F. (2008). Las Causas Estructurales de la Problemática Ambiental del Tramo urbano De la Cuenca del Río Consotá, Municipio de Pereira, Risaralda. Congreso Internacional de Asentamientos Humanos Informales. Bogotá D.C.

Díaz Giraldo, C. (2007). Metodología interdisciplinaria desde el estudio de la problemática ambiental del tramo urbano de la cuenca del Río Consotá hacia el fortalecimiento de la gestión ambiental local. Manizales : Universidad Nacional .

Farinós, J., \& Romero, J. (2007). El gobierno del desarrollo territorial sostenible. A modo de presentación. Territorialidad y buen gobierno para el desarrollo sostenible, págs. 11-18.

Fernández Macano, B. (2009). Sobre la tipología de territorios. Territorios e territorialidades. Expressão Popular, pp. 197215. Obtenido de https://web.ua.es/es/giecryal/documentos/ documentos839/docs/bernardo-tipologia-de-territoriosespanol.pdf 
Gutierréz, F. (2012). Del discurso del desarrollo a la visión territorial sostenible. Perspectiva Geográfica V.17, 233 - 258.

Gutiérrez, F. G. (2010). Organización territorial, desarrollo sostenible y nuevas visiones sobre el territorio en Colombia (1991-2010). Perspectiva Geográfica Vol. 15, 239-260.

Haesbaert, r. (2011). del mito de la desterritorialización: del fin de los territorios a al desterritorialidad. México D.F.: siglo XXI. Obtenido de http://www.scielo.org.mx/pdf/crs/v8n15/ v8n15a1.pdf

Hernández, N. (2007). Insostenibilidad y Sostenibilidad en el desarrollo de la vivienda informal. En C. ed.), Procesos urbanos informales y territorio: Ensayos en torno a la construcción de sociedad, territorio y ciudad. (pág. 277). Bogotá: Universidad Nacional.

Lefebvre, H. (2000). la production de l'espace. París: Anthropos.

Lindon, A. (2002). la construcción social del territorio y los modos de vida en la periferia metropólitana. Territorios, 27- 41.

Martínez, A. (2010). Planes de desarrollo, derechos humanos y exclusión, Risaralda 1997-2007. Pereira: Universidad Católica de Pereira.

Massiris, A. (2009). Desarrollo territorial sostenible . En J. Farinos, J. Romero, \& J. Saloom, Cohesión e inteligencia territorial (pág. 97). Valencia: Universidad de Valencia.

Montañez, G., \& Delgado, O. (1998). Espacio, territorio y región: conceptos básicos para un proyecto nacional. Cuadernos de geografía, Vol. 7, No 1-2. 
Ortiz, A. (1998). Diseño de una metodología flexible para la modificación o creación de cabeceras de circuito judicial en Colombia. Propuesta Metodológica de Ordenamiento Territorial Judicial . Bogotá D.C.: OM Ingeniería y Ambiente - Consejo Superior.

Santos, M. (2000). La naturaleza el espacio: técnica y tiemo; razón y emoción. Barcelona: Ariel.

Secretaria de planeación . (2010). Diagnóstico Unidad de planificación 7 (Río Otún). Pereira .

Silveira, L. (2009). Confines de la racionalidad: el espacio geográfico contemporáneo. En O. y. Delgado Mahecha, Globalización y territorio: reflexiones geográficas en América Latina (págs. 3153). Bogotá: Universidad Nacional de Colombia.

Soja, E. (2008). Postmetrópolis: critical studies of cityes and regions. Los Angeles: Traficantes de Sueños.

Torres, C., Atanassova, D., \& Rincón, J. (2007). ¿Es posible pensar la ciudad informal o la ciudad formal? Aproximación a algunos problemas urbanos y a las estrategias de intervención estatal desde la perspectiva de mejoramiento integral de barrios. En Castillo, Procesos urbanos informales y territorio: Ensayos en torno a la construcción de sociedad, territorio y ciudad. . Bogotá : Universidad Nacional.

Tuan, Y. F. (2007). Topofilia. un estudio de las percepciones, actitudes $y$ valores sobre el entorno. Barcelona: Melusina.

Zambrano, F., \& Bernard, O. (1993). Ciudady Territorio: el proceso de poblamiento en Colombia. Bogotá: Tercer mundo Editores. 


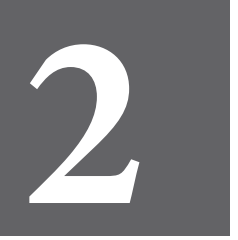

CAPÍTULO

DOS 



\title{
TIC y Lenguaje: fortaleciendo habilidades lectoras
}

\section{ICT and Language: strengthening reading skills}

\author{
Jhon Estiwar Gómez Palacio \\ Universidad Tecnológica de Pereira \\ jhesgomez@utp.edu.co
}

\section{Resumen}

Dado el auge de las Tecnologías de la Información y Comunicación en el currículo escolar, se hace relevante indagar sobre el impacto de su uso en el fortalecimiento de las habilidades de comprensión lectora dentro del aula de clases. Por esta razón, el objetivo de la presente investigación consistió en identificar las transformaciones emergentes a partir de la implementación de las Tecnologías de Información y comunicación (TIC) específicamente un periódico digital creado por los docentes del área de lenguaje de la Institución Educativa Suroriental de la ciudad de Pereira y puesto en práctica con sus estudiantes de grado sexto. 
De esta manera, el documento se centra en describir los mecanismos de interactividad que se generan entre los estudiantes, el contenido digital y el profesor a través de la utilización de métodos cualitativos para lograr la construcción de conocimientos durante la aplicación del periódico digital "Voces y susurros", promoviendo una intencionalidad significativa y estimulando las relaciones interactivas en el triángulo didáctico.

La interacción con el periódico digital evidencia entonces, algunas diferencias y similitudes referente a las habilidades en comprensión lectora estudiadas, con base al apoyo de los recursos educativos digitales diseñados e implementados, cumpliendo un papel potencializador en la interacción y motivación entre profesor, estudiantes y contenido.

Palabras clave: TIC, Comprensión Lectora, Aprendizaje Significativo

\section{Abstract}

Given the increase in Information and Communication Technologies in the school curriculum, it is important to question the impact of strengthening reading comprehension skills. For this reason, the objective of this research is to identify the emerging transformations for the implementation of Information and Communication Technologies (ICT), specifically with a digital newspaper (created by teachers from the Southeast Educational Institution) in the city of Pereira. and develop it with your sixth grade students.

In this way, the document focuses on describing the mechanisms of interactivity through the use of qualitative methods to achieve the construction of knowledge during the application of the digital newspaper "Voces y susurros", promoting meaningful intentions and stimulating interactive relationships in the didactic triangle. 
Interaction with the digital newspaper shows some differences and similarities with respect to reading comprehension skills based on the support of ICT designed and implemented, assuming a potential role in the interaction and motivation between the teacher, the students and the content.

Key words: ICT, Reading Comprehension, Meaningful Learning

\section{Introducción}

Los cambios del mundo actual no se limitan solamente a su estructura social, se vinculan estrechamente a nuevas dinámicas propiciadas por tecnologías de información y comunicación que afectan la vida cotidiana y que conllevan directamente al surgimiento de nuevas y diversas necesidades de aprendizaje en la sociedad del conocimiento con contenidos dinámicos e instrumentos digitales en las interacciones del triángulo didáctico.

En el caso de Colombia, en los últimos años, se han obtenido porcentajes por debajo del promedio de los países participantes en las pruebas internacionales de educación del Programa de Evaluación Internacional de Estudiantes (PISA, por sus siglas en inglés), que hace la Organización para la Cooperación y el Desarrollo Económicos (OCDE) y que evalúa entre estos países el desempeños académico en comprensión lectora de los escolares de quince años en diferentes países, evaluándolos en formato distinto al papel donde se les propone a los estudiantes acceder, comprender, evaluar e integrar información disponible en textos digitales, carentes de estructura lineal y que requieren la utilización de herramientas de navegación para desplazarse en una página o entre sitios diferentes (PISA, 2005).

Sin embargo, conocer estas características no ha sido suficiente para poner en práctica y desarrollar estas habilidades en los estudiantes colombianos. De esta manera, el Ministerio de 
Educación Nacional (MEN, 2008) en sus estándares básicos de tecnología e informática, plantea la necesidad de una alfabetización tecnológica donde estudiantes y docentes se formen para el uso e interacción con las TIC (Tecnologías de la Información y Comunicación) y apoyen e impulsen de esta forma los procesos de mejoramiento de la educación en las distintas áreas.

En este sentido, para adoptar las TIC y los cambios que ellas suponen en las instituciones educativas, se deben establecer estrategias para su incorporación, que incluyan recursos educativos de buena calidad, metodologías adecuadas a sus contextos, ambientes propicios para el desarrollo y herramientas de apoyo a la labor docente que posibiliten acceder, manejar y utilizar la información con la cual el estudiante desarrolle su capacidad de síntesis, organización, sistematización y por último, evaluar el cumplimiento de sus necesidades de información en el mundo actual.

Lo anterior permite estudiar posibilidades que faciliten la adquisición de estas competencias para la construcción de significados y buscar un mejoramiento de la comprensión lectora dentro del aula.

\section{Planteamiento del problema y justificación}

En esta perspectiva, la institución educativa Suroriental de la ciudad de Pereira, desde el año 2014 comienza a desarrollar encuentros y discusiones con su plantel educativo alrededor de esta temática, resultando en un diagnóstico que recopila las principales problemáticas que poseen en su contexto para el fortalecimiento de las habilidades en comprensión lectora, como por ejemplo las dificultades que se presentan en el área de Lengua Castellana desde los procesos de enseñanza-aprendizaje, evidenciando que sobre este hecho incide, por un lado, el que gran parte de los estudiantes no poseen los recursos suficientes para acceder a una bibliografía básica y, por otro, la poca motivación 
de los estudiantes hacia la lectura, lo cual se manifiesta en un uso muy limitado de las fuentes bibliográficas tanto físicas como digitales a las que pueden acceder a través del colegio.

De esta forma, se inició un proceso de elaboración conjunta y análisis de diversas propuestas que podrían ofrecer un mejoramiento de esta situación, abriendo una serie de debates y lluvia de ideas con diferentes estrategias que incluyeron, según las necesidades del contexto, escenarios virtuales y transformaciones en las prácticas pedagógicas. Sin embargo, se manifestó un temor general de incluir las TIC en sus clases cotidianas, tanto en su manejo tecnológico como en los posibles daños que se podrían generar.

Igualmente, este hecho no impidió que los docentes que incluyeran las Tecnologías de información y comunicación en sus procesos de enseñanza-aprendizaje diseñaran un plan donde un periódico digital llamado "Voces y Susurros" busque identificar algunas transformaciones emergentes en los procesos de enseñanza-aprendizaje que posibiliten el fortalecimiento de estas habilidades. En consecuencia, se plantea la siguiente pregunta: ¿Es posible identificar transformaciones en las dificultades que presentan los estudiantes de grado $6^{\circ}$ en el área de Lengua Castellana con los procesos de enseñanza-aprendizaje en comprensión lectora de la Institución Educativa Suroriental a través de la implementación del periódico digital creado por los docentes?

\section{Objetivos}

Por esta razón, esta investigación se centra en identificar aquellos mecanismos de interactividad emergentes entre los estudiantes, contenido y profesor a través de la utilización de métodos cualitativos para lograr el fortalecimiento de habilidades lectoras a través de la aplicación de un periódico digital, definiendo como objetivos específicos caracterizar las competencias en 
comprensión lectora de los estudiantes del grado $6^{\circ}$ de la Institución Educativa Suroriental, distinguir las transformaciones de las dificultades en la competencia en comprensión lectora con la inclusión del periódico digital en las clases de español y finalmente, contrastar los resultados de la caracterización frente a las transformaciones después de la implementación del periódico digital.

\section{Referente teórico}

En primer lugar, es necesario hacer referencia a la definición que aportan las pruebas PISA para la comprensión lectora y los niveles de profundidad en los que se sitúa el esquema del ICFES; además, se argumenta el por qué usar las TIC en procesos significativos de enseñanza-aprendizaje:

Así que se aborda la comprensión lectora, como aquel proceso más complejo que identificar palabras y sus significados: es la capacidad para entender lo que se lee, tanto en referencia al significado de las palabras que forman un texto, como con respecto a la comprensión global del texto mismo. Esto, con el fin de utilizar la información productivamente y de manera eficiente para hacer parte de la sociedad de forma exitosa. (OCDE, 2009).

En esta línea, se enmarca el esquema conceptual de evaluación del Instituto Colombiano para el Fomento dela Educación Superior (ICFES) - las pruebas estatales que evalúan los saberes adquiridos por los estudiantes en los distintos momentos educativos - y que a partir del año 2000, se estructuró alrededor de la evaluación de cinco competencias: (1) identificación o repetición (de lo que dice el texto), (2) resumen o paráfrasis, (3) información previa o enciclopédica, (4) gramática y (5) pragmática; y tres niveles de lectura: (1) literal, (2) inferencial y (3) crítico.

Con estas reformas, privilegiaron la evaluación de los niveles de comprensión por encima del conocimiento de categorías 
gramaticales o la memorización de información, construyendo enfoques que valoraran lo comunicativo por encima de los aspectos formales del lenguaje (ICFES, 2013).

Ahora bien, teniendo en cuenta la comprensión como este proceso de interacción entre el texto y el lector, Strang (1965), Jenkinson (1976) y Smith (1989) describen estos tres niveles de comprensión:

Nivel Literal: En este nivel, el lector identifica las frases y palabras clave del texto sin una intervención muy activa de su estructura cognoscitiva e intelectual. Corresponde a una reconstrucción del texto con el reconocimiento de la estructura base.

Lectura literal en un nivel primario (nivel 1). Se centra en la información que está explícitamente expuesta en el texto, por evocación de hechos. Este reconocimiento consiste en identificar los elementos del texto, como:

- De detalle: identifica nombres, personajes, tiempo y lugar de un relato.

- De ideas principales: la idea más importante de un párrafo o del relato.

- De secuencias: identifica el orden de las acciones.

- Por comparación: identifica caracteres, tiempos y lugares explícitos.

- De causa o efecto: identifica razones explícitas de ciertos sucesos o acciones.

Lectura literal en profundidad (nivel 2). Se efectúa una lectura más profunda, ahondando en la comprensión del texto, reconociendo las ideas que suceden y el tema principal. 
Nivel Inferencial: Se caracteriza por relacionar significados que permiten al lector leer entre líneas, presuponer y deducir lo implícito; es decir, busca relaciones que van más allá de lo leído, explica el texto más ampliamente, agrega informaciones y experiencias anteriores.

Este nivel puede incluir las siguientes operaciones:

- Inferir detalles adicionales, según las conjeturas del lector, pudieron haberse incluido en el texto para hacerlo más informativo, interesante y convincente;

- Inferir ideas principales, no incluidas explícitamente;

- Inferir secuencias, sobre acciones que pudieron haber ocurrido si el texto hubiera terminado de otra manera;

- Inferir relaciones de causa y efecto, realizando hipótesis sobre las motivaciones o caracteres y sus relaciones en el tiempo y el lugar. Se pueden hacer conjeturas sobre las causas que indujeron al autor a incluir ciertas ideas, palabras, caracterizaciones, acciones;

- Predecir acontecimientos sobre la base de una lectura inconclusa.

- Interpretar un lenguaje figurativo, para inferir la significación literal de un texto.

Nivel Crítico: El lector emite juicios sobre el texto leído, lo acepta o rechaza, pero, con fundamentos. La lectura crítica tiene un carácter evaluativo donde interviene la formación del lector, su criterio y conocimientos de lo leído. Los juicios pueden ser:

- De realidad o fantasía: según la experiencia del lector con las cosas que lo rodean.

- De adecuación y validez: compara lo que está escrito con otras fuentes. 
- De apropiación: requiere evaluación en las diferentes partes, para asimilarlo.

- De rechazo o aceptación: depende del código moral del lector.

En este proceso de comprensión se realizan diferentes operaciones cognitivas y éstas ocurren en los niveles mencionados, sin embargo, autores como Goodman (1996) postulan que existen dos niveles adicionales de comprensión lectora: apreciativo (cuarto nivel), y creador (quinto nivel).

Nivel Apreciativo: Comprende las dimensiones cognitivas anteriores, donde el lector tendrá que referirse a los valores estéticos, el estilo, los recursos de expresión, etc. Incluyendo:

- Respuesta emocional al contenido: El lector debe verbalizarla en términos de interés, excitación, aburrimiento, diversión, miedo, odio.

- Identificación con los personajes e incidentes, sensibilidad hacia los mismos, simpatía y empatía.

- Reacciones hacia el uso del lenguaje del autor.

- Símiles y metáforas: se evalúa la capacidad artística del escritor para pintar mediante palabras que el lector puede visualizar, gustar, oír y sentir.

Nivel Creador: El lector crea a partir de la lectura. Incluye cualquier actividad que surja relacionada con el texto:

- Transformar un texto dramático en humorístico.

- Agregar un párrafo descriptivo.

- Autobiografía o diario íntimo de un personaje.

- Cambiar el final al texto. 
- Reproducir el diálogo de los personajes y, dramatizando, hacerlos hablar con otro personaje inventado, con personajes de otros cuentos conocidos.

- Imaginar un encuentro con el autor del relato, realizar planteos y debatir con él.

- Cambiar el título del cuento de acuerdo a las múltiples significaciones que un texto tiene.

- Introducir un conflicto que cambie abruptamente el final de la historia.

- Realizar un dibujo.

- Buscar temas musicales que se relacionen con el relato.

- Transformar el texto en una historieta, etc.

En este sentido, el reconocimiento de las TIC como instrumento mediador dentro de estos procesos de enseñanzaaprendizaje:

Permite crear entornos que integran los sistemas semióticos conocidos y amplían hasta límites insospechados la capacidad humana para (re)presentar, procesar, transmitir y compartir grandes cantidades de información con cada vez menos limitaciones de espacio y de tiempo, de forma casi instantánea y con un coste económico cada vez menor. (Coll y Martí, 2001, p.623-655)

La edad contemporánea exige entonces, un desarrollo de competencias digitales, con el surgimiento de nuevas necesidades formativas, la ubicuidad actual de las tecnologías y la creación de nuevos espacios institucionales que posicionan a las TIC como herramientas clave en la transformación de prácticas educativas que reducen barreras espaciales y temporales desde un desarrollo social y cognitivo, posibilitando de esta forma, el trabajo colaborativo con un enriquecimiento mutuo de los estudiantes. 
Desde este punto de vista, Coll (1989) propone las TIC como instrumentos mediadores en la relación docente -contenido -estudiante que configura nuevos entornos o espacios de trabajo y aprendizaje durante la realización de las tareas en el aula de clase. Así, se demuestra que, entre el conocimiento psicológico, la teoría y la práctica educativa hay una relación que se basa en que el uso y ejecución del conocimiento se constituye en una clave fundamental para la mejoría de la educación. Y de esta forma, la tecnología puede incorporarse en las prácticas educativas donde el estudiante explore, profundice, analice y valore contenidos de aprendizaje, en un ambiente donde el docente planifique y realice sus actividades de enseñanza-aprendizaje de forma coherente al aprendizaje significativo.

Por ello, la incorporación de las TIC en las aulas de clase modifican los estándares tradicionales de la educación formal al ofrecer retroalimentación, orientación y ayuda constante en un proceso educativo en doble vía, en donde el maestro y el estudiante comparten sus experiencias y construyen conocimiento, haciendo efectivas las nuevas formas de comunicación, intercambio, acceso y procesamiento de la información.

Bajo esta premisa la IES (Institución Educativa Suroriental) pretende desarrollar competencias cognitivas y procedimentales que conllevan a una posible transformación de los procesos de enseñanza - aprendizaje a través del uso de un recurso como objeto de conocimiento; en este caso, el periódico digital "Voces y susurros", que espera replantear las formas tradicionales de las prácticas pedagógicas $\mathrm{y}$, además, la adquisición de nuevas competencias en la comprensión lectora para el manejo de información en los estudiantes y docentes en su búsqueda, procesamiento y aprovechamiento.

El periódico digital, como recurso, buscará facilitar el trabajo dentro del aula de una forma más interactiva, con conocimientos significativos donde el estudiante sea autónomo, 
libre y trascendental en el fortalecimiento de la competencia de comprensión lectora, tomando el concepto de competencia como el saber hacer algo teniendo en cuenta el contexto (ICFES, 2001) y el de lectura, como el proceso por el cual hay una interacción entre el texto, el contexto y el lector para crear significado (MEN, 1998).

A partir de estas definiciones, la competencia de comprensión lectora que se desarrollará con el periódico digital se basará en una constante interacción entre el lector, el texto y el contexto, y por lo tanto las características propias del lector jugarán un papel muy importante en este proceso.

De esta forma, se atiende según la propuesta de Coll (2014) tanto al sentido como el significado del aprendizaje escolar, renunciando a las connotaciones más individualistas del proceso de construcción de significados y sentidos; y, por último, resituando el proceso de construcción en el contexto de relación y comunicación interpersonal de forma intrínseca al acto de enseñanza. Es en este momento, que se debe relacionar la implementación de las TIC como puente cognitivo para el desarrollo de aprendizajes significativos, que desde una mirada de Ausubel (1983):

El conocimiento es significativo por definición. Es el producto significativo de un proceso psicológico cognitivo (conocer) que supone la interacción entre unas ideas lógicamente (culturalmente) significativas, unas ideas de fondo (de anclaje) pertinentes en la estructura cognitiva (o en la estructura del conocimiento) de la persona concreta que aprende y la actitud mental de esta persona en relación con el aprendizaje significativo o la adquisición y la retención de conocimientos. (p. 11)

Es decir, un aprendizaje significativo es aquel aprendizaje que se da al relacionar dos tipos de conocimientos; los previos, y las nuevas construcciones. Por lo tanto, los conocimientos que adquiere el estudiante en sus experiencias de vida deben estar 
directamente conectados con aquellos que desean adquirir, de manera que funcionen como base para la construcción de nuevos conocimientos.

En consecuencia, un aprendizaje es significativo cuando los contenidos se relacionan de modo no arbitrario con lo que el alumno ya sabe, donde las ideas se relacionan con algún aspecto existente, específicamente relevante de la estructura cognoscitiva del alumno, como una imagen, un símbolo ya significativo, un concepto o una proposición (Ausubel, 1983).

Al darse esta conexión entre los conocimientos anteriormente mencionados (previos- nuevos), se forma una red de información relevante para el estudiante que se convierte en conocimientos claros y disponibles en su estructura cognitiva con el fin de que se haga manifiesta en su contexto.

Es importante recalcar que cada uno de los estudiantes le da un valor y una relevancia diferente a cada concepto, idea, proposición que adquiere y que de esta forma los conecta con sus experiencias y formas de relacionarse con su entorno.

De esta forma, el proceso de enseñanza-aprendizaje desde la teoría de Ausubel (1983), se interpreta como un compartir de significados entre docente-estudiantes con base en un contenido intrínsecamente activo que requiere:

- El tipo de análisis cognitivo necesario para determinar qué aspectos de la estructura cognitiva ya existente son más pertinentes al nuevo material potencialmente significativo;

- Algún grado de conciliación con ideas ya existentes en la estructura cognitiva, es decir, percibir similitudes y diferencias y resolver contradicciones aparentes o reales, entre conceptos y proposiciones nuevos y ya establecidos; $y$ 
- La reformulación del material de aprendizaje en función del vocabulario y del fondo intelectual idiosincrásico de la persona concreta que aprende.

De igual modo, el docente se convierte en protagonista en el proceso de enseñanza - aprendizaje, al tomarse la tarea de conocer y diagnosticar lo que el alumno ya sabe, modificar sus prácticas de una forma en que emplee recursos que faciliten el paso de la estructura conceptual del contenido a la estructura cognitiva del estudiante de manera significativa, permitiendo entonces, que el alumno tenga un contacto directo con el objeto de conocimiento para luego llevar a la práctica lo aprendido.

Para lograr este paso de estructuras efectivamente, es necesario partir de materiales que posean un significado en sí mismo, es decir, que sus elementos estén organizados en una estructura lógica y coherente que permita crear razones y motivos en el estudiante para aprender, y así, la nueva información aprendida modificará la estructura cognitiva del individuo a partir de los intereses y significaciones que el alumno le dé a lo aprendido.

Estas nuevas significaciones ya no son propiamente orientadas desde la pedagogía tradicional, actualmente involucra nuevas herramientas didácticas que posibilitan un sin fin de oportunidades para acceder, seleccionar, sintetizar, sistematizar y evaluar todo tipo de información, las cuales han llevado a que la forma como se enseña tenga en cuenta qué procesos afinan más un pensamiento crítico y creativo para ser utilizados en un contexto social de manera significativa.

Por lo tanto, el reto actual de los docentes radica en la capacidad de crear nuevos significados en las aulas de clase a través de la inclusión de las tecnologías en las prácticas educativas, donde el uso de herramientas TIC, constituye una fuente principal del conocimiento al crear nuevas posibilidades de expresión y desarrollo con las nuevas extensiones de la información. 
Entonces, para que un aprendizaje mediado por las tecnologías pueda considerarse significativo, debe ser funcional, activo y continúo a través de una interacción permanente de los estudiantes con el medio natural y social de forma directa, al identificar constantemente conceptos y proposiciones relevantes del conocimiento adquirido en las experiencias cotidianas de vida.

\section{Metodología}

De esta forma, se busca que la implementación de las TIC generen cambios significativos en cada uno de los actores y sus interacciones en el proceso de enseñanza aprendizaje, puesto que en los estudiantes podría mejorar su concepción para integrar y comprender los contenidos; el docente tendrá la posibilidad de explorar diferentes tipos de herramientas digitales, evaluar su funcionalidad y encargarse de seleccionar los recursos que considere pertinentes en la mediación del conocimiento y, de esta manera; el contenido ofrecerá opciones de navegación entre informaciones con diferentes formatos de representación, al combinar e integrar sistemas simbólicos, que logran una evolución cognitiva de manera efectiva y significativa.

Así que, teniendo en cuenta los objetivos planteados y los referentes conceptuales, este documento se dedica inicialmente al abordaje teórico, argumentando desde los autores que fueron tenidos en cuenta para el desarrollo de la investigación como David Ausubel (1983) con la teoría del aprendizaje significativo y César Coll (2004) con las TIC como instrumentos mediadores en la relación del triángulo didáctico. Posteriormente, se describe el protocolo de análisis y sistematización de los datos desarrollados en la investigación; en él se puede encontrar cada fase desarrollada dentro de la metodología aplicada y evidenciar algunas diferencias y similitudes antes y durante la aplicación del periódico digital en relación al apoyo de los recursos educativos en el proceso de enseñanza - aprendizaje de la comprensión lectora, con base en el siguiente proceso: 
Tabla 1. Diseño Metodológico

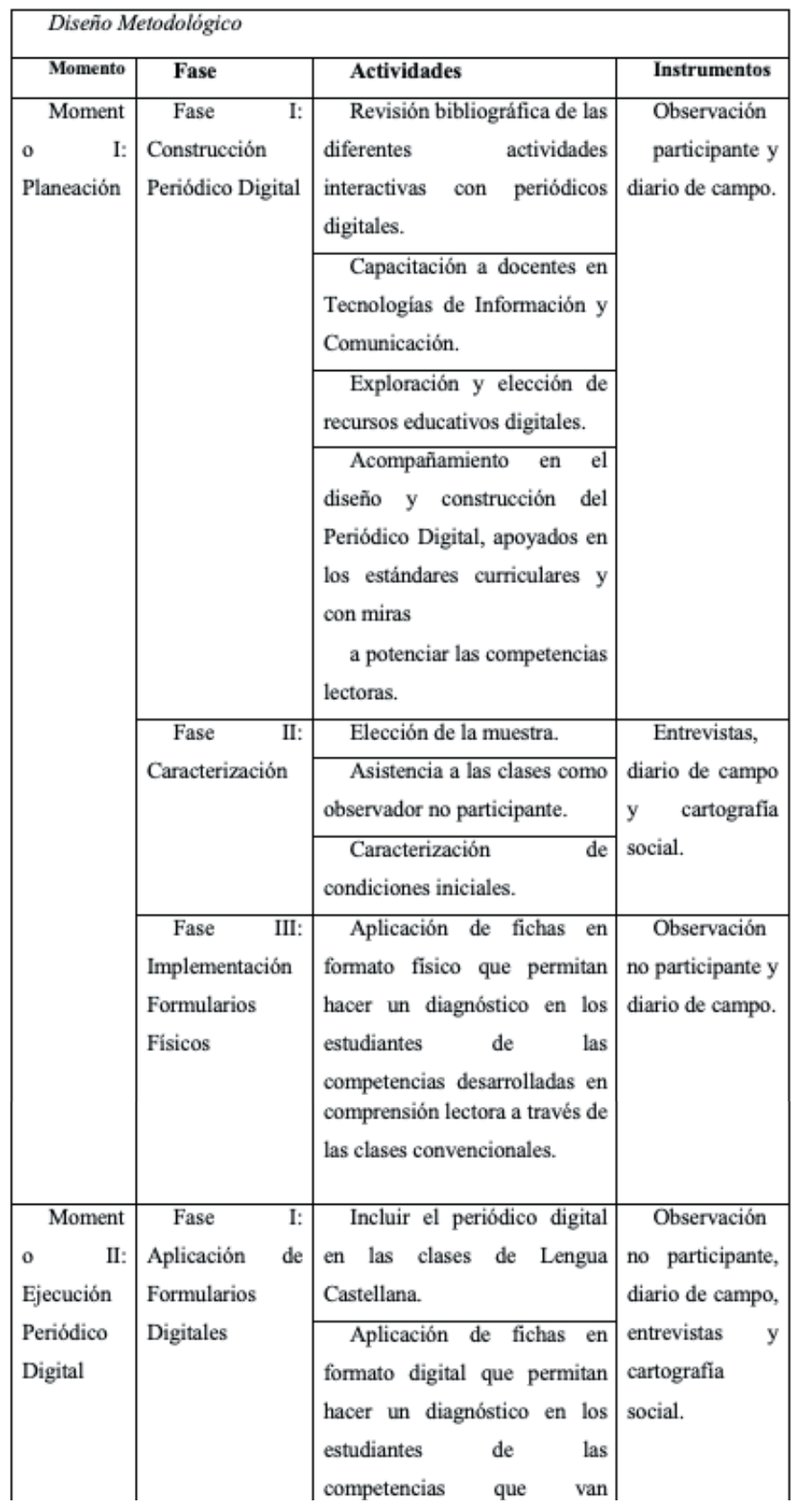




\begin{tabular}{|c|c|c|}
\hline & & $\begin{array}{l}\text { desarrollando en comprensión } \\
\text { lectora a través del periódico } \\
\text { digital. }\end{array}$ \\
\hline & & $\begin{array}{l}\text { Caracterización del proceso } \\
\text { de enseñanza- aprendizaje. }\end{array}$ \\
\hline $\begin{array}{l}\text { Moment } \\
0 \quad \text { III: } \\
\text { Análisis }\end{array}$ & $\begin{array}{l}\text { Fase I: } \\
\text { Comparación de } \\
\text { resultados }\end{array}$ & $\begin{array}{l}\text { Señalar palabras claves en } \\
\text { los formularios recolectados en } \\
\text { cada fase. }\end{array}$ \\
\hline & & $\begin{array}{l}\text { Realizar una base de datos } \\
\text { con los conceptos encontrados. }\end{array}$ \\
\hline & & $\begin{array}{l}\text { Agrupar las palabras, } \\
\text { conceptos y párrafos que se } \\
\text { parezcan. }\end{array}$ \\
\hline & & $\begin{array}{l}\text { Asignar un término de } \\
\text { relación a cada grupo } \\
\text { encontrado. }\end{array}$ \\
\hline & & $\begin{array}{l}\text { Analizar e interpretar la } \\
\text { información obtenida en el } \\
\text { Momento I - Fase III con la del } \\
\text { Momento II - Fase I para } \\
\text { identificar transformaciones y } \\
\text { similitudes. }\end{array}$ \\
\hline
\end{tabular}

ZZFuente: Elaboración propia (2015)

Después, se ofrece un análisis conjugado entre teoría y datos obtenidos dentro del proceso metodológico que responde al impacto de las TIC sobre las prácticas educativas en la adquisición de competencias, fortalecimiento de habilidades y aprendizaje de la comprensión lectora. Y finalmente, se comparte el análisis experiencial y los aportes relevantes resultado del desarrollo de este proceso investigativo.

\section{Resultados}

En este sentido, la Institución Educativa Suroriental busca alinearse a lo que la sociedad contemporánea exige, comprometiendo sus instalaciones y labor docente en el uso efectivo de las Tecnologías de Información y Comunicación con 
el fin de fortalecer los procesos cognitivos de los estudiantes con alternativas curriculares y herramientas didácticas innovadoras para los procesos comunes de educación. En relación con esto, Coll (2006) señala:

Empieza a haber un acuerdo cada vez más generalizado sobre el hecho de que, con los cambios sociales, políticos, culturales y demográficos, relacionados con la llamada sociedad de la información, estamos asistiendo a una transformación sin precedentes de la educación en general y de la educación escolar en particular. (p.6)

Esta interacción - que surge de manera emergente entre estudiante-contenido- profesor a través del periódico digital realizado y que puede explorarse en el siguiente enlace http:// iesperiodico.wix.com/vocesysusurros facilitó a los estudiantes el estudio, comprensión, aplicación, generalización y profundización de los contenidos digitales, utilizando las TIC en este caso, como instrumento mediador (Coll, 2004). Esta mediación, permitió identificar las operaciones cognitivas desarrolladas por los alumnos con la aplicación de las fichas digitales, no obstante, se evidenció una semejanza con las acciones constatadas en la primera fase:

Tabla 2. Comparativo Acciones Identificadas con mediación de las TIC

\begin{tabular}{|c|c|c|}
\hline \multicolumn{3}{|c|}{ Comparativo Acciones Identificadas con mediación de las TIC } \\
\hline Niveles & Operaciones Cognitivas & Aociones identificadas \\
\hline \multirow[t]{4}{*}{$\begin{array}{l}\text { Comprens } \\
\text { ión Literal }\end{array}$} & \multirow{4}{*}{$\begin{array}{l}\text { Recupera información } \\
\text { explicitamente planteada } \\
\text { en el texto. }\end{array}$} & $\begin{array}{l}\text { * Identifica nombres, personajes, } \\
\text { tiempo y lugar de un relato }\end{array}$ \\
\hline & & $\begin{array}{l}\text { * Identifica la idea más importante } \\
\text { de un párrafo o relato }\end{array}$ \\
\hline & & $\begin{array}{l}\text { * Identifica caracteres, tiempos y } \\
\text { lugares explicitos }\end{array}$ \\
\hline & & $\begin{array}{l}\text { * Identifica razones explícitas de } \\
\text { ciertos sucesos o acciones. }\end{array}$ \\
\hline
\end{tabular}




\begin{tabular}{|c|c|c|}
\hline \multirow[t]{2}{*}{$\begin{array}{l}\text { Comprens } \\
\text { ión } \\
\text { Inferencial }\end{array}$} & \multirow{2}{*}{$\begin{array}{l}\text { Permite, utilizando los } \\
\text { datos explicitados en el } \\
\text { texto, más las experiencias } \\
\text { personales y la intuición, } \\
\text { realizar conjeturas o } \\
\text { hipótesis. }\end{array}$} & $\begin{array}{l}\text { * Realiza hipótesis sobre las } \\
\text { motivaciones o caracteres y sus } \\
\text { relaciones en el tiempo y el lugar. }\end{array}$ \\
\hline & & $\begin{array}{l}\text { *Predice acontecimientos sobre la } \\
\text { base de una lectura inconclusa, } \\
\text { deliberadamente o no. }\end{array}$ \\
\hline \multirow[t]{2}{*}{$\begin{array}{l}\text { Comprens } \\
\text { ión Crítica }\end{array}$} & \multirow[t]{2}{*}{$\begin{array}{cc}\text { Emite } & \text { juicios } \\
\text { valorativos } & \end{array}$} & $\begin{array}{l}{ }^{*} \text { Emite juicios según la experiencia } \\
\text { con las cosas que lo rodean o con los } \\
\text { relatos o lecturas. }\end{array}$ \\
\hline & & $\begin{array}{l}\text { * Rechaza o acepta dependiendo del } \\
\text { código moral y del sistema de valores. }\end{array}$ \\
\hline \multirow[t]{2}{*}{$\begin{array}{l}\text { Comprens } \\
\text { ión } \\
\text { Apreciativa }\end{array}$} & \multirow[t]{2}{*}{$\begin{array}{l}\text { Representa la respuesta } \\
\text { emocional o estética a lo } \\
\text { leido }\end{array}$} & $\begin{array}{l}\text { * Verbaliza en términos de interés, } \\
\text { excitación, aburrimiento, diversión, } \\
\text { miedo, odio. }\end{array}$ \\
\hline & & $\begin{array}{l}\text { * Se identifica con los personajes e } \\
\text { incidentes, sensibilidad hacia los } \\
\text { mismos, simpatia y empatia. }\end{array}$ \\
\hline $\begin{array}{r}\text { Comprens } \\
\text { ión Creadora }\end{array}$ & $\begin{array}{l}\text { Incluye } \text { todas las } \\
\text { creaciones personales o } \\
\text { grupales a partir de la } \\
\text { lectura del texto. }\end{array}$ & $\begin{array}{l}\text { * Introduce un conflicto o cambio } \\
\text { abrupto al final de la historia, }\end{array}$ \\
\hline
\end{tabular}

Fuente: Elaboración propia (2015)

Sin embargo, al ahondar en cada uno de los niveles y teniendo en cuenta las competencias que evalúa el ICFES (2013) en las pruebas de lectura crítica, se encontraron características diferentes en algunas dimensiones, mostrando una igualdad en la competencia general con disimilitudes particulares. Por esta razón, se describen a continuación dichas dimensiones:

- La primera competencia es la de identificar y entender los contenidos explícitos de un texto. Esto es, el estudiante debe identificar los eventos, las ideas, las afirmaciones y los demás elementos locales presentes en el texto, y debe entender esos elementos. 
- La segunda competencia es la de comprender cómo se articulan las partes de un texto para darle un sentido global. El estudiante debe comprender la manera como se relacionan los elementos locales de un texto a nivel semántico y formal.

- La tercera competencia es la de reflexionar a partir de un texto y evaluar su contenido. El estudiante debe, por ejemplo, analizar argumentos, identificar supuestos, advertir implicaciones y reconocer estrategias discursivas (p.10).

Con base en estas competencias y en los planteamientos teóricos de Strang (1965), Jenkinson (1976), Smith (1989) y Goodman (1996), mencionados en el marco teórico de este documento, se discuten las transformaciones emergentes durante el desarrollo y fortalecimiento de los niveles de comprensión lectora con la implementación del periódico digital:

Desde el nivel "literal" se presentó un aumento considerable de datos encontrados, tanto en conceptos como en repeticiones, demostrando un incremento en la identificación de nombres, personajes, tiempos, lugares, ideas principales, sucesos y acciones dentro de los textos y noticias que leen de forma digital. En el caso de realizar hipótesis o conjeturas sobre las motivaciones o caracteres y sus relaciones con el tiempo, además de predecir acontecimientos según la comprensión inferencial, se identificó un incremento en los conceptos encontrados en los formularios digitales y una igualdad en las repeticiones. Es decir, los estudiantes presentaron aptitudes en la búsqueda de relaciones que van más allá de lo leído a través del periódico digital, ya que se hizo notorio los intentos de agregar informaciones y experiencias anteriores que relacionaron con saberes previos mediante la formulación de hipótesis y nuevas ideas.

Al referir la comprensión "crítica", los hallazgos demuestran que los estudiantes en esta dimensión disminuyeron la emisión de juicios sobre el texto leído con base en la cantidad de conceptos encontrados. Sin embargo, al analizar los conceptos repetidos, se 
encontró que las aceptaciones o rechazos con fundamentos que se presentaron fueron mayores a través de las fichas digitales que en las clases cotidianas, demostrando facultades en la formación como lector que expone su criterio y conocimientos ante lo leído.

En cuanto a la comprensión "apreciativa", se identificó un aumento de las respuestas emocionales al contenido digital por parte del estudiante, encontrando habilidades para verbalizar esta emoción en diversos términos. Durante la implementación del periódico digital, los formularios permitieron distinguir el grado en que el lector ha sido impactado por el contenido como en las clases tradicionales. Por esto, se encontraron relaciones de interés, excitación, aburrimiento y odio con los personajes o el texto, pero en mayor medida.

En el nivel "creativo", hubo un encuentro de conceptos y repeticiones superior durante la ejecución de los formularios a través de la plataforma digital que manifiestan un desarrollo del estudiante para pensar y crear actividades relacionadas con el texto mejor que en el proceso presencial y tradicional. De esta forma, los estudiantes identificaron y analizaron los conflictos de las noticias y textos digitales a través de la exposición de propuestas y actos que podrían cambiar abruptamente el final de las mismas a largo o corto plazo, con acciones que ellos mismos harían o que responsabilizan a terceros para la resolución de estos conflictos encontrados.

En síntesis, todas las dimensiones obtuvieron un aumento en alguno o ambos aspectos detallados, demostrando como las TIC - en este caso el periódico digital "Voces y Susurros"- se han convertido en poderosos instrumentos para los procesos educativos formativos. Los nuevos recursos y posibilidades educativas que ofrecen las tecnologías hacen posible el aprendizaje (Coll, 2011). 


\section{Conclusiones}

La gran cantidad de experiencias enmarcadas en la innovación educativa con Tecnologías de Información y Comunicación, la continua aparición de nuevos recursos y dispositivos tecnológicos, y su constante evolución en el mercado, trae consecuencias en los campos sociales, económicos y educativos que conllevan a estudiar y determinar la eficacia de su uso en las instituciones para fortalecer competencias y mejorar procesos de enseñanzaaprendizaje, centrándose aún más en el estudio de los cambios que se producen en los actores del triángulo didáctico como consecuencia de su participación e implicación en actividades educativas, de su naturaleza y características, de los factores que los facilitan, los dificultan y los obstaculizan, y de las consecuencias que tienen para ellas (Coll, 2001). Pues la aparición de nuevas necesidades formativas, la omnipresencia de las TIC y la importancia de implementar nuevos procesos de aprendizaje para adquirir competencias asociadas a nuevos espacios personales y colectivos permite indagar y analizar las interacciones que se dan dentro del aula.

En este sentido, el periódico digital "Voces y susurros" proporcionó un ambiente de aprendizaje óptimo para la creación de estrategias didácticas y espacios de interacción entre el profesorestudiantes-contenido, permitiendo así, orientar al estudiante a detectar las ideas fundamentales, organizarlas e interpretarlas significativamente, contribuyendo de la siguiente forma en los procesos cognitivos:

Con el uso del periódico digital, se hace notorio como el ritmo de aprendizaje de cada estudiante es diferente, haciéndose responsable de su propio proceso y autónomo en el tiempo de ejecución de las actividades. En consecuencia, el alumno incrementa el control consciente del proceso de autorregulación y contribuye al mejoramiento no solo de los resultados, sino del aprendizaje en sí mismo. (Coll, Mauri, Onrubia, 2008). 
Coll (1999) refiere que esta actividad constructiva del estudiante se aplica a contenidos que ya poseen un grado considerable de elaboración, cómo es el caso de "Voces y Susurros" donde los contenidos que constituyen el núcleo de los aprendizajes escolares, son conocimientos y formas culturales representados. Por esta razón, se hace necesario agrupar de nuevo los conceptos repetidos en los formularios digitales en cada uno de los niveles de profundización y que permiten dar cuenta de la información seleccionada en esta fase por los escolares.

Los espacios virtuales de comunicación que emergen de la configuración del periódico digital se convierten en escenarios adecuados para la formación y el aprendizaje. Sin embargo, el estudiante es quien tiene la responsabilidad y autonomía para hacer que funcione de esta manera, pues es el encargado de elegir qué tipo de contenidos son de su interés y darle sentido, rechazando aquellos textos, noticias o información a la que no le encuentra lógica alguna. Por consiguiente, se realiza una descripción detallada de la información investigada, seleccionada y clasificada en este proceso con el periódico digital.

- Con esta plataforma, los estudiantes pueden participar en la organización y secuencia de su exploración con un campo más amplio que ofrece la web para la búsqueda y elección de información, demostrando que:

El aprendiz requiere la acción de un agente mediador para acceder a la zona de desarrollo próximo, éste será responsable de ir tendiendo un andamiaje que proporcione seguridad y permita que aquél se apropie del conocimiento y lo transfiera a su propio entorno. (Vygotsky, 1974, p.03).

Conforme a la relación estudiante-contenido Coll (1990) plantea que cuando el alumno se enfrenta a una nueva información, lo hace siempre dispuesto con una serie de conceptos y conocimientos adquiridos en el transcurso de sus experiencias 
previas, y que utiliza como instrumentos de interpretación para determinar qué informaciones seleccionará, cómo las organizará y qué tipos de relaciones establecerá entre ellas. Este argumento, permite agrupar como punto de partida, los conceptos y cantidad de repeticiones encontrados en las fases de caracterización para un próximo análisis de la selección de contenidos que tuvieron los alumnos.

Las estrategias didácticas aplicadas con el uso del periódico digital buscaron un nivel estable de interés, ganas y disposición por parte del estudiante, explicado en palabras del docente, refiere que:

Sí hay un aprendizaje significativo, los trabajos tienen otro tipo de construcción. Están haciendo uso de herramientas que se apropian de ellas y que de allí [el estudiante] podría fortalecerse también...El periódico digital permite hacer uso de herramientas existentes y hace innovaciones, permite la creación de contenido digital con ellas mismas. (Oscar Arley Noreña - Docente de Lengua Castellana, 2015).

De este modo, el profesor evidencia que de no existir una correspondencia entre el nuevo conocimiento y las bases previas con las que cuenta el alumno, no se podría generar un aprendizaje significativo (Ausubel, 1983). Por esta razón, el docente tuvo que evaluar continuamente los recursos educativos digitales presentes en el periódico digital para fortalecer cada vez más la interacción estudiante-contenido, estudiante-profesor, estudiante-contenidoprofesor.

Finalmente, con base en estas conclusiones, es oportuno pensar en la continuación del análisis del periódico digital como un factor influyente en el fortalecimiento de las dimensiones de la comprensión lectora que no se evidencian en esta investigación, siendo pertinente incluir nuevos recursos digitales en la interacción docente-periódico digital-estudiantes para analizar su efecto a mediano y largo plazo en las operaciones cognitivas 
que fueron objeto de estudio en esta investigación. En esta misma línea, se hace conveniente pensar en el direccionamiento de futuras investigaciones con el uso del periódico digital hacia el encuentro de posibles transformaciones de los imaginarios que emergen con la inclusión de las TIC en los procesos de enseñanzaaprendizaje del área de Lengua Castellana.

\section{Referencias Bibliográficas}

D, AUSUBEL, J,NOVAK. (1983). Psicología Educativa: Un punto de vista cognoscitivo 2. México: Ed.TRILLAS.

Ausubel, D. P., Novak, J.D., y Hanesian, H. (1978) Educational Psychology: A Cognitive View (2 ${ }^{\mathrm{a}} \mathrm{Ed}$.). New York: Holt, Rinehart and Winston.

Caño, A. Luna, F. (2005), Proyecto PISA: Ejemplos de Ítems de Lectura. Instituto Vasco de Evaluación e Investigación Educativa, Bilbao.

Coll, C. (1988), Significado y sentido en el aprendizaje escolar. Infancia y Aprendizaje,41, 131-142.

Coll, C. (1990a). Aprendizaje Escolar y Construcción del Conocimiento. Buenos Aires: Paidós

Coll, C. (1990b). Un marco de referencia psicológico para la educación escolar: La concepción constructivista del aprendizaje y de la enseñanza. En: Desarrollo psicológico y educación II. Madrid: Alianza.

Coll, C (1999). Psicología de la instrucción: la enseñanza y el aprendizaje en la educación secundaria. Barcelona: Horsori. 
Coll, C. (2001). Concepciones y tendencias actuales en psicología de la educación. En: C. Coll, J. Palacios y A. Marchesi. (Comps.), Desarrollo psicológico yeducación. 2. Psicología de la educación escolar (29-64). Madrid: Alianza.

Coll, C. (2004a). Psicología de la educación y prácticas educativas mediadas por las tecnologías de la información y la comunicación. Sinéctica, 25, 1-24.

Coll, C. (2004b). La misión de la escuela y su articulación con otros escenarios educativos: reflexiones en torno al protagonismo y los límites de la educación escolar. En COMIE (Ed.). VI Congreso Nacional de Investigación Educativa. Conferencias Magistrales. (pp.15-56). México, DF. Comité Mexicano de Investigación Educativa.

Coll, C. (2006). Lo básico en la educación básica. Reflexiones en torno a la revisión y actualización del currículo de la educación básica. Revista Electrónica de Investigación Educativa, 18,1. Recuperado el 8 de enero de 2010, de http:// redie.uabc.mx/vol8nol/contenido-coll.html.

Coll, C. y Martí, E. (2001). La educación escolar ante las nuevas tecnologías de la información y la comunicación. En: C. Coll, J. Palacios y A. Marchesi (comps.), Desarrollo psicológico y educación. 2. Psicología de la educación escolar (623-655). Madrid: Alianza.

Coll, C. y Martín, E. (1990). Aprendizaje y desarrollo: la concepción genético-cognitiva del aprendizaje. En C. Coll, J. Palacios y A. Marchesi (Ed) Desarrollo psicológico y educación II. Psicología de la educación. Madrid: Alianza Editorial.

Coll, C., Mauri, T. y Onrubia, J. (2005). Technology and pedagogical practices: ICT as mediation tools in joint teacher-student activity. American Educational Research Association. Annual Meeting. Montreal. 
Coll, C., Miras, M. (1990): La representación mutua profesor/ alumno y sus repercusiones sobre la enseñanza y el aprendizaje. En: C. Coll, J. Palacios y A. Marchesi (comps.): Desarrollo psicológico y educación. Vol II. (297-313)

Coll, C. Y Onrubia, J. (1999). Evaluación de los aprendizajes y atención a la diversidad. En Coll, C. (Coord.), Psicología de la instrucción: la enseñanza y el aprendizaje en la educación secundaria (p. 141-168). Barcelona: Horsori/ICE UB.

Coll, C; Solé, Isabel (1989) Aprendizaje significativo y ayuda pedagógica. Cuadernos de Pedagogía, 168, 16-20.

Goodman, K. (1996). La lectura, la escritura y los textos escritos: una perspectiva transaccional sociopsicolingüística. Textos en contexto 2: Los procesos de lectura y escritura. 5 - 68 . Argentina: Asociación Internacional de lectura.

ICFES (2013). Sistema Nacional de Evaluación Estandarizada de la Educación, Alineación del examen SABER 11º. Bogotá, D.C.

Jenkinson, M. D. (1976). Modos de enseñar”, en Staiger, R. C. (comp.), La enseñanza de la lectura. Buenos Aires: Huemul.

Smith, C. B. (1989). La enseñanza de la lecto-escritura: un enfoque interactivo, Madrid: Aprendizaje Visor.

Strang, R. (1965). Procesos del aprendizaje infantil. Buenos Aires: Paidós. 


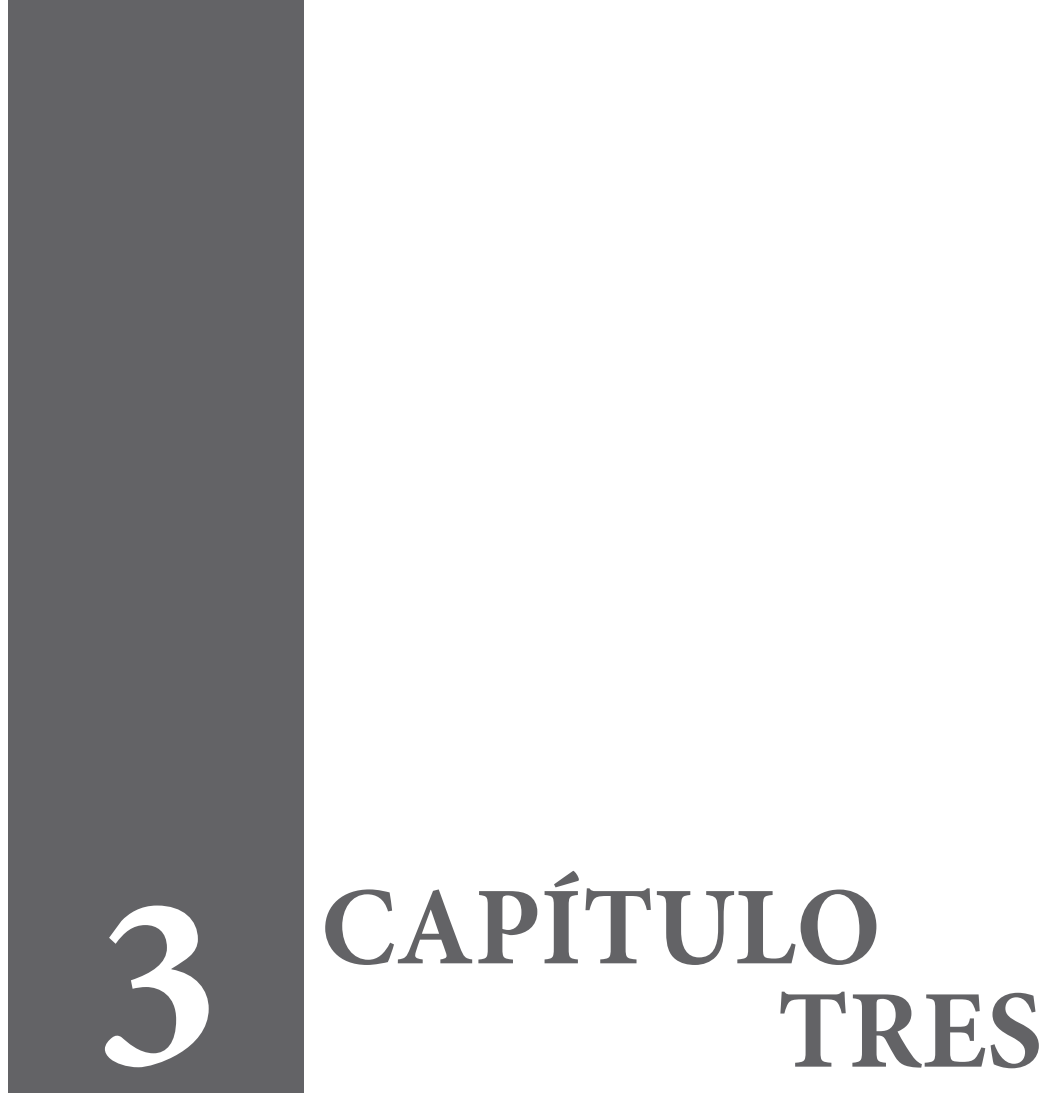





\title{
Ferias de la memoria. Una metodología de investigación narrativa para los estudios de memoria e identidad \\ Caso de estudio transformaciones de la cultura cafetera ${ }^{1}$
}

\section{Memory fairs. A narrative research methodology for memory and identity studies Case study transformations of coffee culture}

\author{
Carolina Saldarriaga Ramírez $z^{2}$ \\ Universidad Tecnológica de Pereira \\ carolina.saldarriaga@utp.edu.co
}

1 Por su participación en la creación y ejecución de las Ferias de la memoria, la autora agradece a Daniel Alejandro Vergara. Igualmente por su apoyo en la logística y convocatoria social en Marsella agradecemos a Adriana Grisales bibliotecaria de la Biblioteca León de Greiff. En Santa Rosa de Cabal al profesor Guillermo Aníbal Gartner y al historiador Jaime Fernández. Finalmente la autora agradece de manera especial al profesor Darío Ángel por sus aportes en la reflexión metodológica y quien dirigió la tesis de maestría de la cual proviene el presente artículo.

2 Candidata a doctora en Sociedad y Cultura de la UB. Magíster en Ciencias Sociales. Especialista en turismo cultural. Administradora Ambiental. Miembro del grupo de investigación en Gestión de cultura y educación ambiental. Universidad Tecnológica de Pereira. 


\section{Resumen}

La investigación narrativa permite conocer las identidades a partir de la construcción de relatos memoria. Se trata de recolectar información en la que se revela la forma de vida de un grupo social y el sentido que dan a su experiencia individual y grupal. A través de un proceso de investigación narrativa llevado a cabo durante cuatro años en municipios del departamento de Risaralda, Colombia, se diseñó una metodología denominada Ferias de la memoria. Este artículo pretende reflexionar sobre la construcción de relatos memoria como herramienta para el acercamiento a la identidad y la memoria cultural, exponer el desarrollo metodológico del estudio y sugerir las ferias como instrumento para los estudios de memoria.

Palabras claves: Memoria, identidad, patrimonio, Paisaje Cultural Cafetero, metodologías de investigación narrativa

\section{Abstract}

Narrative research allows to know identities from the construction of stories. It involves the collection of information that reveals the way of life of a social group and the meaning they give to their individual and group experience.

Through a narrative research process carried out for four years in municipalities in the department of Risaralda, Colombia, a methodology called Memory Fairs was designed. This article aims to reflect on narrative research as a tool for the approach to identity and cultural memory and expose the methodological development of the study.

Keywords: Memory, identity, heritage, Coffee Cultural Landscape, narrative research methodologies 


\section{Introducción}

Los estudios sobre memoria han ocupado un lugar destacado entre los estudios culturales, que cada vez reúnen a investigadores de un mayor número de disciplinas. En los estudios sobre memoria, el propósito va más allá del análisis en función de variables contrastadas con un esquema teórico, se busca la comprensión de los relatos a partir de los mismos relatores en su contexto específico.

La memoria no es un dato empírico que exista previamente en la cultura como fenómeno que puede ser investigado, por eso la narrativa es la estrategia para revelar el relato, para hacerlo claro a los ojos de quien relata y de quien lo examina. El relato -y por tanto el sentido- no es claro hasta que es expuesto, porque solo así el grupo o el individuo se comprende a sí mismo como parte de una historia que es construida en común. Las herramientas metodológicas acá expuestas, se proponen como un medio para la construcción de narrativas-memoria a través de la participación de múltiples actores.

Durante el periodo 2012 a 2016, se construyeron relatos desde los que un grupo de caficultores y personajes típicos de la vida cafetera se describen y se interpretan; estos fueron documentados en una serie ejercicios de participación denominados Ferias de la memoria y también mediante el desarrollo de entrevistas, visitas de campo a familias, historiadores, campesinos caficultores, líderes locales de los municipios de Pereira, Marsella, Santa Rosa de Cabal, Apía y Santuario en el departamento de Risaralda (Colombia). En estos ejercicios se buscó identificar el imaginario de lo cafetero, la identidad y las transformaciones de la cultura cafetera posterior a la crisis del café y a su declaratoria como patrimonio mundial por la Unesco en 2011, desde las memorias de los propios sujetos, que pudiera ser comparado con el imaginario que reproduce la institucionalidad cafetera. 
Se presentan las Ferias de la Memoria como un recurso metodológico que ha sido aplicado en diferentes municipios del Paisaje Cultural Cafetero desde 2012 y que han servido para el objeto de investigación citado, la descripción de la investigación realizada sus aciertos y dificultades, permiten sugerir su utilidad para los estudios de memoria.

\section{Objetivo.}

Mostrar las Ferias de la memoria como una herramienta de investigación narrativa útil en los estudios de memoria, patrimonio e identidad

\section{Identidad, memoria y patrimonio}

En el debate sobreel conceptodeidentidad podemosidentificar dos tendencias. Una lo asocia a los rasgos y representaciones culturales de un grupo social en un territorio específico; es decir, se le atribuye un carácter simbólico, y otra que lo enmarca en aquellos contenidos de una cultura que la delimita y congrega a través de sus producciones culturales. El primer enfoque es polémico en particular porque es difícil su descripción por un observador externo, y el segundo es cuestionado porque cada vez resulta más complejo definir qué es propio de un grupo social, en especial cuando los procesos de globalización han generado una fusión entre culturas que imposibilita definirlas con precisión. En ambas posturas se admite que la identidad concede características diferenciadoras a los grupos que les permite definirse y desarrollar un sentido de pertenencia. ${ }^{3}$

Según Jorge Orlando Melo (2006), casi hay consenso en que realmente no existe nada en la vida social que defina la identidad de un país o una región, y en que lo único que constituye la identidad es el discurso por el cual sus miembros se reconocen como miembros de esa comunidad.

3 Véanse por ejemplo las discusiones de Néstor García Canclini en (García-Canclini, 1999) o Jorge Orlando Melo en (Melo, 2006) 
Para Guitart, Vila, \& Gómez (2010), las identidades se construyen precisamente a partir de la apropiación, por parte de los actores sociales, de determinados repertorios culturales considerados simultáneamente como diferenciadores (hacia afuera) y definidores de la propia unidad y especificidad (hacia adentro). Es decir, la identidad no es más que la cultura interiorizada por los sujetos, considerada bajo el ángulo de su función diferenciadora y contrastiva en relación con otros sujetos (Giménez, 2003, pág. 18). El autor reconoce el carácter mutable de la identidad y plantea que no está definida por "el conjunto de rasgos culturales que en un momento determinado la delimita y distingue de otros actores, pues los grupos étnicos pueden $-\mathrm{y}$ suelen- modificar los rasgos fundamentales de su cultura" (Giménez, 2003, pág. 18). Otro tanto plantea Maffesoli (2004), quien defiende las identidades múltiples en oposición a la identidad estable.

Así, la identidad de un grupo puede variar y sus contenidos y prácticas se pueden mezclar, mutar, perder o mantener. Pese a esto, la identidad de un grupo se mantiene definida, al menos nominalmente. En tal sentido; por ejemplo, los cafeteros colombianos no han perdido dicha condición porque los hombres ya no usen el carriel ${ }^{4}$ o la producción de café haya menguado. Este grupo social posee una autoconcepción que lo congrega y le da cohesión ${ }^{5}$. En otras palabras, no son las producciones materiales e inmateriales las que definen la identidad. De esta forma, se propone que son las fronteras mismas y la capacidad de mantenerlas en la interacción con otros grupos lo que define la identidad (Barth,1976).

4 Bolso de cuero masculino utilizado en la región desde tiempos de la colonia.

5 Para una descripción extensa del ser cafetero, véase el dossier entregado por el Ministerio de Cultura a la Unesco para la inscripción del Paisaje Cultural Cafetero como patrimonio mundial en www.paisajeculturalcafetero.org.co 
Por lo tanto, en un grupo no se da una sola identidad, y es válido hablar de identidades ${ }^{6}$, porque son muchas las formas y los contenidos que aglutinan a un grupo y lo define en un momento determinado. Además, los contenidos definitorios de la identidad, o lo que Giménez (2009) llama marcadores culturales, son dinámicos, pues "las identidades son construcciones históricas $y$, como tales, condensan, decantan y recrean experiencias e imaginarios colectivos. Esto no significa que, una vez producidas, las identidades dejen de transformarse" (Restrepo, 2007, pág. 25). Con esto, podemos concluir que la identidad no implica el mantenimiento intacto de esos elementos constitutivos y auténticos de un grupo, "estos marcadores pueden variar en el tiempo y nunca son la expresión simple de una cultura preexistente supuestamente heredada en forma intacta de los ancestros" (Giménez, 2009, pág. 19), pues es propio de las culturas la capacidad de reconfigurarse y asumir nuevas formas de ser.

La identidad es, entonces, un discurso interiorizado que contiene los elementos que nos habilitan para darle sentido a nuestra realidad, comprendernos, y diferenciarnos de otros. Independiente de la producción cultural material e inmaterial, sus mutaciones, o pérdidas; un grupo siempre tiene un discurso desde el cual narra su vida, toma del pasado y del presente aquello que le sirve para demarcar su identidad, un discurso que además es dinámico pues puede cambiar. Para Restrepo, (2007, pág. 26)” las identidades son discursivamente constituidas, como cualquier otro ámbito de la experiencia, de las prácticas, las relaciones y los procesos de subjetivación. En tanto realidad social e histórica, las identidades son producidas, disputadas y transformadas en formaciones discursivas concretas".

6 Para Restrepo (2007, pág. 31), "En tanto práctica significante, las identidades son polifónicas y multiacentuales. Ninguna identidad supone un significado estable y compartido por todos los individuos y colectividades de forma homogénea. Las identidades no son definidas de una vez y para siempre, sino que las cadenas denotativas y connotativas asociadas a una identidad específica se desprenden de prácticas significantes concretas, de las interacciones específicas entre diversos individuos donde se evidencia la multiplicidad de sus significados". 
Entendemos por identidad "la historia de vida que elaboramos sobre nosotros mismos y que constituye nuestros recuerdos, ideas y creencias alrededor de quiénes consideramos que somos" (Bruner 2003, citado por Guitart, Vila, \& Gómez, 2010, pág. 2), son los atributos culturales, a los que se da prioridad sobre el resto de las fuentes de sentido (Castells, 1998), "aquella parte del autoconcepto de un individuo que deriva del conocimiento de su pertenencia a un grupo (o grupos) social junto con el significado valorativo y emocional asociado a dicha pertenencia" (Henry Tajfel 1984: 292, citado Guitart, Vila, \& Gómez, 2010, pág. 3) y que define la diferencia con otros grupos.

En la construcción del discurso que define o da sentido, un grupo utiliza generalmente algunos dispositivos (denominados en Giménez (2009) "materiales de construcción”) desde los que se tejen y dan soporte a las identidades, por lo que la memoria y el patrimonio se constituyen en los dispositivos desde los que se hila el discurso de identidad. A la pregunta ¿quiénes somos?, los sujetos responden exponiendo estos materiales que les sirve de referente y que están cargados de imaginarios, interpretaciones, objetos, sucesos; en suma, que están cargados de memoria. En efecto, la memoria es el gran nutriente de la identidad (Candau J., 1998, pág. 5), es elemento constitutivo del sentimiento de identidad (Pollak, 1992: 204 citado por Jelin 2002) "hasta el punto de que la pérdida de memoria, es decir, el olvido, significa lisa y llanamente pérdida de identidad" (Giménez, 2009, pág. 20). Por lo tanto, la memoria es un soporte de las identidades, sin memoria no tendríamos identidad (Colasurdo, Sartori, \& Escudero, 2010). Para Elizabeth Jelin, "hay un plano en que la relación entre memoria e identidad es casi banal, y sin embargo importante como punto de partida para la reflexión: el núcleo de cualquier identidad individual o grupal está ligado a un sentido de permanencia (de ser uno mismo, de mismidad) a lo largo del tiempo y del espacio. "Poder recordar y rememorar algo del propio pasado es lo que sostiene la identidad" (Gillis, 1994, Citado por Jelin 2002, pág. 7). 
Adicionalmente, el conjunto de bienes materiales e inmateriales que seleccionamos de forma colectiva para reconocerlos como patrimonio son el soporte de la memoria (Pereiro 2004, citado por Colasurdo, Sartori, \& Escudero, 2010). Usamos estos bienes como testimonio o testigo, como un ancla al pasado, un recurso nemotécnico que nos enlaza con lo que fuimos y con lo que somos. Según Candau J. (2002), "podemos afirmar que el patrimonio cultural es producto de la activación de la memoria, que seleccionando elementos heredados del pasado los incluye en la categoría de patrimonio cultural, siguiendo criterios de antigüedad, afecto, sentimiento, política, etc. y los grupos sociales construyen con este bagaje de "cosas" conmemorativas, sentidas, significativas, en fin, su narración en apología a lo que son y lo que los constituye como iguales", "como un sentimiento de pertenencia por medio experiencias compartidas, dentro de las que se encuentran las expresiones simbólicas" (McMillan, 1996, citado por Villaseñor \& Zolla, 2012, pág. 78).

Esta relación de mutua constitución implica un vaivén: para fijar ciertos parámetros de identidad (nacional, de género, política o de otro tipo) el sujeto selecciona ciertos hitos, [ciertos bienes] ciertas memorias que lo ponen en relación con «otros». Estos parámetros, que implican al mismo tiempo resaltar algunos rasgos de identificación grupal con algunos y de diferenciación con «otros» para definir los límites de la identidad, se convierten en marcos sociales para encuadrar las memorias (Jelin, 2002, pág. 7).

Siguiendo a Cohen (1985, págs. 12-14), lo que define a las comunidades no son los límites reales del grupo, sino la construcción simbólica que sus miembros hacen del grupo y de sus límites. Por esta razón, el sentido de pertenencia y las prácticas culturales compartidas constituyen elementos identitarios de las comunidades (Villaseñor \& Zolla, 2012, pág. 78). 
Por su parte, Halbwachs (2004), propone que "el pasado no se conserva: se reconstruye a partir del presente". Esto implica que el individuo no construye su identidad por sí solo, pues es necesaria "la presencia de lo social, aún en los momentos más

«individuales». Uno no recuerda solo sino con la ayuda de los recuerdos de otros y con los códigos culturales, compartidos, aun cuando las memorias personales son únicas y singulares" (Jelin, 2002, pág. 20), son los encuentros colectivos, los escenarios de transmisión de los recuerdos y códigos lingüísticos, rutinarios, conductuales y prácticos que dan al grupo un sentido de identidad. Así, Augé (1998, pág. 70), reconoce que "todos los planteamientos rituales demuestran que la identidad individual se construye al mismo tiempo que la relación con los demás y a través de esta relación"; para Jelin (2002, pág. 5) "lo colectivo de las memorias es el entretejido de tradiciones y memorias individuales, en diálogo con otros, en estado de flujo constante, con alguna organización social", pues "la gente recuerda individualmente, pero es el grupo social el que define lo que es memorable" (Peter Burke, citado por Archila, 2004, pág. 31).

De esta manera la vida social se configura según la reconstrucción que el grupo haga de su pasado, dotándolo de sentido para actuar sobre la realidad presente, una realidad que es colectiva, donde los individuos desde su subjetividad transmiten entre generaciones las memorias de aquello que les sirve para interpretar, comprender y ejercer la vida práctica, la que es a su vez dinámica y reinterpretada según las necesidades.

\section{Historia y memoria}

El origen del acercamiento entre memoria e historia proviene de la crisis del historicismo en la década del sesenta, cuando surgen nuevas formas de hacer historia "que dieron un papel más protagónico a los sectores subalternos, para lo cual se acudió a fuentes alejadas de los archivos oficiales" (Pinilla, 2013, pág. 96). 
La historia y su credibilidad como fuente que da cuenta de los acontecimientos del pasado han sido cuestionados por los estudios de la memoria, siendo acusada de ser positivista, limitada al archivo y de poner distancia entre los sujetos y su pasado. Por su parte, desde la historia se ha señalado que la memoria, al ser producto de la subjetividad de un narrador, se vincula de manera emotiva en el relato, lo que abre paso a la exageración o la especulación ${ }^{7}$.

Cuando la memoria se asociaba solo a los individuos, había una delimitación clara entre memoria e historia: los individuos tenían su memoria, las colectividades su historia. Con el concepto de memoria colectiva, acuñado inicialmente por Halbwachs, esta delimitación se ha vuelto difusa. Según lo plantea Pierre Nora la "memoria ha tomado un sentido tan general e invasivo que tiende a reemplazar pura y simplemente [... el término historia”. La idea de memoria ha tomado su fuerza en cuanto esta ha reclamado la fidelidad con el pasado apelando a la experiencia vivida y al recuerdo, desde los cuales reclama que su verdad es más "verdadera" que la verdad contada por la historia. (Ramírez, 2009)

Según Zan (2008), los primeros historiadores, como Heródoto, dicen que escriben la historia para mantener la memoria de los acontecimientos del pasado y evitar que el paso del tiempo los suma en el olvido. Pero llama la atención sobre el riesgo de la memoria escrita puesto que "puede superponerse y reemplazar o alienar la memoria propia y el relato de los sobrevivientes (pág. 48). Pinilla (2013, pág. 96) aporta que la memoria es un terreno de disputa en donde participa la versión oficial de la historia, ya que "los recuerdos son constantemente elaborados por una memoria inscrita en el espacio público, sometidos a los modos de pensar colectivos, pero también influidos por los paradigmas científicos de la representación del pasado" (Pinilla, 2013, pág. 96, citando a Traverso, 2007). En el vínculo con el pasado entonces "es tan necesario el nexo directo de la memoria como la ambición 7 Para ampliar este debate véase Ricoeur, 2000, Candau, 2002, Zan, 2008, Lythgoe, 2008, Pinilla, 2013 y Ángel, 2014. 
de verdad de la historia" (Lythgoe, 2008, pág. 90). Si bien el debate sigue abierto, Halbwachs (2004) hace una distinción entre memoria e historia, él concluye: "la historia es una y las memorias son múltiples".

Frente a esta discusión, Nora (1984, pág. 56) expone una opción de conciliación, pues argumenta que tanto memoria como historia tienen un rol frente a la relación de los grupos con el pasado, señalando que "la confusión entre memoria e historia es una parte de la dinámica social de la cual no podemos escapar. Pero la única manera de no volverse esclavo de ella es convertirse en crítico de la historia misma”.

historia y memoria no deberían oponerse de manera binaria, ni tampoco fundirse, o confundirse. Sus relaciones son complejas [...] cuando trata cuestiones de la memoria, incluyendo, por supuesto, las cuestiones del olvido, de la represión o la elusión [...]. La historiografía puede aportar a la esfera pública una memoria críticamente testeada y veraz, que los distintos grupos que conforman la sociedad internalizan como pasado recordado. En cualquier caso, la memoria como parte de la experiencia de un grupo está ligada a la manera como ese grupo se relaciona con su pasado, en tanto éste influye sobre su presente y su futuro (Zan, 2008, pág. 49).

Tanto la memoria como la historia son narraciones históricas, de diferente orden, pero en ambas el narrar puede entenderse como una de varias maneras de representar el pasado (Ramírez, 2009). La memoria colectiva, es la manera como los grupos humanos - clase social, grupo religioso o familia- conservan el recuerdo de su pasado (Halbwachs, 2004, pág. 6). La historia no parte del reconocimiento de la experiencia vivida como lo hace la memoria. La historiografía sigue la serie huella-documentoarchivo y es donde se establece la separación de la memoria y la historia (Ramírez, 2009). 
Consideraciones epistemológicas sobre los estudios de memoria cultural

La investigación narrativa permite conocer las identidades a partir de la construcción de relatos. Se basa en la recolección de información que revela la forma de vida de un grupo social y el sentido que dan a su experiencia individual y grupal. Si la identidad es un discurso, se relata para dotar de sentido la vida. La narrativa es entonces la estrategia para revelar el relato, para hacerlo claro a los ojos de quien relata y de quien lo examina. Por ello, el relato -y por tanto el sentido- no es claro hasta que es expuesto, porque solo así el grupo o el individuo se comprende a sí mismo como parte de una historia que es construida en común. Por lo tanto, "investigar con los relatos de las personas contribuye a comprender, por ejemplo, cómo construyen las identidades" (Sparkes \& Devís, 2007, pág. 1) y qué recursos materiales e inmateriales utilizan para construirlas. De acuerdo con Jelin (2002, pág. 9), “el acontecimiento rememorado o «memorable» será expresado en una forma narrativa, convirtiéndose en la manera en que el sujeto construye un sentido del pasado, una memoria que se expresa en un relato comunicable, con un mínimo de coherencia".

Las narrativas no tienen sentido en sí mismas (Ángel D., 2014, pág. 19) ni pretenden reproducir los acontecimientos con la mirada del historiador. Las narrativas, constitutivas de la memoria, son interpretación; quien interpreta es el propio relator que va hilando un discurso en el que se descifra, se explica a sí mismo en relación con otros; "el territorio de la investigación narrativa no cuenta con fronteras rígidamente definidas, ya que más bien se caracteriza por la intersección disciplinaria, sus proponentes la consideran epistemológicamente como una manera diferente de conocer el mundo" (Blanco, 2011, pág. 138).

Para Sparkes \& Devís, (2007, pág. 1) los investigadores sociales cualitativos han aumentado su interés en formas de investigación 
narrativa porque, "de acuerdo con Polkinghorne (1995), la narración es "la única forma lingüística adecuada para mostrar la existencia humana como acción contextualizada". Para ellos, "las descripciones narrativas muestran que la actividad humana es una implicación en el mundo con propósito" (Sparkes \& Devís, 2007, pág. 1). Marc Augé (1998), señala que los académicos toman la vida social como un relato y que la narración es una condición ontológica de la vida social.

Las narrativas permiten concretar espacios de diálogo que expresan la trayectoria y los efectos que la construcción de la identidad ha generado sobre la memoria cultural de un grupo y encontrar:

(...) las formas específicas, las trayectorias, las tensiones y antagonismos que habitan históricamente y en un momento dado las identidades concretas. Que en términos teóricos se pueda hacer una genealogía de una identidad concreta, se pueda evidenciar su contingencia histórica e, incluso, lo reciente y arbitrario de su configuración, no significa que los actores sociales que se reconocen en ella no la experimenten como si esta identidad fuese esencial, ancestral e inmutable (Restrepo, 2007, pág. 26).

Los estudios sobre memoria, -que se han nutrido de la investigación narrativa- han ocupado un lugar destacado entre los estudios culturales, que cada vez reúnen a investigadores de un mayor número de disciplinas, y no se restringen a la antropología, la cual monopolizó los análisis de la cultura hasta la década de los años ochenta. Hoy, con el avance de las ciencias del lenguaje efectuado por el análisis crítico del discurso, con el interés de disciplinas como la sociología, la historia y la economía por los fenómenos culturales; y con la modalidad de investigaciones y de programas académicos centrados en problemas en vez de disciplinas, los estudios culturales han incorporado diversos puntos de vista, hasta convertirse en prácticas académicas transdisciplinares (Ángel D. , 2014). 
Los estudios sobre memoria cultural no pueden ser inscritos en el esquema metodológico de los estudios de caso. Estos últimos se conciben como estudios que abordan un problema empírico y pretenden explicarlo a la luz de una teoría. En esta forma, la teoría proporciona las variables que pueden operacionalizarse en indicadores que permiten contrastar el caso con los postulados de la teoría que pretende explicarlo. En este sentido, en una metodología elaborada según los estudios de caso, se debe elaborar un instrumento, un plan de análisis de los datos obtenidos y se prevén unos resultados, según la pregunta orientadora del estudio (Ángel D. , Investigación narrativa , 2015).

En los estudios sobre memoria, el propósito no es el análisis en función de variables contrastadas con un esquema teórico, sino más bien la comprensión de los relatos a partir de los mismos relatores en su entorno específico, por ello es importante para el investigador, comprender el contexto en el cual se construye el relato: social, cultural, histórico, político, económico y las relaciones de poder para emprender el diálogo. Es preciso considerar que las metodologías de sistematización, como la teoría fundada, con una perspectiva fenomenológica (Creswell, 1998) y el análisis crítico del discurso (Wodak, 2003), (Van Dijk, 2008); provienen de disciplinas como la psicología y la lingüística, cuyo interés por el lenguaje requiere los procedimientos analíticos.

En los estudios de memoria cultural, la obtención de relatos se considera como interpretaciones narrativas de una cultura realizadas por la misma cultura. Es decir, en términos hermenéuticos, se trata de la auto interpretación de una cultura (Ángel \& Herrera, 2011), puesto que las culturas no pueden ser interpretadas sino a partir de sí mismas. Esto significa que no hay ninguna cultura autorizada a interpretar a las demás mediante ningún método elaborado por esa cultura y considerado como universal por ella misma.

Bruner (2003), señala la narración como la forma de pensamiento y expresión de la visión del mundo de una cultura 
e implica algún tipo de estructura de la que las personas no son totalmente conscientes cuando cuentan sus historias.

Pareciera que esto conduce al relativismo de las culturas, pero la hermenéutica ofrece una mediación que supera ese relativismo (Bernstein, 1985). Se trata de producir diálogo intercultural y ese diálogo es necesariamente narrativo, lo que implica que los términos del diálogo se encuentran en cada cultura que dialoga, no en un método que se pretende universal. Por eso, de acuerdo con Ángel (2012), se ha elaborado una metodología inspirada en la etnografía, como opción metodológica por excelencia de los estudios culturales. En tal sentido, se diseñaron las Ferias de la Memoria propuestas en este documento, como espacios de intercambio en los que el relato del otro provoca el relato propio como se explicará más adelante.

Es preciso anotar que la memoria no es un dato empírico que exista previamente en la cultura como fenómeno que puede ser investigado. En muchas ocasiones, ya se encuentran relatos que pueden ser recogidos, pero casi siempre estos relatos son provocados por la investigación de memoria. Para Elizabeth Jelín (2002, p. 4) "en realidad, toda memoria es una reconstrucción más que un recuerdo". Es decir, esta investigación no aborda un objeto social preexistente, sino que lo provoca, lo captura y lo ordena para devolverlo a la cultura. De esta manera, los estudios de memoria cultural son acciones sobre la cultura, que la dota de una memoria (Ángel D. 2014).

Dado que la metodología aborda un diálogo intercultural, los interlocutores deben hacerse evidentes y anunciarse, puesto que quien promueve estos relatos es un interlocutor que tiene una serie de supuestos, un "haber previo" (Gadamer, 1977) o punto de vista ineludible que debe hacerse explícito y que alude a una preocupación por un tema. En este sentido, se debe reconocer el carácter subjetivo de este diálogo, sin ocultarlo bajo formas de reflexión en voz pasiva o de otros artilugios del discurso, por 
ello es importante también tener presente y aclarar el contexto (intereses, objetivos, relaciones de poder) desde el cual emerge el relato.

Clifford Geertz, en su ensayo "Descripción densa: hacia una teoría interpretativa de la cultura" (2000), refiere la descripción densa que se obtiene de narraciones distendidas, la cual relaciona la narración con el contexto en el que ocurre, con el fin de hacerla accesible a quienes no pertenecen a esa cultura. Este es un trabajo de interpretación que empieza por el relato de quienes pertenecen a una cultura y es leído por otra cultura que sabe de su limitación interpretativa.

Ferias de la memoria: Una propuesta metodológica para los estudios de memoria

Las Ferias de la Memoria son un recurso metodológico que se ha aplicado en diferentes municipios del Paisaje Cultural Cafetero colombiano desde el año 2012. Esta metodología consiste en el desarrollo de encuentros colectivos a través de una dinámica de diálogo que hemos denominado La memoria del otro.

La memoria del otro permite propiciar espacios para el intercambio de saberes y de historias entre los participantes, partiendo de la idea de que cada persona guarda recuerdos asociados a la construcción del pueblo, a los fenómenos políticos, sociales y culturales. También hay historias no compartidas que van cayendo en el olvido. Por eso, la memoria del otro busca acercar las historias y construir a partir de las memorias individuales, una narración que reúne convergencias y contradicciones, consensos y disensos, recuerdos y olvidos, en proceso de gestación de un relato que va trascendiendo el ámbito individual.

Los relatos surgen de la conversación y el diálogo intergeneracional en narraciones orales públicas, que se activan a través de dispositivos de memoria. Estos dispositivos anclan 
los recuerdos, los convocan, los provocan, los activan, mediante la presentación de objetos, imágenes, de lugares que puedan suscitar el interés por conversar y narrar. La memoria del otro, sus recuerdos y sus relatos se consideran un dispositivo de memoria que activa la memoria de los demás participantes.

Las ferias se organizan a partir de un proceso de investigación previa en la que luego de haber definido los objetivos, se analiza el contexto histórico, social, político, económico y cultural del grupo. Posteriormente se identifican en la zona a los custodios de memoria, es decir, las personas que poseen material gráfico, audiovisual, sonoro, que susciten historias de la vida, de los personajes, de las tradiciones, de las costumbres o de la historia del pueblo o un suceso específico y que quieren compartir (depende del objetivo de investigación) y en algunos casos reproducirlo; también es muy importante identificar sabedores o portadores de memoria que son personajes que han vivido largo tiempo en el área o que participaron o conocen de primera mano los sucesos de interés: familias fundadoras del lugar, colonos, abuelos, etc. Las instituciones locales como casas de la cultura, bibliotecas, oficinas de cultura y turismo pueden remitirnos con perfiles de participantes que cumplan con nuestros intereses: sabedores, portadores de memoria, testigos, entre otros.

Luego de identificar a los posibles participantes, a cada actor se le realiza una visita previa donde se concreta su participación, se identifican los dispositivos de memoria, su potencial como relator, se realiza una pre-clasificación de los dispositivos y un análisis de las necesidades logísticas que conllevará su traslado hacia el sitio seleccionado para la feria.

Antes de la feria, y si se considera pertinente para el objeto de la investigación, también se hace una convocatoria pública para que cualquier persona se inscriba y presente objetos y materiales y narren también sus historias. La convocatoria es abierta, pues se entiende que cada persona recibe su propio bagaje cultural y 
lo dota de memoria. Las características de cada participante dan cuenta de un proceso de transmisión que se da en el entorno del relator. Así, por ejemplo, un niño posee un relato que está asociado a las historias que vive y que su familia le cuenta, crea su propio discurso con los retazos de experiencia que en los espacios educativos y en el hogar recibe; un abuelo posee un relato un poco más elaborado que está sustentado en la sumatoria de su experiencia individual, los imaginarios que construye a partir de su contacto con los demás y con las instituciones que lo rodean (los medios de comunicación también hacen ésta labor); así entonces es tan importante caracterizar el relato como el relator, pues cada participante le imprime a su discurso un carácter especial que es importante identificar. Acá es importante que el investigador registre en video la feria y él o un auxiliar tome atenta nota, en forma de caracterización, de las personas asistentes, se sugiere diseñar un formato de inscripción al inicio de la feria y allí consignar los datos de caracterización de cada participante e ir haciendo observaciones respecto a las posiciones, gestos, tono de voz, etc.

Posteriormente, se organiza un encuentro -la feria- en el que la actividad base es una exposición de las piezas y los objetos obtenidos, cada objeto puede estar acompañado de una ficha de caracterización ${ }^{8}$. En dicha reunión los custodios exponen sus historias sobre los dispositivos y comparten ideas y relatos con los otros asistentes, en el caso de los portadores de memoria, se abre un espacio para escuchar sus narraciones y se les pide a los demás participantes que narren los recuerdos que les suscitan los recuerdos del portador, al momento de hablar se les pide presentarse y contar un poco quiénes son. El papel del investigador es muy activo en tanto este debe facilitar el diálogo a partir de preguntas, comentarios, coordinar la participación, profundizar en temas de especial interés de acuerdo con los objetivos de su investigación.

8 Se puede poner en ella el nombre del tenedor, la época, procedencia, uso, etc. Se busca con esto que el objeto active desde su exposición los recuerdos de los otros participantes. 
Posterior a la feria, se clasifican y se documentan los relatos de acuerdo con el objetivo e interés: por temas, por persona, por dispositivo de memoria, se construye el relato etnográfico o se pueden exponer los relatos individuales. (La tabla 1 propone un paso a paso metodológico).

El análisis de los resultados de las Ferias de memoria, asumen la posición metodológica del relator de historias (Sparkes \& Devís, 2007), en la que el producto es el propio relato. Los investigadores se embarcan en un análisis de las técnicas narrativas que utilizan las personas cuando cuentan sus historias y que les sirven para interpretar y dar sentido al mundo. Las historias, por lo tanto, hacen el trabajo de análisis y de teorización.

Desde este punto de vista, el investigador participa del momento en que se está contando la historia puesto que interactúa dialógicamente con el narrador con la misión de acompañarle, ayudarle a evocar el relato y participar incluso corporalmente. Para conseguirlo, es muy importante que los investigadores elaboren un relato creativo, en lugar de un relato realista, donde la escritura se convierte en un método de análisis y la teoría se encuentre en la historia. Esto exige pensar con los relatos y no sobre ellos, así como una implicación desde dentro y no un análisis desde fuera. "Para Frank (1995, p. 23), pensar con un relato significa experimentarlo de manera que afecta a la vida de uno o escribirlo, es decir, representarlo de manera que afecte a la vida de los lectores y lectoras" (citado por Sparkes \& Devís, 2007, p. 7). 
Tabla 1. Metodología para la construcción de relatos a través de las Ferias de la memoria.

\begin{tabular}{|c|c|}
\hline 1. PLANEACION & 4. SINTESIS \\
\hline $\begin{array}{l}\text { - Determinar los objetivos de la } \\
\text { investigación narrativa. } \\
\text { - Analizar el contexto de investigación } \\
\text { - Obtener información sobre } \\
\text { potenciales participantes: bola de nieve, } \\
\text { convocatoria pública, etc. } \\
\text { - Realizar visitas a potenciales } \\
\text { participantes y custodios de memoria } \\
\text { (identificar dispositivos de memoria, } \\
\text { portadores de memoria) } \\
\text { - Gestión de recursos: materiales, } \\
\text { documentales, logísticos, humanos. } \\
\text { - Diseñar instrumentos de recolección } \\
\text { de datos de participantes } \\
\text { - Diseñar protocolo de relatoría y } \\
\text { registro de asistencia a la feria y capacitar a } \\
\text { los asistentes de investigación }\end{array}$ & $\begin{array}{l}\text { - Ejecutar protocolo de sistematización de } \\
\text { asistencia } \\
\text { - Realizar inventario, clasificación, } \\
\text { etiquetado y sistematización de relatos } \\
\text { - Ejecutar estrategias de retroalimentación de } \\
\text { relatos (entrevistas, historias de vida, etc.) }\end{array}$ \\
\hline $\begin{array}{l}\text { 2. SELECCIÓN DE DISPOSITIVOS DE } \\
\text { MEMORIA }\end{array}$ & 5. REPORTE \\
\hline $\begin{array}{l}\text { - Curaduria de dispositivos: Realizar } \\
\text { inventario, clasificación, etiquetado y } \\
\text { sistematización (fotografia, ficha técnica) de } \\
\text { dispositivos de memoria } \\
\text { - Diseñar fichas de caracterización de } \\
\text { dispositivos de memoria y metodologia } \\
\text { expositiva } \\
\text { - Diseñar las preguntas orientadoras }\end{array}$ & $\begin{array}{l}\text { - Preparar el documento de investigación para } \\
\text { reporte de datos obtenidos: informe, artículo, } \\
\text { informe etnográfico. Publicación de relatos de } \\
\text { acuerdo a objetivos de investigación }\end{array}$ \\
\hline 3. EJECUCIÓN DE LAS FERIAS & 6. RETROALIMENTACION \\
\hline $\begin{array}{l}\text { - Realizar convocatoria } \\
\text { - Realizar montaje de exposición de } \\
\text { dispositivos de memoria con fichas de } \\
\text { caracterización } \\
\text { - Preparar equipos de grabación } \\
\text { - Ejecutar la feria } \\
\text { - Ejecutar protocolo de relatoría y } \\
\text { registro de asistencia }\end{array}$ & $\begin{array}{l}\text { - Exponer los resultados obtenidos ante el } \\
\text { público participante y comunidad académica y } \\
\text { público en general }\end{array}$ \\
\hline
\end{tabular}

Ferias de la memoria aplicadas al contexto de la cultura cafetera.

Como se mencionó, esta metodología fue diseñada para una investigación sobre los cambios en la identidad cafetera y los efectos de la crisis del café y del proceso de patrimonialización ante la Unesco ${ }^{9}$ sobre algunos de sus referentes culturales. Las ferias fueron realizadas con el apoyo del Ministerio de Cultura a través del Programa Nacional de Concertación en los

9 El Paisaje Cultural Cafetero fue declarado patrimonio mundial por la Unesco el 25 de junio de 2011. 
municipios de Santuario, Santa Rosa de Cabal, Marsella y Pereira en el departamento de Risaralda. La primera versión se realizó en la Casa de la Cultura de Santa Rosa de Cabal y contó con la presencia de dos historiadores y un gestor social reconocido por su trabajo de curaduría de archivos fotográficos y su conocimiento de la historia local. Esta feria partió de la exposición pública de la información, los objetos y los datos que los custodios traían, los asistentes participaron con preguntas y complementaron las exposiciones iniciales. Este primer ejercicio permitió ajustar la metodología, pues, al darle mayor protagonismo a un grupo de participantes reconocidos por su trayectoria, se eclipsó el relato de los demás invitados, quienes suscribieron los relatos que por provenir de un grupo "autorizado" adquirió para ellos un carácter de supuesta "legitimidad irrefutable".

Ese mismo año se realizó la feria en el municipio de Santuario, con grupos conformados por estudiantes de colegio; una semana antes de la feria, se pidió a cada grupo que trajera objetos y documentos guardados por ellos o por sus familias, o algún objeto con valor histórico, familiar o cultural, y que indagaran sobre ellos. A la feria llegaron decenas de objetos y cada estudiante se encargó de exponer al resto del colegio las historias que averiguaron, los resultados agregados de todos los municipios fueron utilizados para la creación de dos programas de radio y tres cortos documentales sobre la cultura cafetera.

El proceso de investigación, lejos de haberse desarrollado bajo una fórmula metodológica rígida, tuvo múltiples cambios y ajustes que terminaron por enriquecer la reflexión, no sólo acerca de la metodología misma, sino también sobre los objetos y sujetos de estudio. Algunas ferias fueron difíciles de desarrollar, dado el origen diverso de los participantes, en tanto en algunas de ellas, como la primera realizada en el municipio de Marsella, participaron adultos mayores adolescentes y niños, lo que generó una especie de desorden en los relatos, participación activa de unos sobre la pasividad de otros, pérdida de interés de los jóvenes frente 
al relato extenso de algunos adultos mayores, monopolización del discurso en algunos momentos y en general sucesos que "desajustaban" el diseño metodológico previo, lo que se traducía en un nuevo proceso de reflexión metodológica y ajuste.

Con las experiencias anteriores, se rediseñaron las ferias, se comprendió la ventaja de entablar un diálogo donde todos los participantes presentaran sus relatos en condiciones de igualdad, sin categorías de expertos que puedan afectar o limiten las exposiciones de los demás, pues la cuestión más allá de pretender enseñar o difundir imaginarios y relatos memoria, es construir en conjunto una narración que dé cuenta de las identidades de un grupo específico, en este caso de cafeteros.

En agosto de 2014, se realizó una Feria de la Memoria en la Casa de la Cultura de Marsella. Allí, se trabajó con un grupo de mujeres a las que se les visitó previamente, con el fin de identificar sus historias y su disposición para participar como custodias de la memoria, además de observar la calidad y el estado de los objetos custodiados. Luego, se procedió con el itinerario de la feria. Los ejercicios previos de visita y análisis de objetos dieron como resultado una feria más ordenada y la obtención de mejores relatos.

Los resultados de estas ferias se utilizaron para alimentar el Banco de la Memoria, una plataforma web que funcionaba como wiki de la memoria y que buscaba compilar y resguardar la información que se obtenía de estas actividades, así como permitir a los participantes ver en línea la información que aportaban, fue una forma de devolver a la cultura su propia interpretación.

Estas Ferias de la Memoria tienen una semejanza con los talleres de memoria que realizaba Arturo Alape con los jóvenes de Ciudad Bolívar en Bogotá (Alape, 2003), en los cuales reunía a jóvenes alrededor de un tema que le permitía recoger relatos sobre la vida, el pasado y el proyecto de estos jóvenes, de igual forma, 
Pilar Riaño Alcalá (2006) trabajó con jóvenes del barrio Antioquia en Medellín, con quienes aplicó una "teoría feminista del punto de vista”, que privilegia las voces de los participantes, según la cual "esta perspectiva parcial representa un recuento más apropiado del mundo cotidiano" (p. IX) y encontró algunos disparadores de memoria, que en el presente estudio se denominan dispositivos, en los que se anclan recuerdos que provocan relatos, como álbumes $\mathrm{y}$ anecdotarios.

Posteriormente, la investigadora se cercioró de que las transcripciones de las sesiones de sus talleres pudieran ser usadas en el trabajo comunitario de los jóvenes con los que trabajó. Por su parte, Blanco (2011) realizó un estudio en el que aplicaba la investigación narrativa en el conocimiento del fenómeno de las vacaciones familiares en México en la segunda mitad del siglo $\mathrm{XX}$, concluyendo que la elaboración de este tipo de narrativas por mujeres que cuentan con ciertas características sociodemográficas y socioeconómicas, remite no sólo a aquello que algunos autores refieren como el "conocimiento situado", sino también son una forma diferente de "hacer historia", por cuanto los relatos personales remiten a contextos históricos y sociales específicos (Blanco, 2011).

Elizabeth Jelin (2002, pág. 8) distingue dos tipos de memoria: la habitual y la narrativa; para ella, la memoria habitual está dada por el comportamiento cotidiano o vida normal que se expresa en prácticas en las que "no hay nada «memorable» en el ejercicio de esas memorias" y la memoria narrativa es aquella que se da cuando se rompen las rutinas, que involucran al sujeto de manera diferente puesto que allí entran en juego los sentimientos y afectos que empujan a la reflexión y búsqueda de sentido, señala, citando a Bal (1999), que es este compromiso afectivo lo que transforma esos momentos y los hace «memorables».

Para el análisis realizado interesaban tanto las memorias habituales en tanto son aquellas las que permiten identificar el 
grado de autenticidad y permanencia de la identidad cafetera y el grado de replicabilidad y transmisión a través de costumbres y formas de hacer y de ser; y la memoria narrativa en el sentido de que son éstas las que nos permiten explorar y explicar las memorias habituales para darles sentido a la construcción identitaria cafetera, es decir las habituales se llevan a un nivel narrativo para reconocer la trayectoria de la cultura. En nuestro caso, las Ferias de la Memoria han permitido obtener relatos de memoria habitual y narrativa de unos participantes que en procesos ulteriores otros participantes retroalimentaron.

La revisión del material recogido fue complementada con otras ferias y con entrevistas en profundidad con los actores de memoria de dos veredas del municipio de Marsella y una feria organizada en el sector urbano, además, se hicieron entrevistas buscando contrastar visiones diferentes sobre la identidad cafetera; para ello, se entrevistaron cafeteros que no hicieran parte de ninguna organización y que no estuvieran involucrados en procesos institucionales, y entrevistas con cafeteros que participaran en procesos como asociaciones o que fueran activos en temas relacionados con caficultura y Paisaje Cultural Cafetero.

Estos acercamientos iniciales a partir de las Ferias de la memoria permitieron generar proximidad con los sujetos, en el periodo comprendido entre 2012 y 2016.Simultáneamente, se realizó una revisión y análisis documental que diera cuenta de la teoría e información construida alrededor de la caficultura como práctica cultural, del café como sistema productivo y del Paisaje Cultural Cafetero como proceso de patrimonialización, con el fin de retroalimentar la información de la revisión bibliográfica y las ferias de la memoria se realizaron nuevas entrevistas y en algunos casos se solicitó a participantes clave que entregaran un relato escrito.

Como se refirió anteriormente, el proyecto involucró una plataforma virtual que se denominó Banco de la memoria. En esta 
página, se subieron los resultados más significativos de las ferias y los custodios subieron material audiovisual (fotos, audio y video) de objetos típicos de la cultura cafetera, relatando sus recuerdos en forma de texto. Otros visitantes de la página respondían en forma de comentarios, relatando los recuerdos que les suscitaba el material publicado. La página web se encuentra deshabilitada, pero, en redes sociales aún se puede encontrar información útil sobre el Banco ${ }^{10} 1$.

Finalmente, todos los datos e información obtenida fueron usados por la autora para la construcción de un relato acerca de la trayectoria histórica, la identidad y las características culturales de los cafeteros como por ejemplo la forma de hacer las viviendas de bahareque, el lenguaje popular, las formas de alimentación, entre otros. Asimismo, sirvieron para reflexionar sobre las consecuencias de la crisis cafetera sobre la cultura, en el análisis se relataron también las transformaciones culturales, los elementos que componen el ser cafetero y las raíces de la identidad de este grupo cultural. Los resultados obtenidos permitieron la publicación de dos libros sobre la arquitectura de bahareque: Casa para la memoria y Memorias de Pereira: la Casa; un Diccionario de expresiones populares de la cultura cafetera avalado por la Federación Nacional de Cafeteros y un libro de relatos denominado Relatos Montañeros.

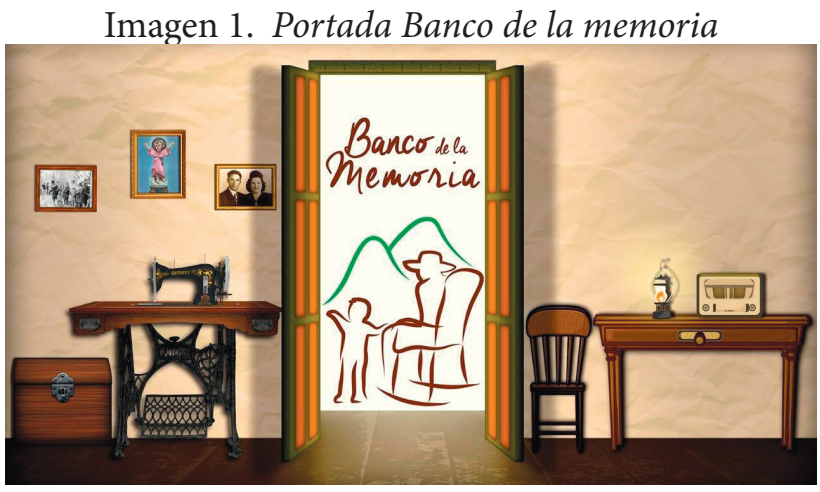


Imagen 2. Infografía para orientar sobre uso de la plataforma web Banco de la memoria

\section{SÉ UN CUSTODIO DE LA MEMORIA}

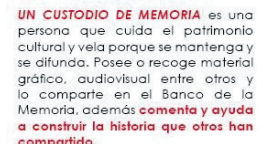
a construir la historia compartido.
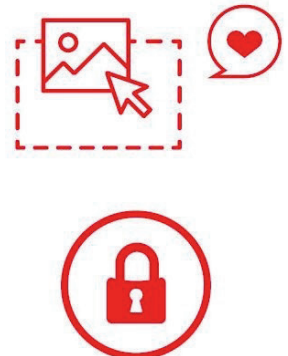

1) REGISTRARSE

Da clic en "Regístrate" que aparece en la

parte superior derecha de esta página.

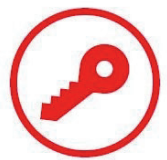

3) INGRESA

¡Ya eres parte!, ahora ingresa con tus datos registrados a través del

botón "Ingresar" que también se encuentra en la parte superior derecha de esta página.

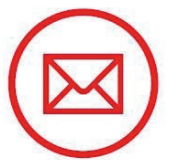

5) ESPERA

El equipo de Casa Creativa confirmará vía correo electrónico cuando tu contenido esté publicado.

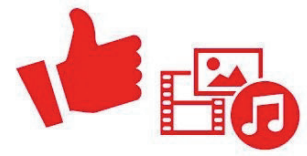

ESTO SIG NIFICA construir en colectivo la memoria histórica del Paisaje Cultural Cofetero. Aportar material para compartirlo y hacerlo visible momentos $u$ objetos, escribir sobre ellos y subirlos al Banco para qu
otros los conozzan y comenten.

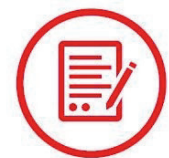

2) FORMULARIO

Completa tus datos personales como

nombre, apellidos

correo electrónico y contraseña.

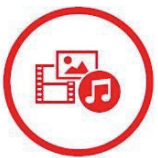

4) COMPARTE

Ahora diŕgete a la pestaña "COMPARTE MEMORIA" y sube lOs archivos e historias que quieras publicar en este espacio.

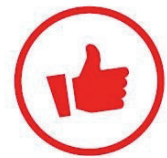

6) PUBLICA

en tus redes sociales $e$ invita a tus amigos a completar la historia del Paisaje Cultural Cafetero.

Resuelve fus dudas en info@bancodelamemoria.com 


\section{Conclusiones.}

Imagen 3. Feria de la memoria en Marsella, Risaralda

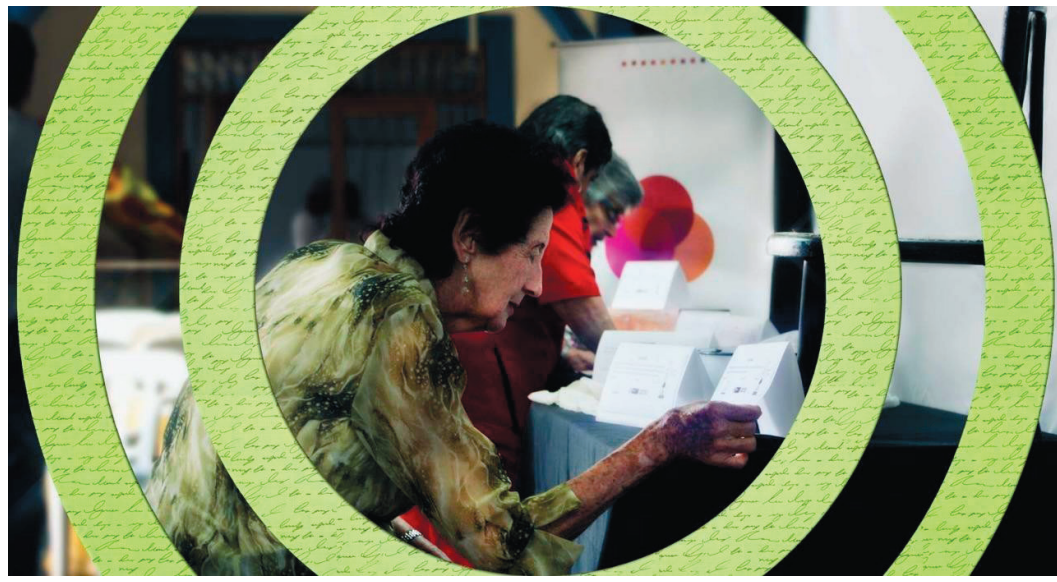

A partir de una corta revisión teórica sobre la investigación narrativa, se mostró que la identidad puede ser estudiada a partir de relatos memoria que un investigador construye con un grupo, se argumenta cómo se puede generar un diálogo de memorias a partir del uso de dispositivos como objetos e historias que incitan recuerdos y que pueden ser compartidos en un espacio colectivo que aquí llamamos Feria de la memoria. Estos relatos obtenidos sirven para la comprensión del pasado, las prácticas y la identidad de un grupo, más allá de los soportes historiográficos tradicionales, como testimonios colectivos de la significación social de sucesos o prácticas.

El discurso narrativo producido en el marco de las ferias contribuye a identificar los marcos identitarios y comprender el grupo social desde sí mismo, porque estos relatos obtenidos son una forma narrativa de explicar la realidad social.

Exponiendo la aplicación de las Ferias de la memoria en un estudio sobre las transformaciones de la cultura cafetera colombiana, como recurso metodológico fundamentado 
en la Etnografía, se mostró su utilidad para ser aplicadas en investigaciones de memoria. Las Ferias permiten explorar a partir de relatos, el sentido que un grupo le da a los sucesos y objetos de la vida cotidiana y facilitan la construcción de conocimiento colectivo a partir de experiencias individuales. Ellas permiten acceder al guion interiorizado de identidad porque de acuerdo con Restrepo (2007) y Giménez (2003) este es discursivamente construido.

La identidad al estar conformada por recuerdos, ideas y creencias, brota en el relato en el que el narrador usa la memoria y el patrimonio como dispositivos que le permiten construir ese discurso o relato identitario, no para el investigador, si no, para encontrar los marcadores culturales que describen la identidad del grupo y ver cómo las personas se involucran o relacionan con su pasado, los sentimientos y afectos que les genera, su vínculo emotivo con este. En suma, ver en la experiencia vivida, del pasado recordado. Siguiendo a Zan (2008), si vemos cómo la gente recuerda y qué elementos utiliza para hacerlo, podemos ver como delimitan su identidad.

En cuanto a la metodología se puede concluir que es fundamental la habilidad del investigador para coordinar la participación de un público heterogéneo en las ferias, esta condición es una ventaja por las múltiples memorias que se pueden recolectar, pero es necesario planificar adecuadamente para garantizar mecanismos de participación sin jerarquías, que ayuden a todos los custodios a relatar con confianza sus memorias. De igual modo es importante definir muy bien el número de personas que es pertinente convocar al mismo tiempo al diálogo, pues si el grupo es muy amplio (más de diez personas), es posible que se pierdan memorias que quizás pudieron aportar al objetivo y que por falta de tiempo puede que no sean escuchadas, suele suceder también que las personas son tímidas o se abruman hablando en público y terminen siendo solo espectadoras, se recomienda entonces que si en el ejercicio de búsqueda de custodios, aparecen muchas voces, se realicen varias sesiones. 
También es importante realizar curaduría de los dispositivos de memoria encontrados para tener previamente conocimiento del tipo de relatos que se podrán revelar y orientar el diseño de preguntas activadoras de memoria, así mismo facilitar el entrecruzamiento de relatos.

En la transcripción de los relatos es importante mantener la voz de los participantes, y armar los textos guiados por el objetivo de investigación, el investigador aporta su mirada en la selección de los relatos y en la organización esquemática para presentar los resultados. Los resultados también pueden ser utilizados en la construcción de un texto etnográfico.

A pesar de haber creado las Ferias de la memoria como forma de acercamiento y rescate de las memorias culturales, es posible complementar con otras herramientas de investigación tradicionales para comprender un grupo y el cambio cultural. Así, los estudios de memoria pueden ser enriquecidos con otros acercamientos metodológicos que bajo la mirada de la Etnografía develan la identidad cultural y los imaginarios del pasado de los grupos.

\section{Referencias Bibliográficas}

Alape, A. (2003). Ciudad Bolívar: la hoguera de las ilusiones. Bogotá: Planeta.

Ángel, D. (2012). La hermenéutica y los métodos de investigación en ciencias sociales. Revista de Estudios de Filosofía 43. Ángel, D. (2014). Cambio de paisaje y persistencia campesina frente a la crisis cafetera en la vereda Muchipay municipio de Topaipí Cundinamarca durante el periodo 1992-2014. Bogotá: Pontificia Universidad Javeriana, Facultad de estudios rurales y ambientales. 
Ángel, D. (2014). Metodología y relato memoria. Estudios de filosofía de la Universidad de Antioquia. Ángel, D. (20 de 10 de 2015). Investigación narrativa. (C. Saldarriaga, Entrevistador)

Ángel, D., \& Herrera, J. D. (2011). La propuesta hermenéutica como crítica y como criterio del problema del método. Revista de Estudios de Filosofía N 42., 9 - 29.

Archila, M. (2004). La Historia hoy ¿memoria o pasado silenciado? Historia y Sociedad No 10, 15-33.

Augé, M. (1998). Las Formas del Olvido. Barcelona: Gedisa.

Barth, F. (1976). Los grupos étinicos y sus fronteras. La organización social de las diferencias culturales. México: Fondo de cultura Económica.

Bernstein, R. (1985). Beyond Objetivism and Relativism: Science, Hemeneutics, and Praxis. Philadelphia: University of Pennsylvania Press.

Blanco, M. (2011). Investigación narrativa: una forma de generación de conocimientos. Argumentos, vol. 24, núm. 67, septiembre-diciembre, 2011, 135-156.

Bruner, J. (2003). Self-Making Narratives. En R. F. (eds.), Memory and the Construction of a Narrative Self (págs. 209-226).

Candau, J. (1998). Memoria e identidad. París: Ediciones del Sol.

Candau, J. (2002). Antropología de la memoria. Buenos Aires: Nueva Visión.Castells, M. (1998). La era de la información. Madrid: Alianza. 
Colasurdo, M. B., Sartori, J., \& Escudero, S. (2010). La implicancia de la memoria y la identidad en la constitución del patrimonio. Algunas reflexiones. Revista del Museo de Antropología Vol 3, 149-154.

Creswell, J. W. (1998). Qualitative inquiry and research design: Choosing among five traditions. Thousand Oaks. California: Sage Publications, Inc.

Gadamer, H.-G. (1977). Verdad y Método. Salamanca: Sígueme.

García-Canclini, N. (1999). Los usos sociales del patrimonio cultural. En A. E, Patrimonio Etnológico, nuevas perspectivas de estudio (págs. 16-33.). México: Consejería de cultura. Junta de Andalucía.

Geertz, C. (2000). La interpretación de las culturas. Barcelona: Gedisa.

Giménez, G. (2003). La cultura como identidad y la identidad como cultura. México: UNAM, Instituto de Investigaciones Sociales.

Giménez, G. (2009). Cultura, identidad y memoria. Materiales para una sociología de los procesos culturales en las franjas fronterizas. Frontera Norte, Vol . 21, Núm . 41, Enero -junio de 2009, 26.

Guitart, E., Vila, I., \& Gómez, J. B. (2010). El carácter fronterizo de las identidades contemporáneas. El caso de Chiapas. Aposta, revista de Ciencias Sociales No 44, 19.

Halbwachs, M. (2004). Los marcos sociales de la memoria. Antrophos. Jelin, E. (2002). Los trabajos de la memoria. Madrid: Siglo 21 Editores. 
Lythgoe, E. (2008). Facultad de Filosofía y Humanidades. Universidad de Chile. Recuperado el 16 de Febrero de 2015, de Consideraciones sobre la relación historia-memoria en Paul Ricoeur: http://www.filosofia.uchile.cl/publicaciones/ revfiloso/60/pdf/lythgoe.pdf.

Maffesoli, M. (2004). Juventud: el tiempo de las tribus y el sentido nómada de la existencia. Jóvenes, revista de estudios sobre juventud \# 8. 28-41.

Melo, J. O. (2006). Contra la Identidad. Malpensante $\mathrm{N}^{\circ} 74$ Noviembre - Diciembre de 2006.

Nora, P. (1984). Les Lieux de Mémoire. París: Gallimard, 1984, pp. XVII-XLIL. Traducción para uso exclusivo de la cátedra Seminario de Historia Argentina Prof. Femando Jumar C.U.R.Z.A. - Univ. Nacional del Comahue.

Pinilla, A. (2013). La memoria como escenario pedagógico para la enseñanza de la historia. (http://revista.colegiohispano. edu.co/ojs/index.php/tomo20/article/view/29, Ed.) Revista Educación y pensamiento versión 20 Colegio Hispanoamericano, 94-103.

Restrepo, E. (2007). Identidades planeamiento teóricos y sugerencias metodológicas para su estudio. Revista Jangwa Pana, $\mathrm{N}^{\circ} 5$, Julio de 200 7, 24-35.

Riaño Alcalá, P. (2006). Jóvenes, memoria y violencia en Medellín. Una antropología del recuerdo y el olvido. Medellín: Editorial Universidad de Antioquia.

Ricoeur, P. (13 de junio de 2000). Historia y memoria: La escritura de la historia y la representación del pasado. Annales. Histoire, Sciences Sociales Núm. 55-4. París: julio-agosto, 731-747. Recuperado 
el 16 de Febrero de 2015, de http://www.h resultado_textos.php? categoria $=$ Verdad $\% 2 C+$ justicia $\% 2 C$ istoria $+\mathrm{y}+$ memoria. $+\mathrm{La}+\mathrm{escritura}+\mathrm{de}+\mathrm{la}+$ historia $+\mathrm{y}+\mathrm{la}+$ representaci\%F3n

Sparkes, A., \& Devís, J. (2007). Investigación narrativa y sus formas de ar educación física y el deporte. En W. Moreno Gómez, \& S. Pulido Quintero, Edu cuerpo en las interacciones e instituciones sociales (págs. 43-63). Medellín: Fur

Van Dijk, T. (2008). El discurso como interacción en la sociedad. En T. Van Dijk, t social (págs. 19 - 66). Barcelona: Gedisa.

Villaseñor, I., \& Zolla, E. (2012). Del patrimonio cultural inmaterial o la patrin Cultura y patrimonio Año 6, núm. 12, 75-101.

Williams, R. (1980). Marxismo y Literatura. Barcelona: Península.

Wodak. (2003). Métodos de analisis critico del discurso. Barcelona: Gedisa.

Zan, J. d. (2008). Memoria e identidad. TÓPICOS. Revista de Filosofía de Santa 41-67. 


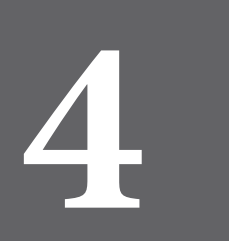

CAPÍTULO

CUATRO 



\section{Inferencia estadística automática empleando embebimientos de espacios de Hilbert y computación Bayesiana aproximada}

\section{Automatic statistical inference based on Hilbert space embeddings and approximate Bayesian computation}

Wilson González Vanegas

Universidad Tecnológica de Pereira

wilgonzalez@utp.edu.co

Resumen

En muchas aplicaciones de ciencia e ingeniería, resulta importante estimar el valor de un conjunto de parámetros que describen un sistema a partir de una serie de muestras $u$ observaciones que representan cierto comportamiento. En la mayoría de los casos, dicha estimación constituye una tarea difícil de realizar debido al ruido contenido en las muestras, por lo que es necesario un tratamiento desde un punto de vista probabilístico. 
En particular, la estimación Bayesiana es una herramienta de gran utilidad en la inferencia estadística de parámetros, ya que permite manejar la incertidumbre propia de las aplicaciones de la vida real. Cuando los sistemas bajo estudios son sencillos es fácil encontrar una expresión para la función de verosimilitud, sin embargo, para modelos más complejos, como aquellos que son altamente no lineales o que presentan un comportamiento estocástico, determinar una expresión analítica para la función de verosimilitud es prácticamente imposible, dificultando así la tarea de estimación empleando enfoques Bayesianos.

En este sentido, las técnicas basadas en simulación numérica han tomado gran importancia puesto que son una alternativa al problema de la función de verosimilitud en los esquemas Bayesianos. En particular, la Computación Bayesiana Aproximada ( $\mathrm{ABC}$ por sus siglas en inglés) ha surgido en los últimos años como una alternativa para realizar inferencia estadística sin utilizar una función de verosimilitud mediante un modelo auxiliar que genera datos simulados del sistema bajo estudio, los cuales son comparados con las muestras observadas empleando estadísticos, cuya selección para garantizar suficiencia no es trivial y constituye toda una línea de investigación. Como alternativa al uso de estadísticos suficientes en la estimación, se emplean los métodos kernel y los espacios de Hilbert dentro del esquema de inferencia Bayesiana, para lo cual es necesario utilizar las funciones de probabilidad de los datos observados y simulados.

La estimación de estas densidades es una etapa de suma importancia durante el proceso de inferencia, y la selección de los parámetros libres, no sólo en dicha estimación sino en el esquema general de $\mathrm{ABC}$, es una tarea que resulta difícil puesto que la dinámica y complejidad de cada aplicación es diferente.

En este trabajo se desarrolla un esquema automático de inferencia estadística con base en embebimientos de espacios de Hilbert, teniendo en cuenta la relevancia de las características 
de los datos en la estimación no paramétrica de las funciones de densidad de probabilidad empleadas en las técnicas ABC. Adicionalmente, se desarrolla una estrategia que favorece la flexibilidad y exactitud de la inferencia en escenarios tanto supervisados como no supervisados mediante un esquema automático que codifica estructuras relevantes en los datos, permitiendo así la sintonización de forma automática de los parámetros libres empleados en el esquema $\mathrm{ABC}$.

Palabras claves: Computación Bayesiana Aproximada, Inferencia estadística, Método kernel, Sistema dinámico no lineal, Teoría de grafos,

\section{Abstract}

In many science and engineering applications, the central aim concerns the estimation of some parameters that describe a system, using a set of samples or observations representing a particular behavior. In most cases, such an estimation is a difficult task due to the noise contained in the samples, demanding a treatment from probabilistic perspectives. In particular, Bayesian estimation is a useful tool for inferring model parameters since it includes prior knowledge to handle the uncertainty, especially in real-life applications. For straightforward systems, it is easy to find and assess an expression for the likelihood function. However, in non-trivial systems, the application of any Bayesian framework is a very challenging task, because the complexity of a model means that the associated likelihood is computationally intractable, or that it is not even possible to determine an analytical formula for the likelihood function. In this regard, numerical simulationbased techniques have been widely used across the literature since they provide an alternative to the problem of applying Bayesian inference with intractable likelihoods. In particular, Approximate Bayesian Computation (ABC) allows statistical inference without using a likelihood function via an auxiliary model that generates simulations of the system, which are compared to the observations. 
Recent progress in this field has included kernel methods and Hilbert spaces to support the Bayesian inference scheme, using probability density functions over the observed and simulated data. The estimation strategy of these densities is an essential component during the inference process, and the selection of free parameters not only in the density estimation but also in the general ABCbased scheme is an increasing challenging task. The present project aims to develop an automatic statistical inference approach based on Hilbert space embeddings and kernel methods, taking into account both the relevance of data in the non-parametric density estimation and the matching between parameters and simulations spaces used in $\mathrm{ABC}$ techniques. Additionally, the central aim is to develop a strategy that favors the flexibility and accuracy for both supervised and unsupervised inference scenarios, looking for an automatic scheme that encodes relevant structures in the data and allows to tuning of the parameters used in $\mathrm{ABC}$ automatically.

Keywords: Aproximate Bayesian Computation, Statistical inference, Kernel method, nonlinear dynamic system, Graph theory.

\section{Introducción}

Una de las áreas de mayor interés en el campo de la estadística inferencial es la teoría de estimación. Esta teoría permite estimar el valor de los parámetros que describen un sistema en particular con base en un conjunto de muestras, las cuales usualmente son el resultado de medir algún comportamiento específico del sistema [1]. En la mayoría de los casos, dichas medidas se encuentran contaminadas por ruido proveniente de diversas fuentes, por lo que la estimación adecuada de los parámetros se convierte en una tarea difícil de realizar, haciendo necesario un tratamiento en términos probabilísticos. 
Para tratar este problema desde la teoría de estimación, se dispone de tres perspectivas diferentes: la estimación puntual, la estimación por intervalos y la estimación Bayesiana [2]. En la estimación puntual, se emplea una expresión matemática cerrada que permite encontrar un único valor para cada uno de los parámetros que se desean inferir, empleando para esto algún criterio en particular; por ejemplo, que se maximice la función de verosimilitud asumiendo alguna distribución específica para los datos, como es el caso de la estimación de máxima verosimilitud, o que se minimice el error cuadrático medio, como es el caso de mínimos cuadrados [3]. Por otra parte, en la estimación por intervalos, se establece un rango en el que se espera encontrar con cierta probabilidad el valor verdadero de los parámetros a inferir, por lo que se tienen intervalos de confianza para el conjunto de parámetros [4]. En general, la estimación puntual y la estimación por intervalos de confianza hacen parte del enfoque frecuentista de la estadística inferencial. Por otra parte, desde la perspectiva de la estimación o inferencia Bayesiana, el objetivo consiste en obtener es una función de densidad de probabilidad para cada parámetro que, que suele denominarse como "distribución posterior" o simplemente "posterior", la cual establece la probabilidad de que un parámetro específico del sistema tome determinado valor [5].

En la estimación Bayesiana es necesario tener conocimiento previo del valor de los parámetros del sistema, el cual se representa mediante una función de densidad de probabilidad, conocida como "distribución a priori" o simplemente "prior". Para encontrar el posterior de los parámetros se emplea el teorema de Bayes, el cual usa una función de verosimilitud encargada de establecer la probabilidad de los datos observados bajo un modelo estadístico dado, a fin de actualizar el conocimiento previo (establecido en el prior) y obtener el posterior [1]. Para sistemas sencillos es fácil encontrar una expresión para la función de verosimilitud. Sin embargo, para modelos más complejos, como aquellos que son altamente no lineales o que presentan un comportamiento 
estocástico, determinar una fórmula analítica para la función de verosimilitud (o siquiera evaluarla) es prácticamente imposible [6].

Para hacer frente a la intratabilidad de la función de verosimilitud, en los últimos años se han propuesto técnicas basadas en simulación numérica, tales como la Computación Bayesiana Aproximada ( $\mathrm{ABC}$ por sus siglas en inglés de Approximate Bayesian Computation), con las cuales es posible obtener una aproximación de la distribución posterior a partir de un modelo auxiliar (que es una descripción matemática del sistema bajo análisis) que toma el lugar de la función de verosimilitud. La idea principal detrás de un método basado en $\mathrm{ABC}$ consiste en la evaluación del modelo auxiliar en un conjunto de puntos muestreados del prior para calcular datos simulados que, en un atapa posterior, se comparan con los datos observados en el sentido de alguna función de distancia, generando así un conjunto de pesos que definen una aproximación del posterior de los parámetros del modelo [7].

El número y tipo de métodos $\mathrm{ABC}$ que se han propuesto en la literatura es tan grande que sería difícil clasificarlos. Sin embargo, se podrían destacar dos grupos: los que trabajan con estadísticos (características) de las simulaciones y observaciones, y los que usan embebimientos de las distribuciones de probabilidad de los datos observados y simulados utilizando funciones núcleo o "kernel". En el primer grupo, estadísticos (que deben ser suficientes) resumen la información contenida en los datos observados y simulados antes de calcular la medida de distancia para reducir la carga computacional debido a la gran cantidad de características y observaciones [8]. En el segundo grupo, se asocian medidas de probabilidad (distribuciones) sobre observaciones y simulaciones, las cuales son embebidas en un espacio de Hilbert con kernel reproductor (RKHS por sus siglas en inglés de Reproducing Kernel Hilbert Space), empleando para esto un kernel de reproducción que respalda el procedimiento de inferencia mediante la comparación entre las medidas de probabilidad [9]. 
Con respecto al esquema $\mathrm{ABC}$ basado en distribuciones de probabilidad, existe una característica que se debe tener en cuenta: las funciones de densidad de probabilidad de los datos observados y simulados son desconocidos en la práctica, ya que tales datos pertenecen a un espacio de parámetros y no a un espacio de probabilidad propiamente. En este sentido, es necesario emplear un esquema de aproximación, para lo cual se pueden utilizar enfoques paramétricos o no paramétricos. En particular, una estimación paramétrica obliga a los datos a seguir una familia particular de distribución, mientras que una estimación no paramétrica representa un modelado más flexible donde la aproximación de las funciones de densidad de probabilidad es conducida a partir de los datos.

En este sentido, el estimador por ventanas de Parzen es una de las técnicas más populares para aproximar las funciones de densidad de probabilidad a partir de los datos, en el cual se utiliza una función kernel para calcular la probabilidad de una sola muestra basada en las demás [10], sin embargo, es común suponer que todas las muestras tienen la misma importancia, sin incluir el concepto de relevancia, lo cual resulta poco apropiado especialmente en aquellas aplicaciones con alta dinámica y estocasticidad, además, al igual que pasa con el número de particiones en un histograma, la selección de parámetros libres de la función de kernel seleccionada es un paso crucial puesto que éstos determinan la forma de la densidad estimada.

En particular, para el kernel Gaussiano (ampliamente utilizado por sus propiedades matemáticas), determinar la matriz de covarianza es esencial porque ésta establece la relación estadística entre las características del conjunto de datos.

En relación con el esquema $\mathrm{ABC}$ basado en embebimientos de espacios de Hilbert, la inferencia estadística de los parámetros del modelo se realiza a partir de la comparación entre las distribuciones asociadas a los datos observados y simulados y la 
inferencia no se realiza directamente en el espacio de parámetros, sino en el espacio de probabilidad [9], por lo tanto, cualquier información sobre el espacio de los parámetros no se tiene en cuenta para calcular la distribución posterior (nos referimos a esta configuración como "inferencia no supervisada"). El anterior enfoque podría conducir a escenarios en los que el modelamiento de la incertidumbre mediante funciones de densidad de probabilidad no es suficiente para comprender la complejidad del sistema bajo estudio y, en tal caso, toda vez que exista información adicional disponible sobre el espacio de parámetros, ésta se podría incluir en el procedimiento general de inferencia para obtener una estimación más precisa (nos referimos a esta configuración como "inferencia supervisada").

\section{Planteamiento del problema y justificación.}

La influencia actual de los métodos basados en Computación Bayesiana Aproximada en distintas áreas del conocimiento ha puesto de manifiesto su importancia en las comunidades académicas [11], la estimación de parámetros para la generación de modelos matemáticos más robustos y con mayor representación de los fenómenos reales es una preocupación latente en ciencia e ingeniería; el conocimiento experto acerca de los fenómenos a estudiar hace de los enfoques Bayesianos una estrategia interesante puesto que es posible usar dicho conocimiento previo para guiar los métodos estadísticos.

Sin embargo, la intratabilidad de la función de verosimilitud aparece acompañada de la necesidad de ajustar otra serie de parámetros libres que los distintos métodos $\mathrm{ABC}$ requieren para lograr una aproximación del posterior. La influencia de estos parámetros libres en el rendimiento de los esquemas $\mathrm{ABC}$ es tan marcada que pueden conducir fácilmente a posteriores completamente alejados de la realidad, por esta razón, se requiere un esfuerzo importante para llevar a cabo dicha sintonización. En un estudio reciente [12], los autores clasifican la gran variedad de métodos $\mathrm{ABC}$ en tres grupos diferentes: enfoques basados en 
estadísticos suficientes, técnicas basadas en pesos de ponderación y métodos basados en ajustes mediante regresión. Veamos cómo la necesidad de ajustar parámetros libres es una tarea transversal a todos ellos.

La adecuada selección de estadísticos suficientes es un paso crucial en muchas técnicas ABC [13]. Wood [14] introdujo una función de verosimilitud sintética representada a partir de una distribución normal multivariada cuyo vector de medias y covarianza se determinan desde los estadísticos escogidos en la tarea de inferencia. La asunción Gaussian de la verisimilitud le permitió el uso del algoritmo de muestreo basado en cadenas de Markov y simulación de Monte Carlo (MCMC) para encontrar muestras del posterior, sin embargo, existen varios parámetros libres que deben ser ajustados por el usuario para cada aplicación.

Por su parte, Fearnhead y Prangle [15] demostraron que la selección óptima de estadísticos para la inferencia de parámetros bajo una función de pérdida cuadrática coincide con la media del posterior real de los parámetros dados los datos observados. Los autores usaron este principio para estructurar el posterior como un modelo lineal capaz de aprender estadísticos a partir de los datos, los cuales son empleados en una etapa subsecuente del esquema $\mathrm{ABC}$ genérico; aunque este esquema permite encontrar de forma inteligente los estadísticos del problema, su enfoque semiautomático requiere aún la sintonización de algunos parámetros libres.

Alternativamente, la inferencia indirecta (usada tradicionalmente en el contexto de la estimación de máxima verosimilitud) fue introducida en el contexto de $\mathrm{ABC}$ por Gleim y Pigorsch [16], en particular, estos autores usaron un vector de cualificación ajustado a partir de máxima verosimilitud como estadísticos del esquema $\mathrm{ABC}$, identificando que una comparación entre dichos vectores asociados a observaciones $\mathrm{y}$ simulaciones permite tener una idea acerca de las muestras con mayor probabilidad de seguir el posterior de los parámetros; de nuevo, la atención de los autores se centra en la determinación de estadísticos en lugar del cálculo automático de los parámetros 
libres.

Comparar estadísticos con el fin de aceptar o rechazar muestras candidatas depende fuertemente de tolerancias que deben ajustarse cuidadosamente. Una alternativa introducida por Nakagome et al. [17] propone un esquema de inferencia basado en ponderación en el que una serie de pesos se asocian a cada una de las muestras que, en lugar de ser aceptadas o rechazadas, son clasificadas a partir de la relevancia indicada por dichos pesos. Concretamente, un operador esperanza condicional establece un mapeo desde el espacio de las características (estadísticos) hacia el espacio de los parámetros; si bien esta estrategia $\mathrm{ABC}$ opera en una forma completamente distinta, el ajuste y selección de estadísticos y parámetros libres asociados a las funciones Kernel persiste. Para tratar de evitar el uso de estadísticos suficientes, Park et al. [9] introdujo el criterio de máxima discrepancia media (MMD por sus siglas en inglés) en el contexto de $A B C$ con el fin de comparar medidas de probabilidad asociadas a los datos observados y simulados, usando un embebimiento de distribuciones en un RKHS basado en kernel. Este enfoque permite la asignación de pesos a cada muestra candidata a partir de un kernel de similaridad (como en el caso del trabajo de Nakagome). Sin embargo, la ausencia de estadísticos suficientes aparece a expensas de una carga computacional más elevada; aunque los autores desarrollaron aproximaciones más ligeras para el cálculo de la MMD, la sintonización de parámetros libres no es eliminada.

Diferentes enfoques $\mathrm{ABC}$ han sido propuestos bajo el concepto fundamental de regresión. Mitrovic et al. [18] modelaron la relación funcional entre los datos simulados y la selección óptima de estadísticos suficientes para codificar la estructura de un modelo generativo; si bien su estructura es flexible y permite regular el tipo y la cantidad de información extraída a partir de los datos, el diseño óptimo de estadísticos requiere gran cantidad de parámetros libres, lo cual conduce a procedimientos de ajuste que son dependientes de cada problema.

Con relación al número de simulaciones necesarias en 
$\mathrm{ABC}$, Meeds y Welling [19] introdujeron un modelo suplente que trabaja como una función de verosimilitud sintética que, en conjunto con una estrategia de regresión basada en procesos Gaussianos, permite definir un número adecuado de simulaciones. Aunque los autores demostraron que su enfoque requiere menos muestras para encontrar estimaciones del posterior, su principal preocupación radica en la necesidad de ajustar una gran cantidad de parámetros libres.

Por otra parte, investigaciones recientes han empleado redes neuronales y aprendizaje profundo para modelar la relación entre el espacio de las características y el espacio de los parámetros. Jiang et al. [20] modelaron el valor esperado del posterior como un estadístico a partir de la conexión del conjunto total de datos simulados a la capa de entrada de una red neuronal profunda. Los autores intentaron usar métodos de regularización para el entrenamiento de la red, pero no encontraron mejoras significativas respecto a otros enfoques del estado del arte. Alternativamente, Creel [21] intentó usar un esquema similar sobre un conjunto reducido de datos simulados para mejorar los tiempos de ejecución del método. Sin embargo, como es bien sabido en el campo de las redes neuronales, la sintonización de parámetros libres es un problema activo en el estado del arte.

En este sentido, resulta imperativo investigar la posibilidad de generar esquemas inteligentes de inferencia basados en técnicas $\mathrm{ABC}$ que permitan el ajuste automático de los parámetros libre. En esta investigación se desarrolla un enfoque automático de inferencia estadística basado en embebimientos de espacios de Hilbert y métodos kernel, teniendo en cuenta la relevancia de los datos en la estimación no paramétrica de funciones de densidad al igual que el alineamiento estadístico entre el espacio de los parámetros y el espacio de las simulaciones utilizados en enfoques ABC. En particular, la atención se centra en el desarrollo de una estrategia que favorece la flexibilidad y la precisión en tareas aproximadas de inferencia estadística para escenarios supervisados y no supervisados, planteando así un esquema automático que codifica estructuras relevantes en los datos y 
permite el ajuste automático de los parámetros libres.

Objetivos.

A continuación, se relacionan los objetivos generales y específicos de la investigación:

\section{Objetivo general}

Desarrollar un esquema $\mathrm{ABC}$ automático basado en embebimientos de espacios de Hilbert que permita la selección automática de parámetros libres en escenarios de inferencia tanto supervisados como no supervisados.

\section{Objetivos específicos}

- Proponer una metodología de estimación no paramétrica de funciones de densidad de probabilidad que resalte la información relevante en los datos con el fin de brindar el soporte a la estimación del posterior en escenarios no supervisados basados en técnicas $\mathrm{ABC}$.

- Desarrollar un esquema de inferencia estadística no supervisada que permita la selección automática de parámetros libres con el fin de mejorar el acierto, la precisión y la flexibilidad de modelos basados en técnicas ABC.

- Proponer una metodología de alineado estadístico que correlacione las dependencias existentes entre el espacio de los parámetros y el espacio de las simulaciones usados en las técnicas $\mathrm{ABC}$, con el fin de brindar el soporte a la estimación del posterior en escenarios supervisados basados en técnicas ABC.

- Desarrollar un esquema de inferencia estadística supervisada que incluya información acerca del espacio de los parámetros y permita la selección automática de todos los parámetros libres, de tal forma que se mejore el acierto, la precisión y la flexibilidad de los modelos basados en técnicas ABC. 


\section{Referente teórico.}

En esta sección se presentan algunos aspectos teóricos relacionados con la investigación, los cuales que permiten al lector tener una interpretación más adecuada de los principales resultados en términos metodológicos y experimentales.

Inferencia Bayesiana aproximada: cuando las funciones de verosimilitud son intratables

Desde un enfoque Bayesiano, el conocimiento completo acerca de un vector de parámetros $\theta \in$ $\theta$ asociado a un modelo específico se expresa a través del posterior $p(\theta \mid y)$, donde $y \in X$ representa los datos observados. Específicamente, una función de verosimilitud $p(y \mid \theta)$ actualiza las creencias acerca del vector de parámetros, contenidas en la distribución prior $p(\theta)$, de acuerdo al teorema de Bayes:

$$
p(\theta \mid y)=\frac{p(y \mid \theta) p(\theta)}{\int_{\theta} p(y \mid \theta) p(\theta) d \theta}
$$

La información que está contenida en el posterior permite todo el análisis del modelo, desde la inferencia predictiva y el chequeo del modelo hasta la toma de decisiones, entre otras [12].

En la práctica, la complejidad del modelo a causa de la no linealidad y/o la estocasticidad de la aplicación hacen que el cálculo del posterior según la Ecuación (1) se haga sumamente complejo debido principalmente a dos razones: $i$ ) las expresiones matemáticas bien sea de la función de verosimilitud y/o el prior conlleva a cálculos tan complejos que no es posible obtener una expresión cerrada para el posterior y éste sólo puede ser conocido a través de muestras encontradas mediante un método numérico; ii) la evaluación de la función de verosimilitud para encontrar muestras del posterior se torna intratable desde el punto de vista computacional y no puede hacerse en ninguna cantidad de tiempo para propósitos prácticos. Bajo estas situaciones, no es posible encontrar muestras del posterior ni de forma exacta ni de forma aproximada usando un enfoque Bayesiano. 
Para enfrentar estos escenarios desafiantes, una alternativa consiste en emplear un modelo menos complejo y más ameno en términos de los cálculos matemáticos y estadísticos. Sin embargo, esto tendría que hacerse a expensas de obtener conclusiones erradas o menos realistas sobre el fenómeno bajo estudio. En este sentido, una opción más elegante consiste en emplear el modelo completo bajo un esquema aproximado que admita cierto margen de error. Es así como en los últimos años han surgido diversas estrategias "libres de verosimilitud" entre las cuales la Computación Bayesiana Aproximada (ABC) es una de ellas.

\section{Fundamentos de $\mathrm{ABC}$}

Las técnicas $\mathrm{ABC}$ fueron introducidas originalmente como una metodología de solución al problema de la inferencia Bayesiana en el campo de la biología molecular donde los sistemas poseen típicamente características altamente dinámicas y estocásticas. El primer algoritmo ABC fue propuesto por Pritchard et al. [22] Durante su estudio de la historia demográfica de los cromosomas tipo- $Y$.

Sin embargo, el uso de métodos $\mathrm{ABC}$ ha migrado rápidamente hacia otras diciplinas como los sistemas biológicos [23], el análisis del clima y la meteorología [24], el modelamiento de sistemas ecológicos [25] y el estudio de imágenes nucleares [26], por mencionar sólo algunos ejemplos. La idea fundamental detrás de un método $\mathrm{ABC}$ consiste en reemplazar la evaluación explícita de una función de verosimilitud por una medida que indique qué tan creíble resulta que el modelo seleccionado pueda haber producido los datos observados, empleando para esto un conjunto de datos simulados que son generados a partir de un "modelo auxiliar" [7]. Estas simulaciones se comparan con los datos observados con el fin de encontrar una aproximación del posterior del vector de parámetros en forma de muestras, en otras palabras, en lugar de encontrar un único valor particular para el vector de parámetros empleando, por ejemplo, la minimización de una función de 
costo como en el caso de mínimos cuadrados, el objetivo de las técnicas $\mathrm{ABC}$ consiste en estimar la distribución posterior de los parámetros.

El esquema $\mathrm{ABC}$ más sencillo se puede resumir en el diagrama esquemático de la Figura 1. La idea principal de este método, conocido como $A B C$ por rechazo, es bastante simple: un conjunto de valores candidatos a formar parte del posterior $\left\{\theta_{n} \sim \zeta(\theta)\right\}_{n=1}^{N}$ se muestrean desde el prior $\zeta(\theta)$ para posteriormente evaluar el modelo auxiliar $\mathcal{M}: \theta \rightarrow X$ (que es una representación matemática del sistema bajo estudio) con el fin de generar un conjunto de datos simulados $\left\{x_{n} \in X\right\}_{n=1}^{N}$. Luego,

cada simulación se compara con los datos observados empleando una medida de distancia $d: x \times x \rightarrow \mathbb{R}^{+}$y una pequeña tolerancia $\xi$, tal que si la distancia en menor o igual que $\xi$, la muestra correspondiente del prior se selecciona como una muestra del posterior; en caso contrario, es rechazada [27]. Típicamente, es dificil evaluar la medida de distancia directamente en el espacio $X$ debido a la gran cantidad de muestras y características de los datos; en tal caso, algunas estrategias emplean un mapeo $s=\vartheta(x)$ antes de calcular la distancia, donde $s \in \delta$ es un espacio de características y $\vartheta: X \rightarrow \delta[8]$.

Figura 1. Diagrama esquemático del método $\mathrm{ABC}$ por rechazo.

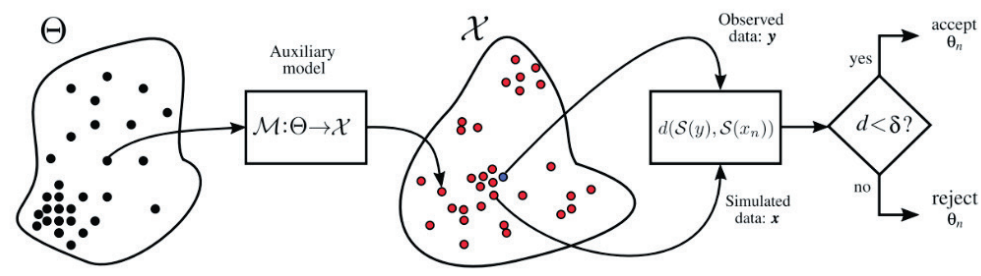

En la práctica, la simplicidad del enfoque anterior conlleva ciertos inconvenientes para una tarea de inferencia en particular. Por ejemplo, la selección de una distancia adecuada para la comparación de simulaciones y observaciones de acuerdo al problema, el valor de una tolerancia apropiada para aceptar o rechazar muestras candidatas, la selección de "estadísticos suficientes" para representar sin pérdida de información los datos observados y simulados, entre otros [27]. En consecuencia, algunos algoritmos más sofisticados han aparecido en los últimos años: por ejemplo, el método $\mathrm{ABC}$ MCMC que emplea 
cadenas de Markov y simulación de Monte Carlo para encontrar mejores aproximaciones del posterior de los parámetros [28]. Una descripción detallada y completa de estos métodos puede consultarse en [7][12] y las referencias allí citadas.

Recientemente, Park et al. [9] propusieron la utilización de espacios de embebimientos de espacios de Hilbert en el contexto de $\mathrm{ABC}$ usando funciones kernel como una alternativa para el uso de estadísticos. La Figura 2 esquematiza esta nueva alternativa en la que se considera que tanto los datos observados como los datos simulados siguen distribuciones de probabilidad $\left\{x_{n} \sim P_{X_{n}}\right\}_{n=1}^{N}$ y $y \sim P_{Y}$, las cuales son embebidas en un espacio de Hilbert con kernel reproductor de funciones $\mathcal{H}$

(RHKS por sus siglas en inglés) empleando un kernel característico $k(\cdot$, ) (ver siguiente subsección para más detalles). Luego, una distancia entre distribuciones de probabilidad $d_{\mathcal{H}}: \mathcal{H} \times \mathcal{H} \rightarrow \mathbb{R}^{+}$soporta la evaluación de un kernel de similaridad $\kappa\left(P_{X_{n}}, P_{Y}\right)$, el cual se encarga de asignar un peso $w_{n}$ a cada muestra del prior, tal que:

$$
\omega_{n}=\frac{\kappa\left(P_{X_{n^{\prime}}}, P_{Y}\right)}{\sum_{n=1}^{N} \kappa\left(P_{X_{n}}, P_{Y}\right)} .
$$

Un kernel de similaridad entre distribuciones de probabilidad tiene la forma [9]:

$$
\kappa\left(d_{\mathcal{H}}^{2}\left(P_{x_{n^{\prime}}}, P_{Y}\right), \epsilon\right)=\exp \left(-\frac{d_{\mathcal{H}}^{2}\left(P_{x_{n^{\prime}}}, P_{Y}\right)}{\epsilon}\right)
$$

donde $\epsilon \in \mathbb{R}^{+}$es una pequeña tolerancia.

Figura 2. Diagrama esquemático del enfoque $A B C$ basado en embebimientos de espacios de Hilbert

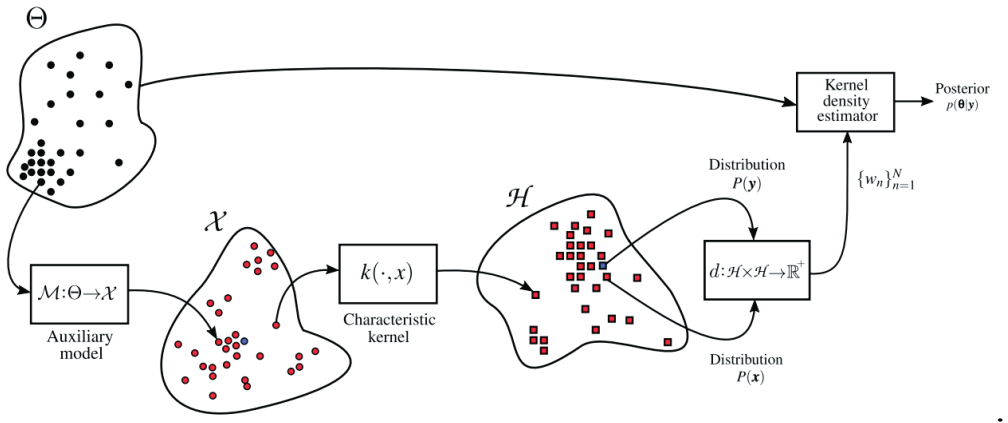


La aplicación de las Ecuaciones (2) y (3) sobre los datos simulados resulta en un conjunto ponderado muestras-pesos que se puede emplear para aproximar el posterior mediante una estimación empírica o usando un estimador de densidad basado en kernel.

\section{Espacios de Hilbert y métricas entre distribuciones}

Un espacio de producto interno $\mathrm{H}$ (el más largo e inclusivo de los espacios vectoriales equipado con producto interno $(;\rangle$,$) que tiene un conjunto de bases ortogonales \left\{\boldsymbol{\beta}_{k}\right\}_{k=1}^{\infty}$ se conoce como un espacio Pre-Hilbert [29]. Un vector $\boldsymbol{x}$ en H puede ser representado a partir de las bases como una combinación lineal de la forma:

$$
\boldsymbol{x}=\sum_{k=1}^{\infty} a_{k} \boldsymbol{\beta}_{\kappa},
$$

donde los escalares $a_{k}$ son los pesos de representación.

La norma al cuadrado entre dos vectores $\boldsymbol{x}_{n}=\sum_{k=1}^{n} a_{k} \boldsymbol{\beta}_{\kappa}$ y $\boldsymbol{x}_{m}=\sum_{k=1}^{m} a_{k} \boldsymbol{\beta}_{\kappa}$, con $m>n$ en HI, puede ser definida usando el producto interno de la siguiente forma:

$$
\begin{aligned}
\left\|\boldsymbol{x}_{n}-\boldsymbol{x}_{m}\right\|_{2}^{2} & =\left\langle\boldsymbol{x}_{n}-\boldsymbol{x}_{m}, \boldsymbol{x}_{n}-\boldsymbol{x}_{m}\right\rangle \\
& =\left\langle\sum_{k=n+1}^{m} a_{k} \boldsymbol{\beta}_{k} \cdot \sum_{k=n+1}^{m} a_{k} \boldsymbol{\beta}_{k}\right) \\
& =\sum_{k=n+1}^{m} a_{k}^{2}
\end{aligned}
$$

Cuando los coeficientes $a_{k}$ se definen de tal forma que satisfacen las siguientes condiciones: $i$ ) $\sum_{k=1}^{n} a_{k}^{2}<\infty$; ii) $\sum_{k=n+1}^{m} a_{k}^{2} \rightarrow 0$ a medida que $m, n \rightarrow \infty$; entonces una secuencia de vectores $\left\{\boldsymbol{x}_{k}\right\}_{k=1}^{\infty}$ así definida se conoce como una Secuencia de Cauchy. Esto es, un vector $\boldsymbol{x}$ se puede expresar usando las bases $\left\{\boldsymbol{\beta}_{k}\right\}_{k=1}^{\infty}$ si y sólo si $\boldsymbol{x}$ es una combinación lineal dichas bases y los coeficientes de representación son cuadráticamente sumables [30].

"Definición". Un espacio de producto interno Hil es "completo" si cada secuencia de Cauchy formada a partir de vectores seleccionados del espacio H converge a un límite en H. Un espacio de producto interno completo se denomina un espacio de Hilbert. 
Los espacios de Hilbert pueden ser espacios de dimensión finita o infinita. Los últimos, por ejemplo, son la base de la teoria de procesamiento de señales en tiempo continuo [31]; otro tipo de espacios de Hilbert muy útiles son los llamados espacios de Hilbert con kernel reproductor (RKHS por sus siglas en inglés).

Un RKHS es un espacio de Hilbert especial que está asociado a una función kernel definida no negativa $\kappa$ tal que ésta reproduce (vía producto interno) cada función $f$ en dicho espacio [29]. Sea $\mathcal{H}$ un espacio de Hilbert de funciones de variable real definidas sobre un conjunto $\mathcal{X}$, equipado|

con un producto interno $\langle;\rangle$ y una función real bivariada $\kappa: x \times x \rightarrow \mathbb{R}^{+}$. Se dice que la función $\kappa\left(x, x^{\prime}\right)$ es definida no negativa si para cualquier conjunto de puntos $\left\{x_{n}\right\}_{n=1}^{N} \subset X$ y cualquier conjunto de números reales, no todos iguales a cero, $\left\{\alpha_{n}\right\}_{n=1}^{N}$, se satisface la siguiente condición:

$$
\sum_{i=1}^{N} \sum_{j=1}^{N} \alpha_{i} \alpha_{j} \kappa\left(x_{i}, x_{j}\right) \geq 0 .
$$

Teorema (Moore-Aconszajo). Para cualquier función definida no negativa $\kappa\left(x, x^{\prime}\right)$ existe un único espacio de Hilbert $\mathcal{H}$ (cuya dimensión puede ser infinita) que se conforma de funciones en $x$ tal que:

$$
\begin{array}{ll}
\text { i) } \forall x \in \mathcal{X}, & \kappa(\cdot, x) \in \mathcal{H} \\
\text { ii) } \forall x \in \mathcal{X}, \quad \forall f \in \mathcal{H}, \quad f(x)=\langle f, \kappa(\cdot, x)\rangle_{\mathcal{H}}
\end{array}
$$

De la condición $i$ ) se infiere fácilmente que cada elemento en el espacio de entrada se mapea a una función en el RKHS generado por el kemel reproductivo $\kappa$ que se escoja. Por otra parte, la condición $i i ́)$ se conoce como la propiedad de reproducción de $\kappa\left(x, x^{\prime}\right)$ en $X$, esto es, si la función de mapeo no lineal $\phi: X \rightarrow \mathcal{H}$ está definida como $\phi(x)=\kappa(;, x)$, se tiene que:

$$
\left\langle\phi(x), \phi\left(x^{\prime}\right)\right\rangle_{\mathscr{H}}=\left\langle\kappa(\cdot, x), \kappa\left(\cdot, x^{\prime}\right)\right\rangle=\kappa\left(x, x^{\prime}\right) .
$$

Por lo tanto, $\phi(x)=\kappa(\cdot, x)$ define completamente y de manera única el espacio RKHS generado por el kernel $\kappa$. 
Una conclusión sumamente importante obtenida en las últimas décadas de investigación en estadistica establece que es posible establecer distancias entre distribuciones de probabilidad usando los conceptos de valor esperado y norma en un RKHS [32]. Sea $P_{X}$ una función de distribución asociada con una variable aleatoria $X \sim P_{X}$. El embebimiento $\mu[\cdot]$ de $P_{X}$ en el RHKS $\mathcal{H}$ se define como [33]:

$$
\mu\left[P_{x}\right]:=\mathbb{E}_{x}[k(x ;)]
$$

donde $\mathbb{E}_{X}$ representa el valor de esperanza sobre $X$ y el kernel de reproducción, usualmente llamado kernel caracteristico, satisface la condición de suficiencia: $k\left(x, x^{\prime}\right)<\infty$.

Una distancia entre dos distribuciones $P_{X}$ y $P_{Y}$ queda entonces definida como:

$$
d_{\mathcal{H}}^{2}\left(P_{X}, P_{Y}\right)=\left\|\mu\left[P_{X}\right]-\mu\left[P_{Y}\right]\right\|_{\mathcal{H}}^{2}=\left\langle\mu\left[P_{X}\right]-\mu\left[P_{Y}\right], \mu\left[P_{X}\right]-\mu\left[P_{Y}\right]\right\rangle_{\mathcal{H}} .
$$

Si se emplea la definición de valor esperado, asignando funciones de densidad de probabilidad $f(x)$ y $g(y)$ para $P_{X}$ y $P_{Y}$, respectivamente, la Ecuación (9) se puede reescribir como:

$$
\begin{gathered}
d_{\mathcal{M}}^{2}\left(P_{X}, P_{Y}\right)=\iint k\left(x, x^{\prime}\right) f(x) f\left(x^{\prime}\right) d x d x^{\prime}-2 \iint k(x, y) f(x) g(y) d x d y \\
+\iint k\left(y, y^{\prime}\right) g(y) g\left(y^{\prime}\right) d y d y^{\prime},
\end{gathered}
$$

donde se ha usado la propiedad de reproducibilidad $\kappa(a, b)=\langle\kappa(\cdot, a), \kappa(\cdot, b)\rangle$ (MooreAronszajn).

\section{Metodología.}

\section{$\mathrm{ABC}$ mejorado en escenarios no supervisados}

En esta sección se presenta una metodología general para detectar información relevante a partir de los datos observados y simulados durante el proceso de estimación no paramétrica de las funciones de densidad de probabilidad en los escenarios no supervisados de inferencia basada en ABC. En particular, se introduce una distancia general para comparar distribuciones de 
probabilidad en un RKHS, la cual sugiere que la extracción de información relevante a partir de las observaciones y simulaciones mejora la aproximación de la distribución posterior en aquellos escenarios donde ninguna información adicional sobre los parámetros del modelo se emplea directamente en el esquema general de $\mathrm{ABC}$.

\section{Aprendizaje a partir de los datos para comparar distribuciones}

Como ya se indicó anteriormente, una distancia entre distribuciones se puede evaluar en un RKHS usando sus funciones de densidad de probabilidad asociadas. En la práctica, las expresiones

analíticas para estas funciones de densidad no son conocidas si se emplea un enfoque no paramétrico, por lo que se puede tener una noción de éstas únicamente a partir de un par de conjuntos de datos independientes e idénticamente distribuidos $X_{n}=\left\{x_{i} \in \mathbb{R}^{d}\right\}_{i=1}^{Q_{x}}, Y=$ $\left\{y_{j} \in \mathbb{R}^{d}\right\}_{j=1}^{Q_{y}}$, para simulaciones y observaciones de tamaño $Q_{x}$ y $Q_{y}$, respectivamente, donde $\left\{X_{n} \sim P_{X_{n}}\right\}_{n=1}^{N}$ y $Y \sim P_{Y}$. En esta investigación se proponen las siguientes estimaciones generales de densidad basadas en kernel:

$$
\begin{array}{ll}
\hat{f}_{n}(x)=\sum_{i=1}^{Q_{x}} \alpha_{i} K_{H_{i}}\left(x, x_{i}\right), & \sum_{m=1}^{Q_{x}} \alpha_{m}=1, \\
\hat{g}(y)=\sum_{j=1}^{Q_{y}} \beta_{j} K_{H j}\left(y, y_{j}\right), \quad \sum_{m=1}^{Q_{y}} \beta_{m}=1,
\end{array}
$$

donde $\left\{\alpha_{i} \in[0,1]\right\}_{i=1}^{Q_{x}}$ y $\left\{\beta_{j} \in[0,1]\right\}_{i=1}^{Q_{y}}$ son los pesos de representación y $\hat{f}_{n}$ y $\hat{g}$ son las aproximaciones de las funciones de densidad de probabilidad asociadas a las distribuciones $P_{X_{n}}$ y $P_{Y}$. Además, $K_{H}(*)$ hace referencia a un kernel Gaussiano multivariado con matriz de covarianza $H \in \mathbb{R}^{d \times d}$. Aunque varias funciones kernel se pueden emplear en la definición, el kernel Gaussiano es usualmente el preferido ya que permite estimar las funciones de densidad con características de aproximación universal, además de su facilidad en el manejo matemático [31]. 
Usando un kernel Gaussiano multivariado con matriz de covarianza $H_{K}$ como kernel caracteristico y sustituyendo las Ecuaciones (II) y (I2) en la Ecuación (IO) se obtiene:

$$
\begin{aligned}
d_{H_{Y}}^{2}\left(P_{X}, P_{Y}\right)= & \sum_{i=1}^{Q_{x}} \sum_{j=1}^{Q_{X}} \alpha_{i} \alpha_{j} K_{H_{X}}\left(x_{i}, x_{j}\right) \\
& -2 \sum_{i=1}^{Q_{x}} \sum_{j=1}^{Q_{y}} \alpha_{i} \beta_{j} K_{H_{X Y}}\left(x_{i}, y_{j}\right)+\sum_{i=1}^{Q_{y}} \sum_{j=1}^{Q_{y}} \beta_{i} \beta_{j} K_{H_{Y}}\left(y_{i}, y_{j}\right) .
\end{aligned}
$$

donde

$$
H_{X}=H_{K}+H_{i}^{p}+H_{j}^{p}, \quad H_{X Y}=H_{K}+H_{i}^{p}+H_{j}^{q}, \quad H_{Y}=H_{K}+H_{i}^{q}+H_{j}^{q} .
$$

La expresión de la Ecuación (13) busca resaltar información relevante en los datos durante la comparación de las distribuciones de probabilidad en dos formas distintas: $i$ ) ponderando los conjuntos de muestras de observaciones y simulaciones usando una representación dispersa que da origen una distancia basada en un embebimiento de un espacio de Hilbert disperso; ií) adaptando las matrices de covarianza de acuerdo a estructuras relevantes contenidas en los datos a través de una distancia basada en un embebimiento adaptativo de espacios de Hilbert.

i) Distancia basada en embebimientos dispersos de espacios de Hilbert (SHSED): Esta alternativa busca extraer información representativa en las distribuciones a ser comparadas a través de la búsqueda de muestras relevantes de las funciones de densidad de probabilidad asociadas. En particular, la caracteristica dispersa radica en que sólo algunos de los elementos en $\alpha \in[0,1]^{Q_{x}}$ y $\boldsymbol{\beta} \in[0,1]^{Q_{y}}$ son distintos de cero, resaltando asi las muestras con mayor relevancia. En este sentido, las matrices de covarianza se dejan fijas tal que $H_{i}^{p}=H_{p}, \forall i=1,2, \cdots, Q_{x}$ y $H_{j}^{q}=$ $H_{Q}, \forall i=1,2, \cdots, Q_{y}$, con el fin de que sean los pesos quienes desarrollen la tarea de extracción de información, dando origen a la distancia basada en embebimientos disperso de espacios de Hilbert (SHSED):

$$
d_{S H S E D}^{2}\left(P_{X}, P_{Y}\right)=\boldsymbol{\alpha}^{T} \boldsymbol{A}^{\left(H_{X}\right)} \boldsymbol{\alpha}+\boldsymbol{\beta}^{T} \boldsymbol{B}^{\left(H_{Y}\right)} \boldsymbol{\beta}-2 \boldsymbol{\alpha}^{T} \boldsymbol{L}^{\left(H_{X Y}\right)} \boldsymbol{\beta},
$$

donde $H_{X}=H_{K}+2 H_{p}, H_{Y}=H_{k}+2 H_{Q}$ y $H_{X Y}=H_{K}+H_{p}+H_{Q}$. Adicionalmente, $\boldsymbol{A}^{\left(H_{K}\right)} \in$ $\mathbb{R}^{Q_{x} \times Q_{x}}, \boldsymbol{B}^{\left(H_{Y}\right)} \in \mathbb{R}^{Q_{y} \times Q_{y}}$ y $\boldsymbol{L}^{\left(H_{X Y}\right)} \in \mathbb{R}^{Q_{x} \times Q_{y}}$ representan matrices kernel con elementos $a_{i j}=$ $K_{H_{X}}\left(x_{i}, x_{j}\right), b_{i j}=K_{H_{Y}}\left(y_{i}, y_{j}\right)$, y $\ell_{i j}=K_{H_{X Y}}\left(x_{i}, y_{j}\right)$, respectivamente. Para encontrar los pesos de representación se soluciona un problema de optimización cuyo objetivo es la minimización de la integral de error cuadrático $\varepsilon(\alpha)=\int_{x}(f(x)-\hat{f}(x))^{2} d x$, tal y como se indica en la Ecuación (15): 


$$
\begin{aligned}
& \underset{\boldsymbol{\alpha}}{\operatorname{argmin}} \quad \varepsilon(\boldsymbol{\alpha})=\boldsymbol{\alpha}^{T} \boldsymbol{A}^{\left(2 H_{P}\right)} \boldsymbol{\alpha}-\frac{2}{Q_{x}} \boldsymbol{\alpha}^{T} \boldsymbol{A}^{\left(H_{P}\right)} \mathbf{1} \\
& \text { s. } a \quad\|\alpha\|_{1}=1 \\
& \alpha_{i} \geq 0, \quad \forall i=1,2, \cdots Q_{x}
\end{aligned}
$$

El problema no lineal de la Ecuación (15) se puede solucionar usando un enfoque programación secuencial como el desarrollo por Hong y Chen [34]. Finalmente, los pesos $\boldsymbol{\beta}$ se determinan mediante un problema de optimización análogo a partir de $\varepsilon(\boldsymbol{\beta})$.

ii) Distancia basada en embebimientos adaptativos de espacios de Hilbert (AHSED): Otra opción interesante surge a partir de la idea de seleccionar de forma adaptativa las matrices de covarianza empleadas en la estimación de las funciones de densidad de probabilidad asociadas a las distribuciones que se pretenden comparar. En particular, se asigna la misma importancia a cada muestra en el conjunto de datos observados y simulados, es decir, $\alpha_{i}=1 / Q_{x}, \forall i=1,2, \cdots, Q_{x}$ y $\beta_{i}=1 / Q_{y}, \forall i=1,2, \cdots, Q_{y}$. De esta forma, es posible establecer la distancia basada en embebimientos adaptativos de espacios de Hilbert (AHSED):

$$
\begin{aligned}
& d_{A H S E D}^{2}\left(P_{X_{n^{\prime}}} P_{Y}\right)=\frac{1}{Q_{Q}^{2}} \mathbf{1}_{Q_{X}}^{T} \boldsymbol{A}^{\left(H_{X}\right)} \mathbf{1}_{Q_{x}}+\frac{1}{Q_{y}^{2}} \mathbf{1}_{Q_{y}}^{T} B^{\left(H_{Y}\right)} \mathbf{1}_{Q_{y}}- \\
& \frac{2}{Q_{x} Q_{y}} \mathbf{1}_{Q_{X}}^{T} \boldsymbol{L}^{\left(H_{X Y}\right)} \mathbf{1}_{Q_{y}},
\end{aligned}
$$

donde las matrices kernel $\boldsymbol{A}^{\left(H_{X}\right)}, \boldsymbol{B}^{\left(H_{Y}\right)}, \boldsymbol{L}^{\left(H_{X Y}\right)}$ tienen el mismo tamaño que en el caso de la distancia SHSED, pero cuyos elementos $a_{i j}, b_{i j}$, y $\ell_{i j}$ emplean matrices de covarianza $H_{X}=H_{K}+$ $H_{i}^{P}, H_{Y}=H_{k}+H_{j}^{Q}$, y $H_{X Y}=H_{K}+H_{i}^{P}+H_{j}^{Q}$. Además, $\mathbf{1}_{\mathcal{D}} \in \mathbb{R}^{\mathcal{D}}$ hace referencia al vector cuyas componentes son todas uno.

Para establecer una comparación más robusta, en esta investigación se emplea una metodología de inferencia Bayesiana en la que es posible encontrar una expresión cerrada para el cálculo de las matrices de covarianza a partir de la minimización del riesgo de Bayes. En este sentido, empleando como función de verosimilitud una estimación de Barzen $p\left(x_{i} \mid H_{i}^{P}\right)=1 /\left(Q_{x}-1\right) \sum_{t=1, t \neq i}^{Q_{X}} K_{H_{i}^{P}}\left(x_{i}, x_{t}\right)$ y un prior inverso de Wishart $H_{i}^{P} \sim W^{-1}(r, C)$, se

puede demostrar que bajo funciones de pérdida cuadrática y con base en entropia se obtienen las expresiones para el estimador de Bayes de las matrices $\widehat{H_{l}^{P}}$ de acuerdo a las Ecuaciones (17) y (I8), respectivamente [35].

$$
\begin{aligned}
& \left.\widehat{H_{i}^{P}}\right|_{\text {cuad }} \\
& =\frac{1}{r-d} \frac{\sum_{t=1, t \neq i}^{Q_{x}}\left|\left(x_{i}-x_{t}\right)^{T}\left(x_{i}-x_{t}\right)+C\right|^{-0.5(r+1)}\left[\left(x_{i}-x_{t}\right)^{T}\left(x_{i}-x_{t}\right)+C\right]}{\sum_{t=1, t \neq i}^{Q_{x}}\left|\left(x_{i}-x_{t}\right)^{T}\left(x_{i}-x_{t}\right)+C\right|^{-0.5(r+1)}},
\end{aligned}
$$




$$
\begin{aligned}
& \left.\widehat{H_{i}^{P}}\right|_{\text {ent }} \\
& \left.=\frac{1}{r+1}\left[\frac{\sum_{t=1, t \neq i}^{Q_{x}}\left|\left(x_{i}-x_{t}\right)^{T}\left(x_{i}-x_{t}\right)+C\right|^{-0.5(r+1)}\left[\left(x_{i}-x_{t}\right)^{T}\left(x_{i}-x_{t}\right)+C\right]^{-1}}{\sum_{t=1, t \neq i}^{Q x}\left|\left(x_{i}-x_{t}\right)^{T}\left(x_{i}-x_{t}\right)+C\right|^{-0.5(r+1)}}\right]\right)
\end{aligned}
$$

donde $C \in \mathbb{R}^{d \times d}$ y $r \in \mathbb{R} \geq d$ representan la matriz de escala y los grados de libertad asociados a la distribución (prior) inversa de Wishart, respectivamente. Una selección frecuente de estos hiper-parámetros consiste en $r=\left(Q_{x}\right)^{2 /(d+4)}$ y $C=1 / Q_{x} \sum_{t=1}^{Q x}\left(x_{t}-\bar{x}\right)\left(x_{t}-\bar{x}\right)^{T}, \bar{x}=1 /$ $Q_{x} \sum_{t} x_{t}[35]$. Finalmente, cabe resaltar que las matrices $\widehat{H_{J}^{q}}$ se estiman con base en el conjunto de datos observados $\left\{y_{j} \in \mathbb{R}^{d}\right\}_{j=1}^{Q_{y}}$, empleando el mismo procedimiento.

\section{Un esquema $\mathrm{ABC}$ mejorado para inferencia en escenarios no supervisados}

Una vez que se han introducido nuevas distancias para la comparación de dos funciones de distribución teniendo en cuenta varias formas de extracción de información, es posible establecer un esquema $\mathrm{ABC}$ mejorado para realizar tareas de inferencia en escenarios no supervisados. El Algoritmo (1) resume el método adoptado en esta investigación.

\section{Algoritmo 1. Esquema ABC mejorado para inferencia no supervisada}

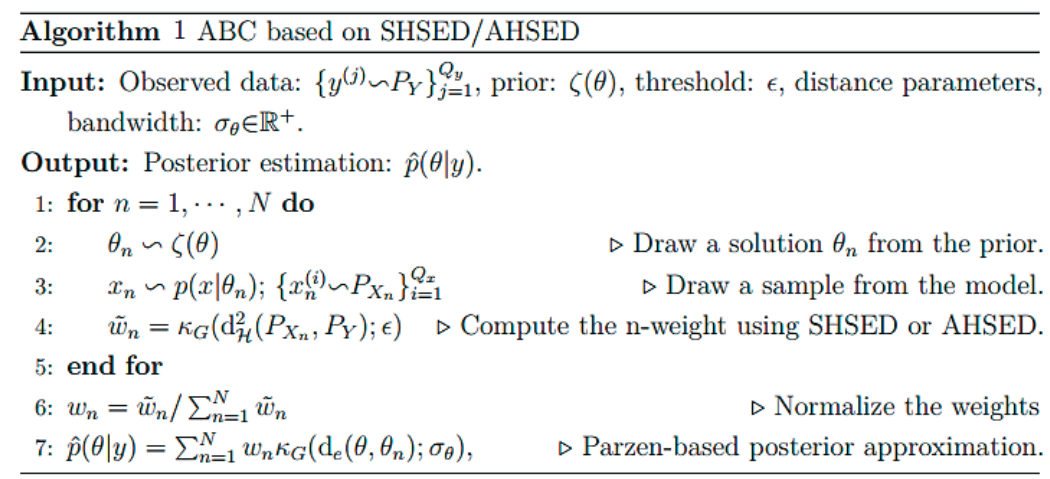




\section{$\mathrm{ABC}$ automático en escenarios supervisados}

El esquema $\mathrm{ABC}$ discutido en la sección previa se dice no supervisado en el sentido en que las decisiones sobre las muestras del espacio de los parámetros $\Theta$ se hacen únicamente a partir de la información del espacio de las observaciones y simulaciones $x$, por lo tanto, dicho enfoque no introduce directamente ningún tipo de información extraída desde $\theta$ en el esquema general de inferencia, dejando así varios parámetros libres sin fijar y cuya sintonización conduce, en general, a rutinas que requieren bastante tiempo y esfuerzo computacional con las búsquedas por grillas y/o validación cruzada [12].

Para hacer frente a estos inconvenientes, en esta investigación se propone una metodología compuesta por dos etapas principales conforme se muestra en el diagrama esquemático de la Figura 3. Resaltado en azul claro, una primera etapa consiste en el alineamiento del concepto de similitud entre las muestras provenientes del prior en el espacio de los parámetros y la idea de similaridad en los datos simulados vistos desde un espacio de características según la función de mapeo $\theta: X \rightarrow$ $\delta$, empleando para esto un esquema de alineado estadistico que aprende una distancia $d_{S}: \delta \times \delta \rightarrow$ $\mathbb{R}^{+}$. Posteriormente, en una segunda etapa (señalada en naranja claro), se introduce una nueva metodología para el cálculo de los pesos de estimación del posterior empleando una representación truncada de identificación local para la determinación del tamaño de un vecindario alrededor de cada punto en el espacio de los parámetros, así, el esquema $\mathrm{ABC}$ que resulta posee una gran ventaja: las dos etapas descritas introducen información adicional dentro del proceso de inferencia que permite la selección automática de todos los parámetros libres, obteniendo así un método $\mathrm{ABC}$ automático para escenarios supervisados.

\section{Alineamiento estadístico de los espacios $\Theta$ y $\delta$}

Con el fin de evitar la influencia de $\epsilon$ y los parámetros de la medida de distancia en la Ecuación (3), resulta conveniente establecer un alineamiento estadistico automático que permita incluir la información contenida en las muestras $\left\{\theta_{n}\right\}_{n=1}^{N}$ de tal forma que se brinde el soporte a la generación de un esquema $\mathrm{ABC}$ automático. Sea $\Psi=\left\{\theta_{n}, x_{n}\right\}_{n=1}^{N}$ el conjunto de $N$ muestras candidatas $\theta_{n} \in$ $\mathbb{R}^{P} \sim \zeta(\theta)$ muestreadas del prior y sus correspondientes simulaciones $x_{n} \in \mathbb{R}^{Q} \sim p(x \mid \theta)$. Se define la función kernel $\kappa_{\theta}: \theta \times \theta \rightarrow \mathbb{R}^{+}$una medida de similitud entre candidatos en $\Theta$ que define la matriz kernel $\boldsymbol{K}_{\theta} \in \mathbb{R}^{N \times N}$ con elementos:

$$
\kappa_{\theta}\left(\theta_{n}, \theta_{n}^{\prime}\right)=\left\{\begin{array}{cr}
\exp \left(-d_{\theta}^{2}\left(\theta_{n}, \theta_{n}^{\prime}\right)\right), & \theta_{n} \in \Omega_{n^{\prime}} \\
0, & \text { en otro caso }
\end{array}\right.
$$

donde $\Omega_{n^{\prime}}$ es el conjunto de los $M$ vecinos más cercanos de $\theta_{n}^{\prime}$ en el sentido de la distancia $d_{\theta}: \theta \times \theta \rightarrow \mathbb{R}^{+}$(ver siguiente subsección).

En esta investigación se emplea la distancia de Mahalanobis con el fin de evitar posibles variaciones de escala en $\theta_{n}$ : 
Figura 3. Esquema gráfico de la estrategia $A B C$ automática propuesta.

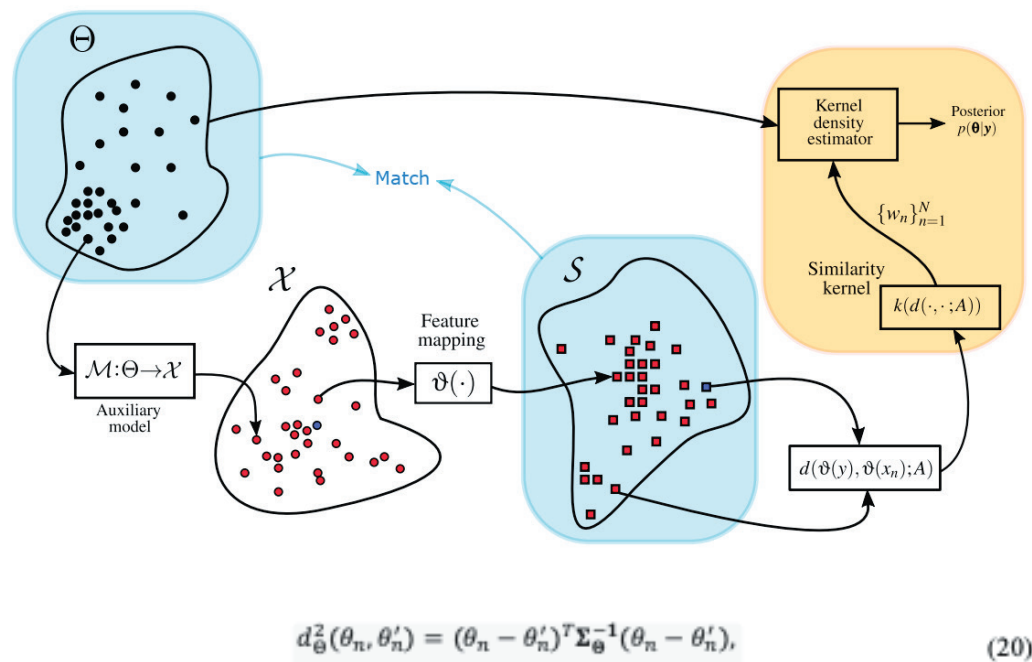

donde $\mathbf{\Sigma}_{\Theta}^{-1} \in \mathbb{R}^{P \times P}$ es la matriz de covarianza empírica de los datos $\left\{\theta_{n}\right\}_{n=1}^{N}$.

Por otra parte, la noción de similitud en el espacio de las características $\delta$ se evalúa mediante el kernel $\kappa_{\mathrm{s}}: \delta \times \delta \rightarrow \mathbb{R}^{+}$que establece la matriz kernel $\boldsymbol{K}_{\mathbf{s}} \in \mathbb{R}^{N \times N}$ con elementos:

$$
\kappa_{s}\left(\theta\left(x_{n}\right), \theta\left(x_{n}^{\prime}\right)\right)=\exp \left(-d_{s}^{2}\left(\theta\left(x_{n}\right), \theta\left(x_{n}^{\prime}\right)\right)\right),
$$

donde $d_{S}: \delta \times \delta \rightarrow \mathbb{R}^{+}$y $\theta: X \rightarrow \delta$. Para realizar la comparación entre pares de elementos en $\delta$, se emplea una distancia de Mahalanobis de la forma [36]:

$$
d_{S}^{2}\left(\vartheta\left(x_{n}\right), \theta\left(x_{n}^{\prime}\right)\right)=\left(\vartheta\left(x_{n}\right)-\vartheta\left(x_{n}^{\prime}\right)\right)^{T} A A^{T}\left(\vartheta\left(x_{n}\right)-\vartheta\left(x_{n}^{\prime}\right)\right),
$$

donde $\Sigma_{s}^{-1}=A A^{T}$ representa la matriz de covarianza de $\theta\left(x_{n}\right) \in \mathbb{R}^{D}$, y $A \in \mathbb{R}^{D \times d}$.

En este sentido, el objetivo principal de esta etapa consiste en emplear la noción de similitud en el espacio de los parámetros $\theta$, representada en la matriz $\boldsymbol{K}_{\boldsymbol{\theta}}$, para establecer la noción de similitud en el espacio de las características $\delta$, expresada en la matriz $\boldsymbol{K}_{\mathbf{s}}$. Lo anterior se puede alcanzar usando una estrategia de alineamiento estadistico entre las dos matrices kemel, para lo cual se puede emplear el alineamiento centralizado con kernel (CKA por sus siglas en inglés) propuesto en el contexto del aprendizaje de métricas (ML por sus siglas en inglés) [37]. En esta investigación se evalúa el alineamiento entre dichas matrices kernel de acuerdo al siguiente estimador [38]: 


$$
\hat{\rho}\left(\boldsymbol{K}_{\theta}, \boldsymbol{K}_{s}\right)=\frac{\left\langle\overline{\boldsymbol{K}}_{\theta}, \overline{\boldsymbol{K}}_{s}\right\rangle_{F}}{\sqrt{\left\langle\overline{\boldsymbol{K}}_{\theta} \overline{\boldsymbol{K}}_{\theta}\right\rangle_{F}\left(\overline{\boldsymbol{K}}_{s} \overline{\boldsymbol{K}}_{s}\right\rangle_{F}}}
$$

donde $\overline{\boldsymbol{K}}$ representa la matriz kemel centralizada $\overline{\boldsymbol{K}}=\tilde{\boldsymbol{I}} \boldsymbol{K} \tilde{\boldsymbol{I}}$, siendo $\tilde{\boldsymbol{I}}=\boldsymbol{I}-\mathbf{1}^{T} \mathbf{1} / N$ la matriz de centralización empirica, $I \in \mathbb{R}^{N}$ la matriz identidad, $\mathbf{1} \in \mathbb{R}^{D}$ el vector de sólo unos y $(\because)_{F}$ la norma de Frobenius.

En la Ecuación (23), $\hat{\rho}(\because)$ es un estimador basado en los datos que busca medir la similaridad entre el espacio de los parámetros y el espacio de las características. En este sentido, la matriz de proyección $\boldsymbol{A}$ se determina a partir de la solución del siguiente problema de optimización:

$$
\widehat{\boldsymbol{A}}=\underset{A}{\arg \max } \log \left(\hat{\rho}\left(\boldsymbol{K}_{s}(\boldsymbol{A}), \boldsymbol{K}_{\theta}\right)\right),
$$

donde la función logaritmo se emplea para facilitar el tratamiento matemático. En esta investigación se emplea una estrategia basada en gradiente descendiente para solucionar el problema de la Ecuación (24) [36].

\section{Identificación de estructuras locales en el espacio de los parámetros}

Ajustar el valor de $\epsilon$ para determinar los pesos de estimación de la distribución posterior de acuerdo a la Ecuación (3) es un paso crucial. Dependiendo de los valores entregados por la distancia que se emplee, una elección particular de $\epsilon$ podría producir un posterior cerrado y sesgado (cuando sólo algunos de los pesos tienen valores más grandes que los demás) o bastante similar al prior (en la condición límite en que $\left.w_{n} \rightarrow \frac{1}{N}, \forall n=1,2, \cdots, N\right)$. En este sentido, la representación truncada que se propone en esta investigación, según la Ecuación (19), introduce una nueva alternativa que evita el efecto de $\epsilon$ empleando el concepto de vecindario a través del conjunto $\Omega_{n^{\prime}}$. La idea central consiste en seleccionar un numero $M$ de vecinos más cercanos que establezca muestras representativas en el conjunto de los parámetros.

El número de vecinos podría ajustarse empiricamente de forma manual, sin embargo, esto equivaldría a cambiar un problema por otro. Por lo tanto, en esta investigación se emplea un enfoque de selección automático de $M$ basado en teoria de grafos para la selección local de vecindarios (LNS por sus siglas en inglés) [39], en la cual se busca determinar el número óptimo de vecinos para cada una de las muestras que componen el conjunto de puntos candidatos $\left\{\theta_{n}\right\}_{n=1}^{N}$. En particular, los vecindarios se calculan a partir de un balance entre medidas de distancia entregadas por la distancia Euclidea y la distancia geodésica, siguiendo el principio que establece que cuando una región alrededor de un punto es lineal y densa, ambas distancias identifican vecindarios similares, pero en caso contrario, la distancia Euclídea sesga su identificación hacia las conexiones más próximas mientras que la distancia geodésica identifica adecuadamente la 
estructura global de los puntos en las cercanias de la muestra analizada [39]. Para efectos de una mejor ilustración, en la Figura 4 se muestran los vecinos más cercanos a una muestra en especifico (señalada como un punto azul) de un conjunto de datos. Nótese cómo la distancia Euclidea selecciona vecinos que no siguen la forma de los datos mientras que la distancia geodésica identifica adecuadamente la estructura de los datos y entrega un vecindario mucho más adecuado. Los detalles del algoritmo LNS empleado para el cálculo del número local de vecinos $\left\{m_{n}\right\}_{n=1}^{N}$, con los cuales se obtiene $M=$ mediana $\left(\left\{m_{n}\right\}_{n=1}^{N}\right)$, se pueden ver en [2].

Figura 4. Vecindarios de una muestra específica según diferentes distancias. (a) Distancia Euclídea. (b) Distancia geodésica.

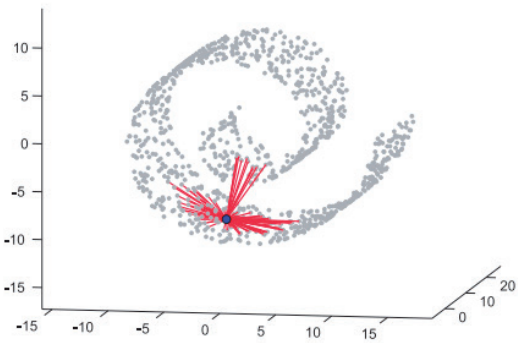

(a)

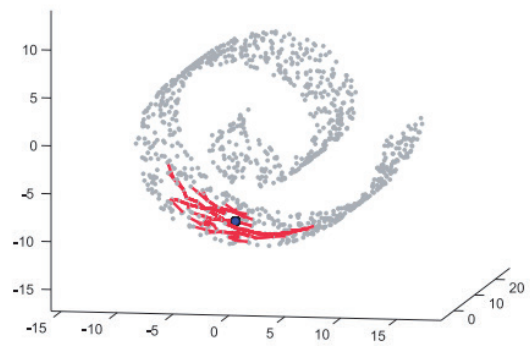

(b)

\section{Un esquema $\mathrm{ABC}$ automático para inferencia en escenarios supervisados}

Una vez que el alineamiento estadistico entre el espacio de los parámetros y el espacio de las características ha sido automatizado por completo gracias a la técnica CKA y el algoritmo LNS, la distancia $d_{S}: \delta \times S \rightarrow \mathbb{R}^{+}$ha sido aprendida completamente. En este sentido, la matriz de proyección $\widehat{\boldsymbol{A}}$ define la noción de similitud en el espacio de las caracteristicas de los datos simulados y observados de una forma lo más parecida posible a la noción de similitud en el espacio de los parámetros; este es precisamente el aspecto que brinda la característica supervisada a la metodologia propuesta en esta investigación. Por lo tanto, con el fin de introducir el concepto de vecindario en el contexto de los métodos $\mathrm{ABC}$, un conjunto de muestras y pesos $\psi=$ $\left\{\theta_{n}, w_{n}\right\}_{n=1}^{N}$ se puede obtener a partir de la siguiente medida de similaridad:

$$
w_{n}=\frac{\kappa_{E}\left(z, z_{N}\right)}{\sum_{n=1}^{N} \kappa_{E}\left(z, z_{N}\right)},
$$




$$
w_{n}=\frac{\kappa_{E}\left(z, z_{N}\right)}{\sum_{n=1}^{N} \kappa_{E}\left(z, z_{N}\right)}
$$

siendo $\kappa_{\mathbb{E}}: \mathbb{R}^{d} \times \mathbb{R}^{d} \rightarrow \mathbb{R}$ un kernel de similitud definido como:

$$
\kappa_{E}\left(z, z_{n}\right)=\left\{\begin{array}{lr}
\exp \left(-\left\|z-z_{n}\right\|_{2}^{2}\right), & z_{n} \in \Upsilon \\
0, & \text { en otro caso }
\end{array}\right.
$$

donde $\mathrm{Y}$ es el conjunto de los $M$ vecinos más cercanos de la proyección de los datos observados vistos en el espacio de las características $z=\vartheta(y)^{T} \hat{\boldsymbol{A}}$, en el sentido de la distancia Euclidea. El Algoritmo (2) resume el método $\mathrm{ABC}$ automático basado en aprendizaje de métrica desarrollado en esta investigación, denominado AML-ABC.

\section{Algoritmo 2. Esquema $A M L-A B C$ para inferencia en escenarios supervisados.}

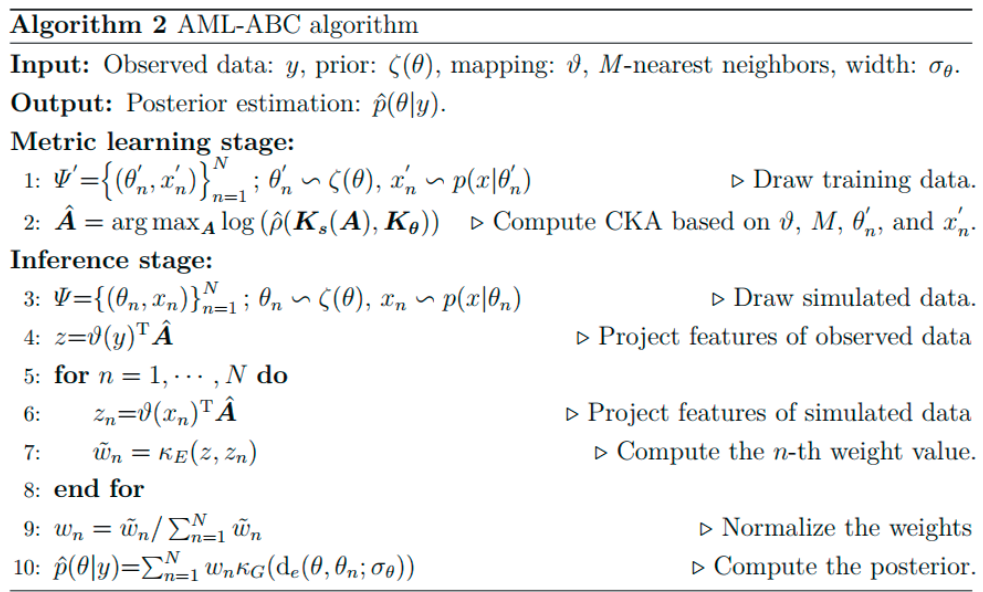




\section{Resultados.}

\section{Inferencia no supervisada}

Una vez que el alineamiento estadístico entre el espacio de los parámetros y el espacio de las características ha sido automatizado por completo gracias a la técnica CKA y el algoritmo LNS, la distancia $d_{S}: \delta \times \delta \rightarrow \mathbb{R}^{+}$ha sido aprendida completamente. En este sentido, la matriz de proyección $\widehat{\boldsymbol{A}}$ define la noción de similitud en el espacio de las características de los datos simulados y observados de una forma lo más parecida posible a la noción de similitud en el espacio de los parámetros; este es precisamente el aspecto que brinda la característica supervisada a la metodología propuesta en esta investigación. Por lo tanto, con el fin de introducir el concepto de vecindario en el contexto de los métodos $\mathrm{ABC}$, un conjunto de muestras y pesos $\psi=$ $\left\{\theta_{n}, w_{n}\right\}_{n=1}^{N}$ se puede obtener a partir de la siguiente medida de similaridad:

$$
w_{n}=\frac{\kappa_{E}\left(z, z_{N}\right)}{\sum_{n=1}^{N} \kappa_{E}\left(z, z_{N}\right)},
$$

siendo $\kappa_{\mathbb{E}}: \mathbb{R}^{d} \times \mathbb{R}^{d} \rightarrow \mathbb{R}$ un kernel de similitud definido como:

$$
\kappa_{E}\left(z, z_{n}\right)=\left\{\begin{array}{lr}
\exp \left(-\left\|z-z_{n}\right\| \frac{2}{2}\right), & z_{n} \in \Upsilon \\
0, & \text { en otro caso }
\end{array}\right.
$$

donde $Y$ es el conjunto de los $M$ vecinos más cercanos de la proyección de los datos observados vistos en el espacio de las características $z=\vartheta(y)^{T} \hat{A}$, en el sentido de la distancia Euclidea. El Algoritmo (2) resume el método $\mathrm{ABC}$ automático basado en aprendizaje de métrica desarrollado en esta investigación, denominado AML-ABC.

Para evaluar el rendimiento del esquema ABC mejorado no supervisado que se propone en esta investigación se consideran dos experimentos: uno de prueba que consiste en una tarea de inferencia en una mezcla de distribuciones, y otro de aplicación que comprende el estudio de un

sistema coológico dínámico no lineal conocido como el modelo o mapa de Ricker [14]. El desempeño de la metodologia propuesta para el caso de la distancia SHSED ${ }^{1}$ se compara con el $\mathrm{ABC}$ por rechazo y dos metodologias del estado del arte. La primera de ellas, el esquema $\mathrm{ABC}$ basado en máxima discrepancia media [9] (MMD por sus siglas en inglés), usa aproximaciones empiricas de las funciones de densidad de probabilidad; la segunda, el esquema Parzen-ABC [40], que utiliza estimaciones tradicionales basadas en ventanas de Parzen con pesos constantes y matriz de covarianza isotrópica. Estas dos altemativas poseen distancias particulares que se pueden incorporar directamente en la línea número cuatro del Algoritmo (1). 


\section{Inferencia en una mezcla de distribuciones de Poisson}

Inicialmente, se considera una mezela finita de distribuciones de Poisson de la forma:

$$
p(x \mid \lambda, \pi)=\pi_{1} \frac{\exp \left(-\lambda_{1}\right) \lambda_{1}^{x}}{x !}+\pi_{2} \frac{\exp \left(-\lambda_{2}\right) \lambda_{2}^{x}}{x !}
$$

donde $\pi=\left[\begin{array}{ll}\pi_{1} & \pi_{2}\end{array}\right]^{T}$ es el vector de coeficientes de la mezcla que satisfacen la condición $\pi_{1}+$ $\pi_{2}=1$ y $\lambda=\left[\begin{array}{ll}\lambda_{1} & \lambda_{2}\end{array}\right]^{T}, \lambda_{1}<\lambda_{2}$ representa el veetor de parámetros asociado al número medio de eventos esperados de las distribuciones.

La tarea de inferencia consiste en la aproximación del posterior de los coeficientes de la mezcla $p(\pi \mid \lambda, x)$, dados los parámetros $\lambda \in\{1,8\}$ y una serie de 50 observaciones sintéticas muestreadas de la Ecuación (27), siendo $\pi \in\{0.3,0.7\}$ el vector de parámetros objetivo a ser estimado. Ya que la distribución de Poisson está definida únicamente sobre el conjunto de los números enteros, las simulaciones y observaciones son, en general, dinámicas y con presencia de características dispersas, lo cual establece un escenario desafiante para la inferencia. Escogiendo como prior una distribución de Dirichlet $\pi \sim \operatorname{Dir}(1,1)$, se evalúa la robustez del esquema $\mathrm{ABC}$ mejorado variando el número de datos simulados de 10 a 300 con pasos de 10 , repitiendo 100 veces el proceso de inferencia para cada uno de estos valores de $N$. En la figura 5 se muestran las curvas del error relativo para cada uno de los coeficientes de la mezcla, usando el valor esperado del posterior como indicador de desempeño de la siguiente forma:

$$
\operatorname{error}\left(\theta^{(z)}\right)=100 \% \times\left(\frac{\left\|\theta^{(z)}-\sum_{n=1}^{W} w_{n} \hat{\theta}_{\kappa}^{(z)}\right\|}{\left\|\theta^{(z)}\right\|}\right),
$$

donde $\theta^{(2)}$ es el valor de referencia de la z-ésima componente del vector de parámetros y $\theta_{n}^{(z)}$ es la n-ésima muestra del posterior asociado a dicha componente con peso asociado $w_{n}$ - Los parámetros para evaluar la distancia SHSED y las demás constantes requeridas para la utilización del método se determinaron a partir de una búsqueda en una malla de puntos buscando obtener el mínimo valor del error. En particular, se determinó $H_{P}=H_{Q}=0.406, H_{\mathrm{k}}=2.154$ y $\epsilon=0.158$; estos parámetros se emplearon en los esquemas MMD-ABC y Parzen-ABC. Nótese que, en este caso, las matrices de covarianza se convierten en anchos de banda (varianzas) escalares debido a la naturaleza univariada de los datos. Finalmente, la tolerancia para el método $\mathrm{ABC}$ por rechazo se estableció en $\xi=10$ con norma Euclidiana de forma empirica a partir del mínimo valor a partir del cual se empezaron a aceptar muestras. 
Según los resultados que se observan en la Figura 5, el esquema SHSED-ABC propuesto en esta investigación conduce a mejores estimaciones del posterior alcanzando los menores errores respecto a las otras altemativas. Por lo tanto, la representación dispersa en los pesos del posterior favorece la identificación de estructuras relevantes en el RHKS, mejorando la comparación de simulaciones y observaciones en el contexto del algoritmo ABC. Adicionalmente, se observa que el desempeño del $\mathrm{ABC}$ por rechazo es bastante ineficiente, y aunque los esquemas MMD-ABC $\mathrm{y}$ Parzen-ABC se comportan de forma similar, no son competitivos con el esquema SHSED propuesto.

\section{Inferencia en un modelo ecológico dinámico no lineal}

Uno de los principales modelos dinámicos no lineales para el estudio de especies coológicas es el modelo o mapa de Ricker, el cual se representa modiante una ecuación diferencial discreta de la forma [41]:

$$
\ln \left(M^{(t)}\right)=\ln (r)+\ln \left(M^{(t-1)}\right)-M^{(t-1)}+e^{(t)},
$$

donde $M^{(t)} \in \mathbb{R}$ representa el tamaño de alguna población animal en el instante de tiempo $t$, $e^{(t)} \sim \mathcal{N}\left(0, \sigma_{\epsilon}^{2}\right)$ siendo $\sigma_{e}$ la desviación estándar de las innovaciones de la población; además, $\ln (r), r \in \mathbf{R}^{+}$, hace referencia a la tasa de crecimiento de la población. Una realización $y$ del modelo se expresa como una serie de tiempo que sigue una distribución de Poisson tal que

Figura 5. Curvas de error relativo para el posterior de los coeficientes de la mezcla. (a) (b)

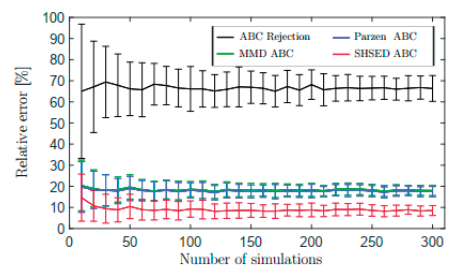

(a)

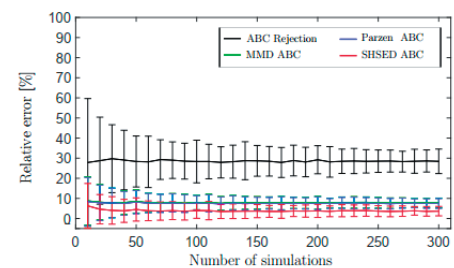

(b)

$y \sim$ Poisson $\left(\phi M^{(t)}\right)$, donde $\phi$ es un parámetro de escala. De esta manera, el modelo de Ricker se puede parametrizar completamente a partir del vector de parámetros: $\boldsymbol{\theta}=\left[\ln (r), \phi, \sigma_{e}\right]^{T}$.

En este experimento, las observaciones se seloccionan como una serie de tiempo de 50 muestras tomada del modelo con los parámetros objetivo ajustados de la siguiente forma: $\boldsymbol{\theta}=$ $[3.8,10,0.3]^{7}$. En la Figura 6 se muestran los datos observados del problema. La inferencia de los parámetros del modelo resulta una tarea desafiante debido a la alta variabilidad causada por el comportamiento estocástico del mapa de Ricker [14]. 
Figura 6. Datos observados para inferir los parámetros en el modelo de Ricker.

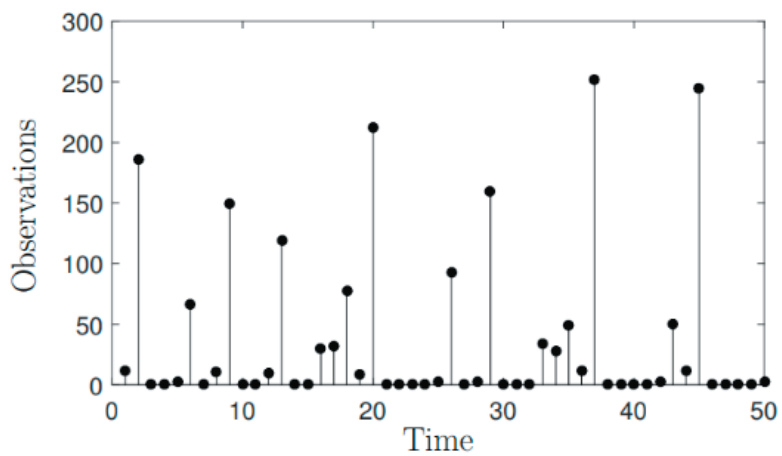

El prior de los parímetros se ajusta de la siguiente forma [41]: $\ln (r) \sim \mathcal{N}(4,0.5)$; $\phi \sim X^{2}(10) ; \sigma_{e} \sim \mathcal{G}^{-1}(3,1.3)$. Para la selección de los parámetros de los métodos ABC se emplea una estrategia similar a la del experimento anterior, usando una búsqueda por grilla intentando minimizar el error de la estimación. En este sentido, la distancia Euclidea y una tolerancia $\xi=75$ se emplea en el enfoque por rechazo, y anchos de banda $H_{P}=H_{Q}=0.0158, H_{k}=2.5$ y $\epsilon=$ 0.158 para los demás métodos basados en embebimientos de espacios de Hilbert. En las Figuras 7 (a) a 7 (c) se muestran las estimaciones del posterior obtenidas para cada componente del vector de parámetros para cada uno de los métodos considerados, donde se observa que los posteriores estimados por el método MMD-ABC son prácticamente idénticos a los encontrados por el método Parzen-ABC.

Por otra parte, el posterior de los parámetros $\ln (r)$ y $\sigma_{e}$ encontrados por el algoritmo SHSED propuesto tienen probabilidades mayores alrededor de valor real de los parámetros en comparación con los demás métodos, siendo nuevamente el enfoque por rechazo el que presenta el peor desempeño. En el caso del posterior de $\phi$, aunque todos los métodos basados en embebimientos de espacios de Hilbert amojan resultados similares, la estrategia SHSED-ABC propuesta intenta ajustar el valor de máxima probabilidad del posterior lo más ajustado posible al valor real de dicho parámetro. Finalmente, para evaluar la estabilidad de los resultados de estimación, se repite 100 veces el proceso completo de inferencia bajo las mismas condiciones descritas previamente. Los resultados se pueden observar en la Figura 7(d), donde es claro que el enfoque SHSED-ABC propuesto es el que presenta menor error en relación con los otros métodos de comparación. 
Figura 7. Resultados obtenidos en el modelo de Ricker. (a)-(c) Aproximación del posterior de los parámetros. (d) Diagrama de cajas y bigotes de la media del error relativo de los tres parámetros para cada método $A B C$.

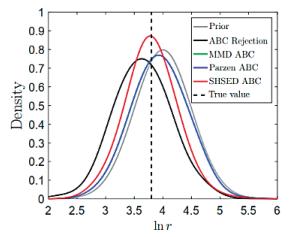

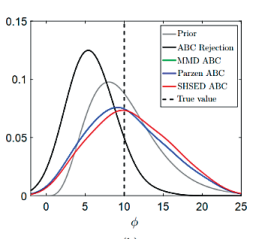

(b)

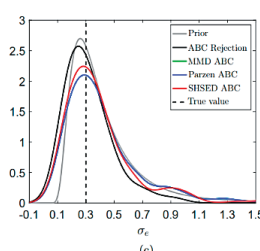

(c)

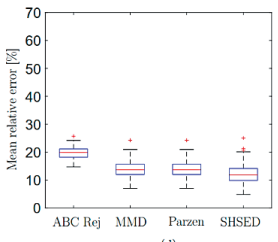

\section{Inferencia supervisada}

Para evaluar el rendimiento de la estrategia AML-ABC propuesta en esta investigación en el caso de escenarios supervisados, se emplean dos experimentos siguiendo el esquema propuesto en [9]. Especificamente, se aborda un experimento a partir de datos sintéticos en una mezcla de distribuciones unifommes, $y$ un experimento de inferencia en una base de datos real relacionada con el estudio dinámico de un sistema biológico poblacional de plagas. Para propósitos comparativos, se emplea el método K2-ABC en el caso del experimento con datos sintéticos debido a su gran desempeño en este tipo de tarea [9]. Por otra parte, en el caso de la base de datos real, se emplean los métodos K-ABC [17], IS-ABC [42], SA-ABC [12] y SL-ABC [14].

\section{Inferencia en una mezcla de distribuciones uniformes}

En este caso, se estudia una mezcla de distribuciones uniformes que introduce un escenario desafiante debido a la naturaleza probabilistica de dicha familia de distribuciones. En particular, el modelo de la mezcla se expresa como:

$$
p(x \mid \pi)=\sum_{c=1}^{N_{c}} \pi_{c} U(c-1, c)
$$

donde $\boldsymbol{\pi}=\left\{\pi_{c}\right\}_{c=1}^{N_{L}}$ son los conficientes de la merala que deben satisfacer la condición $\sum_{c=1}^{N_{c}} \pi_{c}=1$, siendo $N_{c}$ el número de distribuciones de la mezcla. Además, $\mathcal{U}(a, b)$ representa la distribución uniforme con limites $a$ y $b$. 
El objetivo experimental consiste de nuevo en la estimación del posterior de los coeficientes de la mezcla $p(\pi \mid y)$ para cinco componentes $\left(N_{c}=5\right)$, dado un conjunto de observaciones $(y)$ muestreado de la Ecuación (30) con vector de parámetros objetivo: $\boldsymbol{\pi}^{*}=$ $\left[\begin{array}{lllll}0.25 & 0.04 & 0.33 & 0.04 & 0.34\end{array}\right]^{T}$. Concretamente, se emplearon mil muestras $(N=1000)$ generadas desde una distribución prior de Dirichlet, esto es, $\pi \sim$ Dirichlet(1), las cuales se emplearon para general datos simulados compuestos por 400 realizaciones desde la mezcla para cada una de las mil muestras candidatas. Como función de mapeo para la generación del espacio de caracteristicas se empleó un histograma con 10 particiones en el caso del método AML-ABC propuesto. Por otra parte, los anchos de banda de las funciones kernel del esquema K2-ABC se fijaron en $\gamma=0.1$ y $\epsilon=0.001$ [9]. Como indice de desempeño se utilizó la norma Euclidea $\varepsilon=\left\|\boldsymbol{\pi}^{*}-\hat{\boldsymbol{\pi}}\right\|_{2}$, donde $\hat{\boldsymbol{\pi}}$ hace referencia al valor esperado del vector de parámetros calculado a partir de los pesos $\left\{w_{n}\right\}_{n=1}^{N}$ arrojados por cada método.

Puesto que este es un experimento completamente controlado al conocer el valor real de los parámetros del modelo, es posible encontrar una cota para el desempeño máximo del esquema AML-ABC propuesto. Para esto, basta con realizar la etapa de inferencia del Algoritmo 2 empleando $\bar{\omega}=\kappa_{E}\left(\pi^{*}, \pi_{n}\right)$, dando como origen al Mejor Escenario, que es equivalente al caso en que el alineamiento estadistico arrojado por la estrategia CKA es perfecto $\left(\boldsymbol{K}_{s}=\boldsymbol{K}_{\theta}\right)$. Los resultados obtenidos para este experimento indican indices de errores de la siguiente forma (ver Figura \&(a)): $\varepsilon_{\text {Mejor EsC. }}=0.030 \pm 0.039, \varepsilon_{A M L-A B C}=0.064 \pm 0.041, \varepsilon_{K 2-A B C}=0.063 \pm 0.04$. Estos resultados sugieren que es esquema AML-ABC propuesto es una alternativa competitiva con el excelente K2-ABC, pero posee una ventaja crucial: la inferencia se realiza de forma automática sin requerir la sintonización de parámetros usando búsqueda por grillas como en el caso de K2ABC. Por otra parte, en la Figura 8(b) se observan los pesos para el número de vecinos requerido en el enfoque AML-ABC propuesto ( $M=5$ en este caso), donde se observa que la mayoría de los candidatos seleccionados en el Mejor Escenario coindicen con aquellos elegidos por el método $\mathrm{AML}-\mathrm{ABC}$, aunque este último nunca ha visto el valor real (objetivo) de los parámetros. 
Figura 8. Resultados para la mezcla de distribuciones uniforme. (a) Valor medio del posterior de los coeficientes de la mezcla para diferentes métodos. (b) Pesos asociados a los 5 vecinos más cercanos según el esquema $A M L-A B C$.

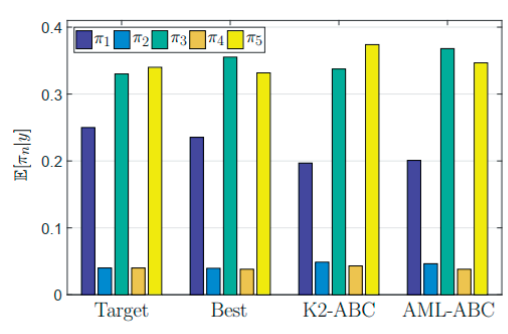

(a)

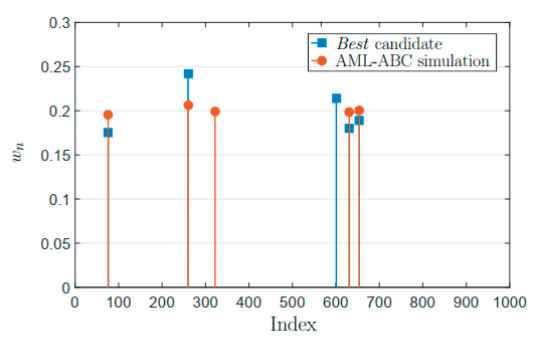

(b)

\section{Inferencia en un problema real de crecimiento dinámico poblacional}

En este experimento con datos reales se considera la inferencia de los parámetros de un modelo que representa las dinámicas de una población adulta de moscardas (Lucilia Cuprina). La descripción matemática del comportamiento de esta plaga se atribuye a los experimentos de Nicholson y su formulación es la siguiente [14]:

$$
N_{t+1}=P N_{\mathrm{t}-\mathrm{t}} \exp \left(-\frac{N_{\mathrm{t}-\mathrm{r}}}{N_{0}}\right) e_{\mathrm{t}}+N_{t} \exp \left(-\delta \epsilon_{\mathrm{t}}\right)
$$

donde $N_{t+1}$ representa el número de moscas en el instante $t+1$, el cual está determinado por la población inicial $N_{0}$, al igual que las observaciones en el pasado $N_{t}$ y $N_{t-\tau}$. Además, los parámetros $e_{t}$ y $\epsilon_{\mathrm{t}}$ representan ruido que sigue distribuciones Gamma de la forma $e_{\mathrm{t}} \sim \mathcal{G}\left(1 / \sigma_{p}^{2}, \sigma_{p}^{2}\right)$ y $\epsilon_{t} \sim \mathcal{G}\left(1 / \sigma_{d}^{2}, \sigma_{d}^{2}\right)$.

En este caso, el objetivo consiste en la estimación del posterior de los parámetros $\boldsymbol{\theta}=$ $\left[P, N_{0}, \sigma_{\mathscr{d}}, \sigma_{p}, \tau, \delta\right]^{T}$ a partir del conjunto de 180 observaciones $^{2}$ que se muestras en la Figura 9. El desarrollo de un esquema de inferencia estadistica en este tipo de sistema se considucta una tarea sumamente compleja ya que la dinámica del modelo permite fäcilmente el paso de un régimen estable a un régimen caótico, esto es, una pequeña variación en alguno de los parámetros puede generar un cambio sustancial en la trayectoria que sigue el tamaî̀o de la población a lo largo del tiempo [14,19]. Esto establece un escenario bastante interesante para evaluar el desempeño y robustez del esquema AML-ABC propuesto. 
Figura 9. Datos observados de una población de moscas para la inferencia en un escenario real.

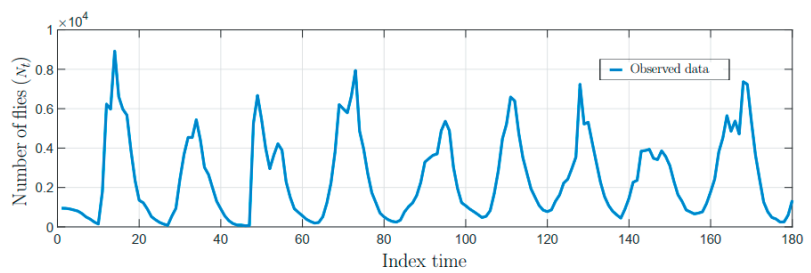

En particular para este experimento, se impusieron distribuciones Log-normales como prior sobre los parámetros [17]: $\log (P) \sim \mathcal{N}\left(2,2^{2}\right), \log \left(N_{0}\right) \sim \mathcal{N}(6,1), \log \left(\sigma_{d}\right) \sim \mathcal{N}(-0.5,1)$, $\log \left(\sigma_{p}\right) \sim \mathcal{N}(-0.5,1), \log (\tau) \sim \mathcal{N}\left(-1,0.4^{2}\right)$. Respecto al esquema AML-ABC, se generaron cinco mil muestras $(N=5000)$ de la distribución prior que fueron empleadas para construir datos simulados compuestos por 180 realizaciones del modelo de la Ecuación (3I) para cada una de las cinco mil muestras candidatas. Además, como función de mapeo para construir el espacio de caracteristicas se emplearon los 10 estadisticos por defecto en el estudio de este sistema [9]: el logaritmo de la media de todos los cuartiles al $25 \%$ de $\left\{N_{t} / 1000\right\}_{t=1}^{180}$ (4 estadisticos), la media de los cuartiles al $25 \%$ de las primeras derivadas de $\left\{N_{t} / 1000\right\}_{t=1}^{180}$ (4 estadisticos) y los picos máximos luego de aplicar un esquema de umbralización con dos tolerancias diferentes sobre $\left\{N_{t}\right\}_{t=1}^{180}$ ( 2 estadisticos). Por otra parte, la norma Euclidea $\varepsilon=\left\|\vartheta(y)-\vartheta\left(x_{n} \mid \widehat{\theta}\right)\right\|_{2}$ se utilizó como indice de desempeño, donde $x_{n} \mid \widehat{\theta}$ representa una simulación a partir del valor esperado del posterior estimado por cada método.

En la Figura 10 se muestran las estimaciones del posterior obtenidas para cada componente del vector de parámetros para cada uno de los métodos considerados. Nótese como el esquema AMLABC propuesto es capaz de extraer información de los datos para actualizar las creencias iniciales sobre los parímetros del modelo, generando posteriores mucho más concentrados respecto al prior. En el caso de $\log \left(\sigma_{p}\right)$, dos modos revelan dos intervalos distintos con valores probables para el modelado de la producción de huevos en la población de moscas. Sin embargo, uno de estos modos es el más predominante, estableciendo asi mayores probabilidades para ciertos valores de este parámetro. Adicionalmente, la Figura 11 muestra la simulación más cercana y más alejada a los datos observados en el sentido de la distancia Euclidea empleando simulaciones generadas empleando el valor esperado del posterior de los parámetros encontrados por el método AML$\mathrm{ABC}$, donde claramente se evidencia que la inferencia se ha realizado sobre un régimen de estabilidad evitando dinámicas caóticas. Por último, en la Figura 12 se muestra el desempeño del enfoque AML-ABC en comparación con los demás métodos para el caso de 100 simulaciones a partir del valor esperado del posterior estimado. Claramente, el método propuesto es bastante competitivo teniendo en cuenta que no requiere ningún proceso de sintonización de parámetros por medio de búsqueda basadas en exploración por grilla de valores. 
Figura 10. Resultados del modelo ecológico dinámico no lineal. En línea a trazos se tiene la estimación del posterior según el esquema $A M L-A B C$ propuesto. En línea continua, el prior de los parámetros
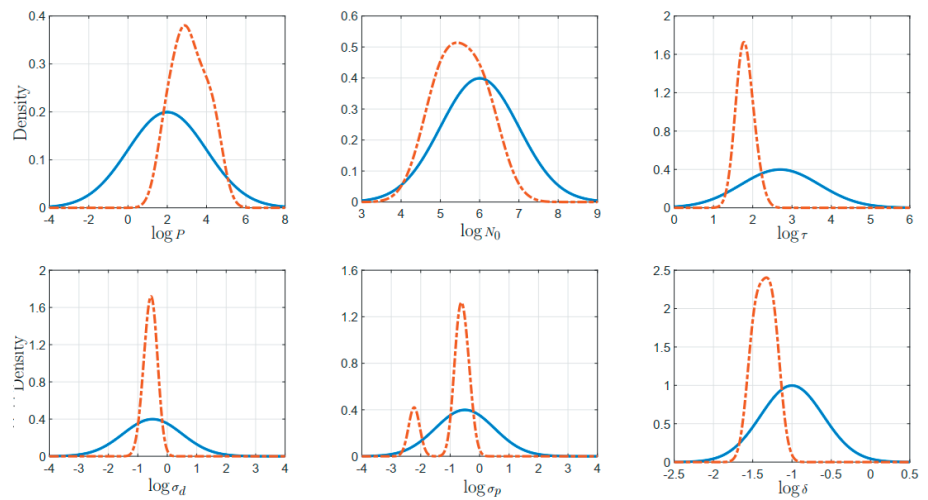

Figura 11. Algunas realizaciones del modelo ecológico empleando el valor esperado de los parámetros.

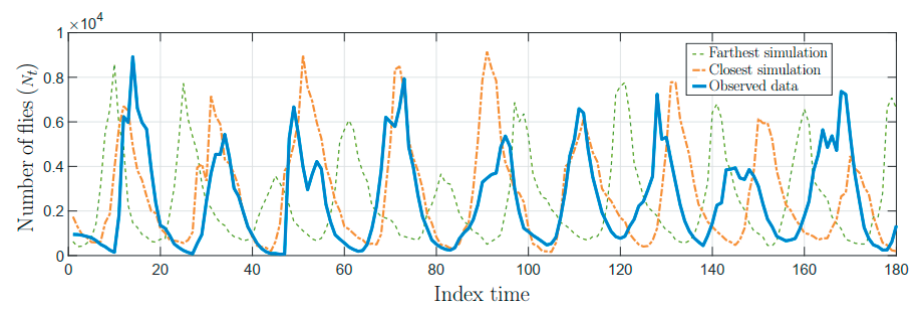

Figura 12. Diagrama de cajas y bigotes de la distancia euclídea de las simulaciones y observaciones en el espacio de las características para cada uno de los métodos $A B C$.

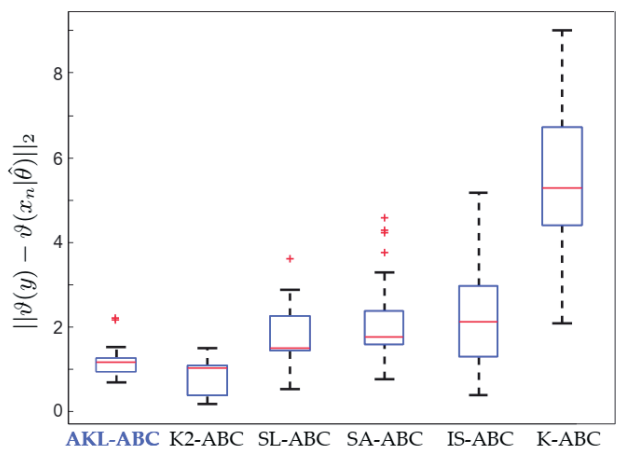




\section{Conclusiones}

\section{Inferencia en escenarios no supervisados}

En esta investigación se propuso una metodología mejorada para el desarrollo de tareas de inferencia estadística aproximada empleando un esquema $\mathrm{ABC}$ basado en embebimientos de espacios de Hilbert. En particular, se desarrollaron dos nuevas distancias para comparar distribuciones de probabilidad asociadas a dos variables aleatorias en un espacio de Hilbert con kernel reproductor (RKHS): una que resalta la información relevante a partir de una representación dispersa de las funciones de densidad de probabilidad asociadas (denominada SHSED), y otra que identifica estructuras relevantes mediante el cálculo adaptativo de similitudes en un RKHS (denotada como AHSED).

Para evaluar la metodología propuesta se estudiaron dos tareas de inferencia en dos sistemas distintos: una mezcla de distribuciones de Poisson y un modelo ecológico dinámico no lineal denominado mapa de Ricker. Los resultados obtenidos demostraron como el esquema $\mathrm{ABC}$ propuesto con base en las distancias introducidas supera el rendimiento de otros enfoques $\mathrm{ABC}$ vigentes en el estado del arte. En síntesis, puede concluirse que es posible mejorar la calidad de las estimaciones del posterior cuando se introducen nuevas distancias en el contexto de los enfoques $\mathrm{ABC}$ que permiten resaltar información relevante contenida en las observaciones y simulaciones.

\section{Inferencia en escenarios supervisados}

En este trabajo se desarrolló una nueva estrategia $A B C$ automática para la estimación del posterior en tareas de inferencia Bayesiana aproximada, denominada AML-ABC. Particularmente, se utilizó una estrategia de aprendizaje de métrica basada en el alineamiento centralizado de kernel (CKA) para cuantificar el grado de semejanza que existe entre el concepto de similitud en el espacio de los parámetros y la noción de similitud en el espacio de las simulaciones transformadas (espacio de las características). 
Concretamente, gracias al aprendizaje de una distancia de Mahalanobis a partir de CKA y teoría de grafos, es posible revelar estructuras de relaciones locales entre simulaciones y muestras candidatas a seguir el posterior.

Es importante señalar que una característica fundamental del enfoque propuesto consiste en la selección automática de parámetros libres, evitando procedimientos costosos de sintonización y búsqueda por grillas de valores. Los resultados obtenidos en datos sintéticos a partir de una mezcla de distribuciones uniformes y en un sistema ecológico real mostraron que el método AML-ABC es una alternativa bastante competitiva respecto a otros enfoques no automáticos. En este sentido, se concluye que es posible generar una versión $\mathrm{ABC}$ automática cuando se incluyen criterios adicionales en el esquema general de tal forma que se eviten procedimientos de ajuste como la búsqueda exhaustiva y la validación cruzada.

\section{Referencias Bibliográficas}

[1] Wasserman, L. (2013). All of statistics: a concise course in statistical inference. Springer Science \& Business Media.

[2] Casella, G., \& Berger, R. L. (2002). Statistical inference (Vol. 2, pp. 337-472). Pacific Grove, CA: Duxbury.

[3] Bickel, P. J., Klaassen, C. A., Bickel, P. J., Ritov, Y. A., Klaassen, J., Wellner, J. A., \& Ritov, Y. A. (1993). Efficient and adaptive estimation for semiparametric models (Vol. 4). Baltimore: Johns Hopkins University Press.

[4] Hahn, G. J., \& Meeker, W. Q. (2011). Statistical intervals: a guide for practitioners (Vol. 92). John Wiley \& Sons.

[5] Box, G. E., \& Tiao, G. C. (2011). Bayesian inference in statistical analysis (Vol. 40). John Wiley \& Sons. 
[6] Toni, T., Welch, D., Strelkowa, N., Ipsen, A., \& Stumpf, M. P. (2009). Approximate Bayesian computation scheme for parameter inference and model selection in dynamical systems. Journal of the Royal Society Interface, 6(31), 187-202.

[7] Turner, B. M., \& Van Zandt, T. (2012). A tutorial on approximate Bayesian computation. Journal of Mathematical Psychology, 56(2), 69-85.

[8] Joyce, P., \& Marjoram, P. (2008). Approximately sufficient statistics and Bayesian computation. Statistical applications in genetics and molecular biology, 7(1).

[9] Park, M., Jitkrittum, W., \& Sejdinovic, D. (2016). K2-ABC: Approximate Bayesian computation with kernel embeddings.

[10] Silverman, B. W. (1986). Density estimation for statistics and data analysis (Vol. 26). CRC press.

[11] González-Vanegas, W., Álvarez-Meza, A., Hernández-Muriel, J., \& Orozco-Gutiérrez, Á. (2019). AKL-ABC: An Automatic Approximate Bayesian Computation Approach Based on Kernel Learning. Entropy, 21(10), 932.

[12] Sisson, S. A., Fan, Y., \& Beaumont, M. (Eds.). (2018). Handbook of approximate Bayesian computation. CRC Press.

[13] Prangle, D. Summary statistics in approximate Bayesian computation. In Handbook of Approximate Bayesian Computation; CRC Press: Boca Raton, FL, USA, 2018; Chapter 5.

[14] Wood, S. N. (2010). Statistical inference for noisy nonlinear ecological dynamic systems. Nature, 466(7310), 1102-1104. 
[15] Fearnhead, P., \& Prangle, D. (2012). Constructing summary statistics for approximate Bayesian computation: semiautomatic approximate Bayesian computation. Journal of the Royal Statistical Society: Series B (Statistical Methodology), 74(3), 419-474.

[16] Pigorsch, E.G.C. Approximate Bayesian Computation with Indirect Summary Statistics; Technical Report. Available online: http://citeseerx.ist.psu.edu/ viewdoc/summary?doi=10.1.1.665.5503 (accessed on 19 September 2019)

[17] Nakagome, S., Fukumizu, K., \& Mano, S. (2013). Kernel approximate Bayesian computation in population genetic inferences. Statistical applications in genetics and molecular biology, 12(6), 667-678.

[18] Mitrovic, J., Sejdinovic, D., \& Teh, Y. W. (2016, June). DR$\mathrm{ABC}$ : approximate Bayesian computation with kernel-based distribution regression. In International Conference on Machine Learning (pp. 1482-1491).

[19] Meeds, E., \& Welling, M. (2014). GPS-ABC: Gaussian process surrogate approximate Bayesian computation. arXiv preprint arXiv:1401.2838.

[20] Jiang, B., Wu, T. Y., Zheng, C., \& Wong, W. H. (2017). Learning summary statistic for approximate Bayesian computation via deep neural network. Statistica Sinica, 1595-1618.

[21] Creel, M. (2017). Neural nets for indirect inference. Econometrics and Statistics, 2, 36-49.

[22] Pritchard, J. K., Seielstad, M. T., Perez-Lezaun, A., \& Feldman, M. W. (1999). Population growth of human Y chromosomes: a study of Y chromosome microsatellites. Molecular biology and evolution, 16(12), 1791-1798. 
[23] Liepe, J., Kirk, P., Filippi, S., Toni, T., Barnes, C. P., \& Stumpf, M. P. (2014). A framework for parameter estimation and model selection from experimental data in systems biology using approximate Bayesian computation. Nature protocols, 9(2), 439-456.

[24] Holden, P. B., Edwards, N. R., Hensman, J., and Wilkinson, R. D. (2018). Abc for climate: dealing with expensive simulators. Handbook of Approximate Bayesian Computation, pages 569-95

[25] Fasiolo, M., \& Wood, S. N. (2015). Approximate methods for dynamic ecological models. arXiv preprint arXiv:1511.02644.

[26] Fan, Y., Meikle, S. R., Angelis, G., and Sitek, A. (2018). Abc in nuclear imaging. Handbook of Approximate Bayesian Computation.

[27] Wilkinson, R. D. (2013). Approximate Bayesian computation $(\mathrm{ABC})$ gives exact results under the assumption of model error. Statistical applications in genetics and molecular biology, 12(2), 129-141.

[28] Marjoram, P., Molitor, J., Plagnol, V., \& Tavaré, S. (2003). Markov chain Monte Carlo without likelihoods. Proceedings of the National Academy of Sciences, 100(26), 15324-15328.

[29] Alabiso, C., \& Weiss, I. (2016). Primer on Hilbert Space Theory. Springer International $\mathrm{Pu}$.

[30] Liu, W., Principe, J. C., \& Haykin, S. (2011). Kernel adaptive filtering: a comprehensive introduction (Vol. 57). John Wiley \& Sons.

[31] Principe, J. C. (2010). Information theoretic learning: Renyi's entropy and kernel perspectives. Springer Science 
[32] Sriperumbudur, B. K., Gretton, A., Fukumizu, K., Schölkopf, B., \& Lanckriet, G. R. (2010). Hilbert space embeddings and metrics on probability measures. The Journal of Machine Learning Research, 11, 1517-1561.

[33] Smola, A., Gretton, A., Song, L., \& Schölkopf, B. (2007, October). A Hilbert space embedding for distributions. In International Conference on Algorithmic Learning Theory (pp. 13-31). Springer, Berlin, Heidelberg.

[34] Hong, X., \& Chen, S. (2013, July). A fast algorithm for sparse probability density function construction. In 2013 18th International Conference on Digital Signal Processing (DSP) (pp. 1-6). IEEE.

[35] Zougab, N., Adjabi, S., \& Kokonendji, C. C. (2014). Bayesian estimation of adaptive bandwidth matrices in multivariate kernel density estimation. Computational Statistics \& Data Analysis, 75, 28-38.

[36] Alvarez-Meza, A. M., Orozco-Gutierrez, A., \& CastellanosDominguez, G. (2017). Kernel-based relevance analysis with enhanced interpretability for detection of brain activity patterns. Frontiers in neuroscience, 11, 550.

[37] Zhang, Q., Filippi, S., Gretton, A., \& Sejdinovic, D. (2018). Large-scale kernel methods for independence testing. Statistics and Computing, 28(1), 113-130.

[38] Cortes, C., Mohri, M., \& Rostamizadeh, A. (2012). Algorithms for learning kernels based on centered alignment. The Journal of Machine Learning Research, 13(1), 795-828. 
[39] Álvarez-Meza, A., Valencia-Aguirre, J., Daza-Santacoloma, G., \& Castellanos-Domínguez, G. (2011). Global and local choice of the number of nearest neighbors in locally linear embedding. Pattern Recognition Letters, 32(16), 2171-2177.

[40] Zuluaga, C. D., Valencia, E. A., Álvarez, M. A., \& Orozco, Á. A. (2015, September). A parzen-based distance between probability measures as an alternative of summary statistics in approximate bayesian computation. In International Conference on Image Analysis and Processing (pp. 50-61). Springer, Cham.

[41] Golchi, S., \& Campbell, D. A. (2016). Sequentially Constrained Monte Carlo. Computational Statistics \& Data Analysis, 97, 98-113.

[42] Gleim, A.; Pigorsch, C. Approximate Bayesian Computation with Indirect Summary Statistics. Available online: http://ect-pigorsch.mee.uni-bonn.de/data/research/ papers (accessed on 10 July 2019) 
Vicerrectoría de Investigaciones, Innovación y Extensión

eISBN 978-958-722-496-2

Colección Trabajos de Investigación 